\title{
Tratamento da dor na fibromialgia com acupuntura
}

Tese apresentada à Faculdade de Medicina da Universidade de São Paulo, para obtenção do título de Doutor em Ciências.

Área de concentração: Patologia.

Orientador: Prof. Dr. Raymundo Soares de Azevedo Neto.

São Paulo 2007 
Temos aprendido a voar como os pássaros A nadar como os peixes Mas ainda não aprendemos a sensível arte de viver como irmãos.

Martin Luther King 


\section{DEDICATÓRIA}

À memória de meus pais.

Ao meu marido Prof. Dr. João Targino de Araujo, obrigada pela paciência e incentivo que recebi para enfrentar este desafio.

Aos meus filhos, noras e genro, aos meus netos e netas, que o meu exemplo continue a iluminar suas mentes mostrando que se pode começar quando se pensa que tudo terminou. 


\section{AGRADECIMENTOS}

Ao Prof.Dr. Raymundo Soares de Azevedo Neto, coordenador da Pós-graduação sensu estrito do Departamento de Patologia da Faculdade de Medicina da Universidade de São Paulo, meus agradecimentos pela confiança, respeito, incentivo e oportunidades com os quais me orientou durante todo processo de doutorado.

À Profa. Dra. Marta Imamura: obrigada pela amizade e o grande incentivo, "tão grande" que me fez chegar ate aqui.

Ao Prof.Dr. Wu Tu Hsing agradeço os ensinamentos e a oportunidade de desenvolver o tema desta tese.

À Prof.Dra. Satiko Imamura a minha gratidão pelos conhecimentos transmitidos para a execução desta pesquisa.

À Dra. Helena Hideko Seguchi Kaziyama agradeço a paciência que teve comigo e com os doentes que não foram poucos. Aprendi muito com você.

Ao Mestre Luiz Paulo Marques de Souza, importante na realização desta pesquisa conduzindo as perguntas dos questionários aplicados. Meu reconhecimento pela amizade e dedicação.

À Dra. Wanda Alves Bastos, amiga de longa data, a sua opinião a respeito desta tese foi muito importante.

Ao Jornalista Laerte Fernandes, agradeço sua boa vontade na leitura e sugestões dadas a respeito da escrita.

Ao Andrei, Adriana e Victor, em especial, meus agradecimentos pela ajuda e boa vontade na execução desta tese.

À amiga Zélia que nos momentos disponíveis auxiliou na organização deste trabalho.

Aos professores da Pós-graduação minha gratidão pelo conhecimento e por contribuírem com sábios ensinamentos.

À secretária da Pós-graduação, Liduvina da Silva Neta de Barros , amiga de todos, muito obrigada pela sua ajuda toda vez que foi solicitada.

À todos os funcionários da secretaria da Divisão de Medicina Física do Instituto de Ortopedia e Traumatologia do Hospital das Clinicas da Universidade de São Paulo, agradeço a disponibilidade, paciência 


\section{SUMÁRIO}

Lista de abreviatura e símbolos

Lista de figuras

Lista de tabelas

Resumo

Sumário

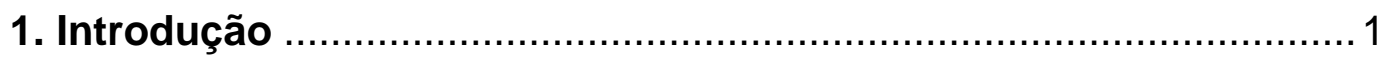

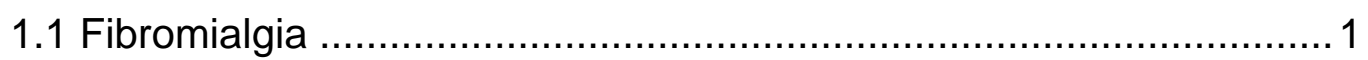

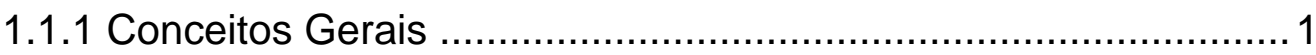

1.1.2 Etiologia e etiopatogenia ...................................................... 2

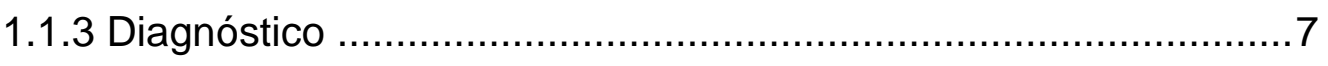

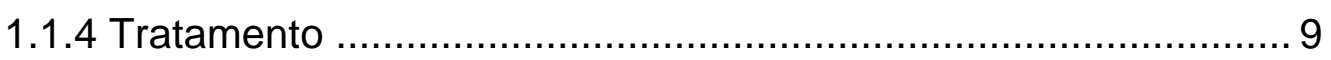

1.1.4.1 Tratamento medicamentoso ……………......................

1.1.4.2 Tratamento não medicamentoso ……………...................10

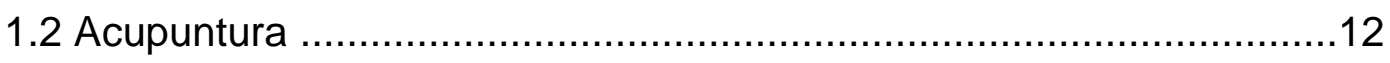

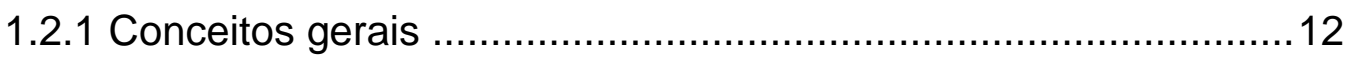

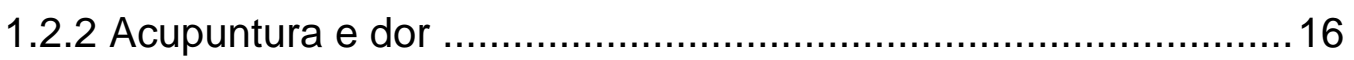

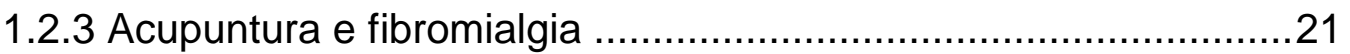

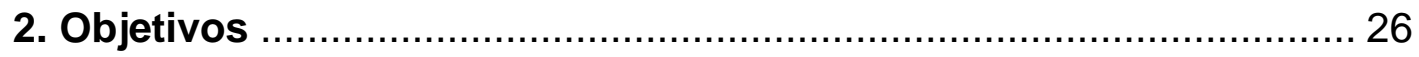

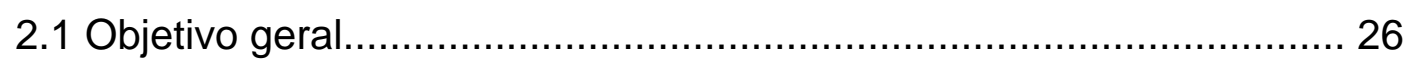

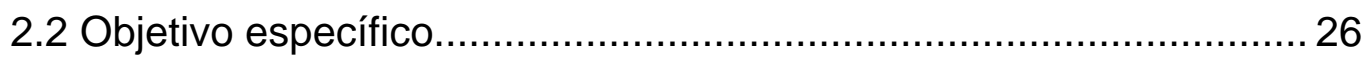




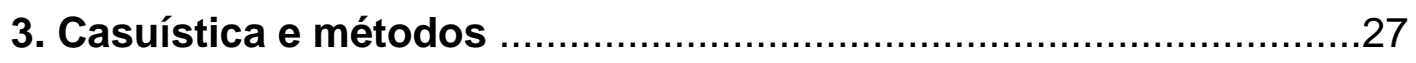

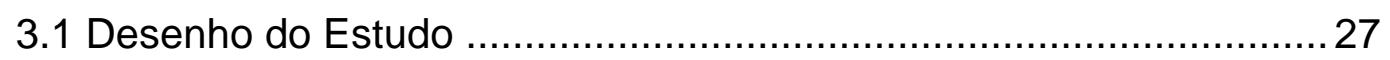

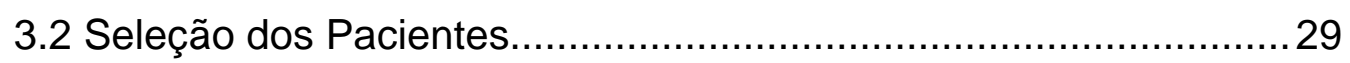

3.2.1. Critérios de inclusão................................................ 29

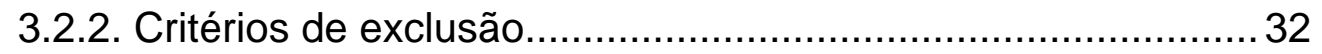

3.3 Caracterização Clínica e Instrumentos de Avaliação...................... 32

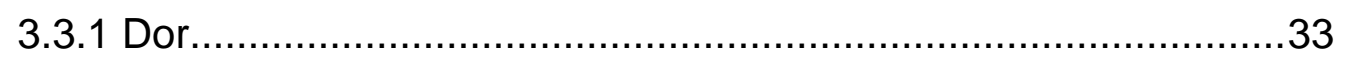

3.3.1.1 Escala visual analógica ( EVA) ..................................33

3.3.1.2 Números de pontos dolorosos (NPD) .............................34

3.3.1.3 Índice miálgico (IM) ........................................... 34

3.3.2 Qualidade de vida................................................... 35

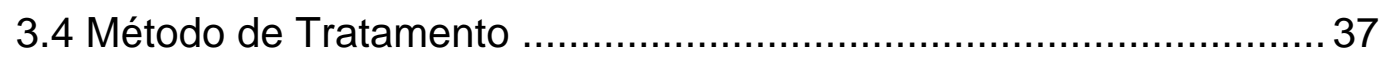

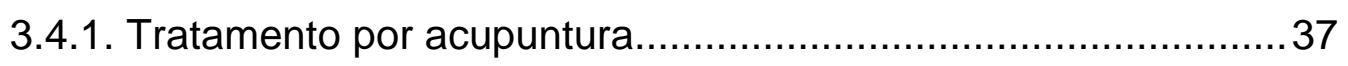

3.4.2 Tratamento convencional: grupo controle...........................42

3.5 Análise Estatística ................................................................. 43

3.5.1 Cálculo da amostra.................................................. 43

3.5.2 Estudo estatístico.....................................................43

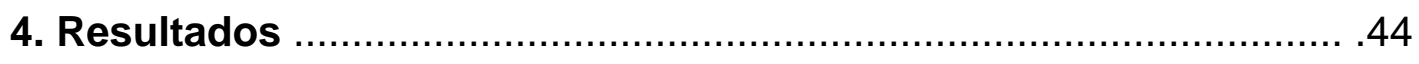

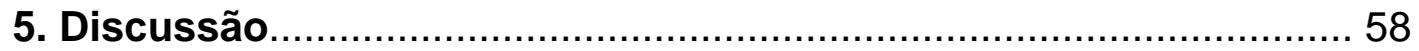

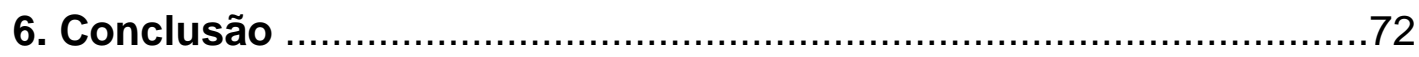

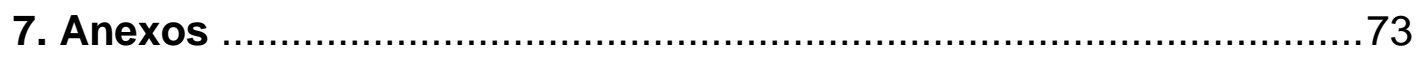

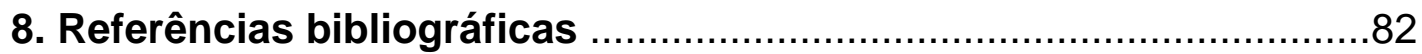




\section{LISTA DE SÍMBOLOS}

$\begin{array}{ll}\mathrm{Kgf} & \text { Quilograma força } \\ \mathrm{Kgf} / \mathrm{s} & \text { Quilograma força por segundo } \\ \mathrm{cm}^{2} & \text { Centímetro quadrado } \\ \mathrm{Kgf} / \mathrm{cm}^{2} & \text { Quilograma força por centímetro quadrado } \\ \circ \mathrm{C} & \text { Graus Celsius }\end{array}$




\section{LISTA DE ABREVIATURAS}

ACTH:

IL: Interleucina

IL-2r: Interleucina 2 receptora

REM: Rapid Eye Movement

GF: Fator de Crescimento

PET: positrons emission tomography

PREP: pontos reativos eletro-permeáveis

NIH: National Institutes of Health

WHO: World Heath Organization

EVA: Escala Visual Analógica

NPD: Número de Pontos Dolorosos

IM: Índice Miálgico

CF: Capacidade Funcional

EGS: Estado Geral da Saúde

VIT: Vitalidade

AF: Aspecto físico

AE: Aspecto emocional

SM: Saúde mental

LU: Lung

LI: Large Intestine

ST: Stomach

SP: Spleen

HT: Heart 
SI: Small Intestine

BL: Bladder

KI: Kidney

PC: Pericardium

LR: Liver

GB: Gallbladder

TE: Triple E

CV: ponto de acupuntura Conception Vessel

GV: ponto de acupuntura Governor Vessel

Ex-HN3: ponto de acupuntura extra Head and Neck 3

LI4: ponto clássico de acupuntura Large Intestine 4

ST-36: ponto clássico de acupuntura Stomach 36

SP-6: ponto clássico de acupuntura Spleen 6

PC6: ponto clássico de acupuntura Pericardium 6

HT7: ponto clássico de acupuntura Heart 7

LI2: ponto clássico de acupuntura Large Intestine 2 


\section{LISTA DE FIGURAS}

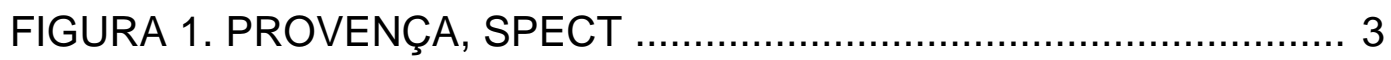

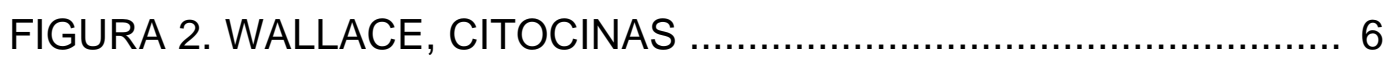

FIGURA 3: ALGIOMETRO DE FISCHER - FIGURA ……................... 8

FIGURA 4: MERIDANOS DA ACUPUNTURA …................................. 15

FIGURA 5: EFEITO DA ACUPUNTURA PELA RESSONÂNCIA

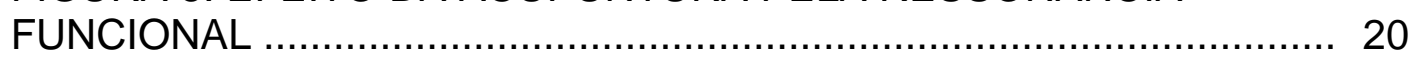

FIGURA 6: PONTOS DA FIBROMIALGIA ........................................... 31

FIGURA 7: TEMPOS DE AVALIAÇÃO: CRONOLOGIA DO ESTUDO .... 33

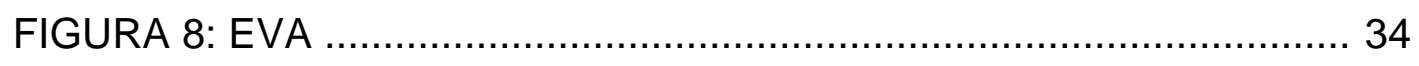

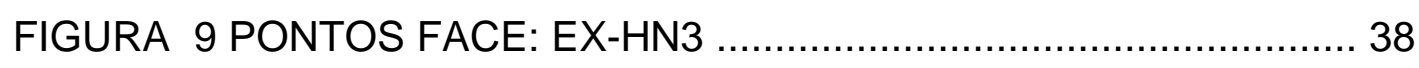

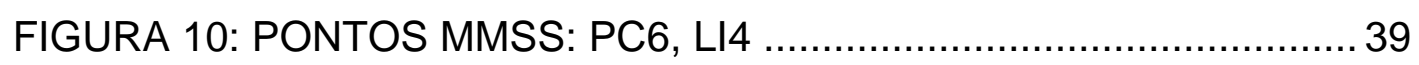

FIGURA 11: PONTOS MMII: GB34, SP6, LV3 …….............................. 40

FIGURA 12: FLUXOGRAMA DOS DOENTES ……............................. 44

FIGURA 13: VAS EVOLUÇÃO NO TEMPO …………......................... 47

FIGURA 14: NPD EVOLUÇÃO NO TEMPO ………….......................... 47

FIGURA 15: IM EVOLUÇÃO NO TEMPO ……………........................... 48

FIGURA 16: GRÁFICO: MELHORA, PIORA, INALTERADO: VAS, NPD, IM

FIGURA 17: GRÁFICO: MELHORA, PIORA, INALTERADO: SF36 55 


\section{LISTA DE TABELAS}

TABELA 1 - CARACTERÍSTICAS DEMOGRÁFICAS ....................... 45

TABELA 2 - RESULTADOS EVA, NPD, IM .................................. 49

TABELA 3 - EVOLUÇÃO EVA, NPD, IM .................................... 51

TABELA 4 - RESULTADOS SF-36 ............................................ 53

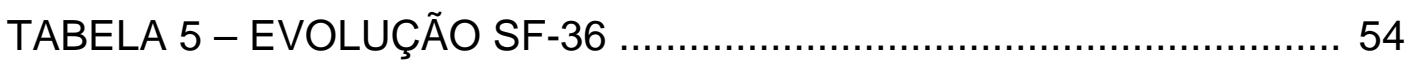




\title{
RESUMO
}

\author{
Araújo,R.A.T. Tratamento da dor na fibromialgia com \\ acupuntura. São Paulo, 2007. Tese (Doutorado) - \\ Faculdade de Medicina, Universidade de São Paulo. 86 p.
}

Fibromialgia é caracterizada por dor crônica músculo-esquelética difusa, distúrbio do sono, fadiga e humor depressivo ou ansiedade. Cinqüenta e oito mulheres com fibromialgia foram alocadas aleatoriamente e divididas em dois grupos: o primeiro $(n=34)$, tratadas duas vezes por semana com acupuntura perfazendo total de 20 sessões, medicadas com antidepressivos tricíclico e utilizando caminhada, exercícios e relaxamento 2 vezes por semana. O segundo grupo $(n=24)$ recebeu o mesmo tratamento exceto a acupuntura.

A avaliação da dor foi realizada através da escala visual analógica (EVA), número de pontos dolorosos (NPD), do índice miálgico (IM) e um questionário SF36 para a qualidade de vida. As avaliações foram feitas antes, após, seis meses, um ano e dois anos depois da primeira avaliação. Foram realizadas por profissionais que desconheciam o grupo ao qual a paciente pertencia. No final das vinte sessões, as pacientes que receberam a acupuntura apresentaram melhora significante nas medidas de dor (EVA, NPD e IM) e em cinco sub-escalas do SF36 em relação ao grupo controle. Após seis meses o grupo de acupuntura apresentou resultado melhor do que o controle em relação ao NPD e ao IM e em uma sub-escala do SF36. Após um ano o grupo de acupuntura mostrou melhora sobre o grupo controle somente em uma sub-escala do SF36. Depois de dois anos do início do tratamento com acupuntura não houve diferença significativa entre os dois grupos em todas as medidas pesquisadas. A associação da acupuntura ao tratamento usual para fibromialgia mostrou-se benéfica para dor e qualidade de vida, mas somente por três meses após o tratamento. 


\title{
SUMMARY
}

\author{
Araújo,R.A.T.. Tratamento da dor na fibromialgia com \\ acupuntura. São Paulo, 2007. Tese (Doutorado) - \\ Faculdade de Medicina, Universidade de São Paulo. 86 p.
}

Fibromyalgia is characterized by chronic widespread pain, disturbed sleep, fatigue and psychological distress. The aim of this study was to evaluate the effect of acupuncture as a treatment for this condition. Fifty-eight women diagnosed with fibromyalgia were randomly allocated to two groups. One group received acupuncture $(n=34)$ twice a week for 20 sessions in addition to tricyclic antidepressants and exercises. The control group $(n=24)$ received only tricyclic antidepressants and exercises. Patients rated their pain intensity using a visual analogue scale (VAS). A blinded assessor evaluated the number of fibromyalgia tender points (TePsN) and the pressure pain threshold over the 18 fibromyalgia tender points (PPT18). The same assessor also evaluated quality of life (QoL) using SF-36. These evaluations were done prior to treatments, at the end of the 20 sessions, and again at six months, one year and two years after the first evaluation. At the end of the 20 sessions, patients who had received acupuncture were significantly better than those who had not in all measures of pain (VAS, TePsN, PPT18) and in five subscales of SF-36. After six months, the acupuncture group was significantly better than the control group in some measures of pain (TePsN and PPT18) and in one subscale of SF-36. After one year, the acupuncture group showed significant advantage in only one subscale of SF-36; at two years there were no significant differences between the two groups on all outcome measures. The addition of acupuncture to usual treatment for fibromyalgia is beneficial for pain and quality of life, but only in the first six months. 


\section{Introdução}

\subsection{Fibromialgia}

\subsubsection{Conceitos Gerais}

A fibromialgia é definida como dor músculo-esquelética difusa com múltiplos pontos dolorosos (Merskey, Bogduk, 1994). O principal sintoma é a dor músculo-esquelética com mais de três meses de duração, associada à fadiga crônica, disfunção cognitiva, distúrbio do sono, rigidez matinal, ansiedade e depressão. A dor crônica e a fadiga afetam de modo negativo tanto a qualidade de vida quanto o desempenho da maioria dos doentes com fibromialgia (Hawley, Wolfe, 1991; Henriksson et al., 1992; Henriksson, 1995; White et al., 1999b). Quando comparada a outras doenças reumatológicas, a fibromialgia apresenta os maiores níveis de dor, incapacidade funcional e estresse psicoafetivo (Hawley, Wolfe, 1991; White et al., 1999).

Ela ocorre na proporção de nove mulheres para um homem e incide mais comumente em indivíduos entre 45 e 64 anos de idade (Forseth, Gran, 1992; Pongratz, Sievers, 2000; Russell, 2001). A fibromialgia atinge $2 \%$ da população nos Estados Unidos (Russel, 2001), percentual confirmado também em outros países, pelos estudos de Raspe e Baumgartner (1992) e Cathebras et al. (1998). Já Lindell et al. (2000) encontraram 1,3\% na Suécia. No Canadá, White et al. em 1999b, encontraram 4,9\% de mulheres atingidas pela fibromialgia para $1,6 \%$ de homens. No estudo de Senna et al. 
(2004) registra-se a ocorrência da síndrome fibromiálgica em 2,5\% da população brasileira, com incidência preponderantemente maior em mulheres, confirmando a tendência revelada em estudos empreendidos em outros países (Lindell et al., 2000; White et al., 1999a).

\subsubsection{Etiologia e Etiopatogenia}

A etiologia é desconhecida (Alarcón, Bradley, 1998; Pongratz, Sievers, 2000; Russell, 2001). Muito se tem discutido a respeito da origem da dor na fibromialgia, se central ou periférica. A maioria dos estudos morfológicos, histoquímicos, imunológicos ou biofísicos tem se mostrado negativos nos músculos, tendões e tecidos periarticulares. Por outro lado, a dor central vem sendo investigada e se resume a alterações do eixo hipotálamo-hipófise-adrenal, na interpretação dos estímulos nociceptivos nos níveis de neurotransmissores e também no fluxo sangüíneo cerebral. O eixo hipotálamo-hipófise-adrenal está hiperativado em pacientes com fibromialgia se comparados com indivíduos normais, levando à produção exagerada de ACTH. Não se sabe, todavia, se esta hiperatividade do eixo hipotálamohipófise-adrenal tem base genética ou se é resultado de estresse adquirido ao longo da vida. Observou-se, ainda, o aumento do nível de neurotransmissores, como também do nível da substância $\mathrm{P}$ no líquido cefaloraquidiano de doentes com fibromialgia (Russell, 1994). Isto é válido também para o fator de crescimento neural, o peptídeo relacionado com o gene da calcitonina e a dinorfina A (Keel et al., 1998). O aumento de 
neurotransmissores resulta na despolarização excessiva das células do corno posterior da medula espinhal e se traduz pela receptividade periférica à percepção do estímulo não doloroso. Isto é acompanhada do fluxo sangüíneo ao córtex pré-frontal e do cíngulo anterior, determinando diminuição do fluxo sangüíneo do núcleo caudado e do tálamo (Alarcón, Bradley, 1998). Os estudos de Mountz e colaboradores (1995) provam a diminuição do fluxo sangüíneo no núcleo caudado e no tálamo quando comparado ao grupo - controle por meio das imagens SPECT (SinglePhoton-Emission-Computed-Tomography), bem como o estudo realizado por Provenza et al. (2002) (Figura 1).
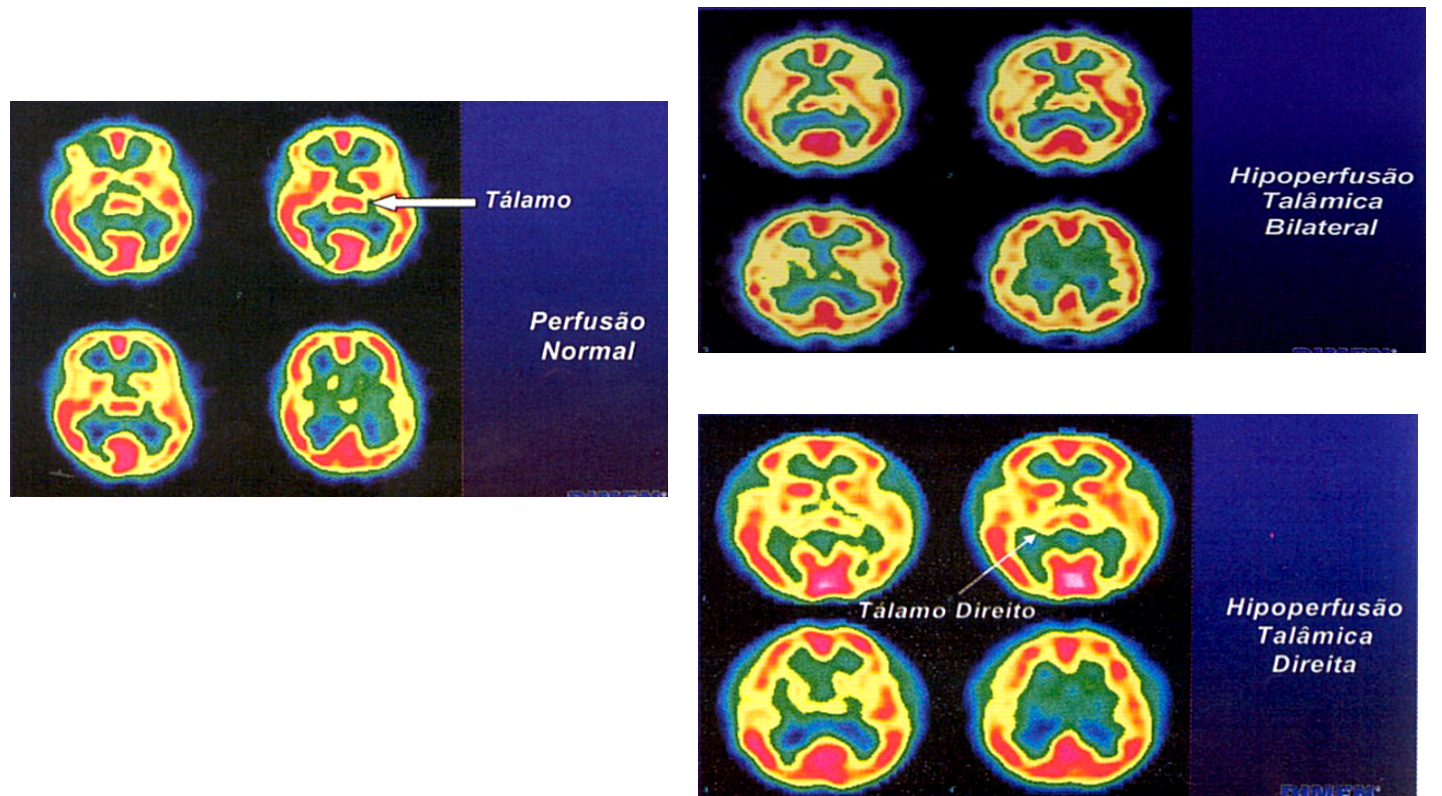

Figura 1. Representação gráfica do resultado do SPECT obtido por Provenza et al. (2002). Observa-se área de hipoperfusão talâmica direita e esquerda em cerebros de fibromiálgicos (reprodução autorizada pelo autor). Fonte: Provenza et al., Rev Bras Reumatol, vol.42, n1, jan/fev, 2002. 
Gracely e colaboradores (2002) estudaram a ressonância magnética funcional, comparando dezesseis pacientes com fibromialgia e dezesseis pessoas normais, como controle. Usaram um estímulo pressórico moderado no leito ungueal do polegar esquerdo dos fibromiálgicos e verificaram que treze áreas cerebrais foram ativadas: córtices sensoriais primários, secundários contra-laterais, lóbulo parietal inferior, córtex da ínsula, giros do cíngulo anterior e posterior contra-laterais e o córtex sensorial secundário ipsilateral. Além das áreas citadas, os giros temporais superiores e o cerebelo foram ativados. Quando se usou a mesma força pressórica nas pessoas normais, nenhuma área foi ativada. Estas áreas só foram ativadas quando a pressão foi o dobro da inicial. Conclui-se por meio deste estudo que a dor na fibromialgia é real.

Alta porcentagem de pacientes com fibromialgia apresenta início insidioso, enquanto outros apresentam sintomas relacionados com 0 processo infeccioso ou estresse, talvez por alteração do sistema imunológico ou sistema endócrino (Alarcón, Bradley, 1998). Alguns pacientes correlacionam os sintomas com episódio traumático, cuja dor permanece depois da cicatrização tissular (Buskila, 2000). Em lesões localizadas na coluna cervical, a chance de desenvolvimento dos sintomas de fibromialgia é $13 \%$ mais freqüente do que se a lesão ocorresse em membros inferiores (Buskila, 2000). A substância P, neurotransmissor armazenado no interior da fibra nociceptiva aferente, está presente na dor crônica músculoesquelética (De Stefano et al., 2000). Existe hiperatividade periférica do sistema nervoso na fibromialgia, bem como na síndrome miofascial. A 
deficiência de antinociceptivos resulta na redução do nível de serotonina como o que tem sido encontrado nos pacientes com fibromialgia. Em 1995, Klein e Berg encontraram anticorpos para a serotonina (5 Hidroxi-Triptofano, $5 \mathrm{H}-\mathrm{T}$ ) em cerca de $70 \%$ dos pacientes com fibromialgia.

A fibromialgia é considerada, atualmente, síndrome de redução de tolerância generalizada à dor, decorrente de baixos níveis de serotonina e altos níveis de substância $\mathrm{P}$ no líquor, possivelmente por disfunção de neurotransmissores. Hiperalgesia e hipoalgesia em animais têm demonstrado a substância P como fator etiológico principal na sensibilização central. O aumento da substância $\mathrm{P}$ é três vezes maior no líquor do paciente com fibromialgia comparado ao controle (Coderre et al., 1993).

Paiva e colaboradores (2002) estudaram a curva do hormônio de crescimento em pacientes com fibromialgia comparados com pessoas normais. Encontraram resposta inibida nos casos de fibromialgia. Ao ministrarem 30mg de piridostigmina e repetirem a curva do hormônio do crescimento, esta se mostrou quase idêntica a dos pacientes do controle.

Sendo assim, a piridostigmina, agente colinérgico, é inibidor da somatostatina, liberando o eixo do hormônio de crescimento.

Wallace et al. (2001), estudando as interleucinas (IL), encontraram diferenças entre voluntários saudáveis e os doentes com fibromialgia. Evidenciou que os valores mais altos das interleucinas estudadas foram encontrados em fibromiálgicos por mais de dois anos. Os resultados mostraram níveis mais elevados da IL-8 na fibromialgia em relação ao controle. Citam ainda que a IL-6 pode induzir muitos sintomas da 
fibromialgia, como a hiperalgesia, a fadiga e a depressão. Segue abaixo um esquema hipotético criado por Wallace et al., 2001 para mostrar a ação das citocinas na fibromialgia (Figura 2):

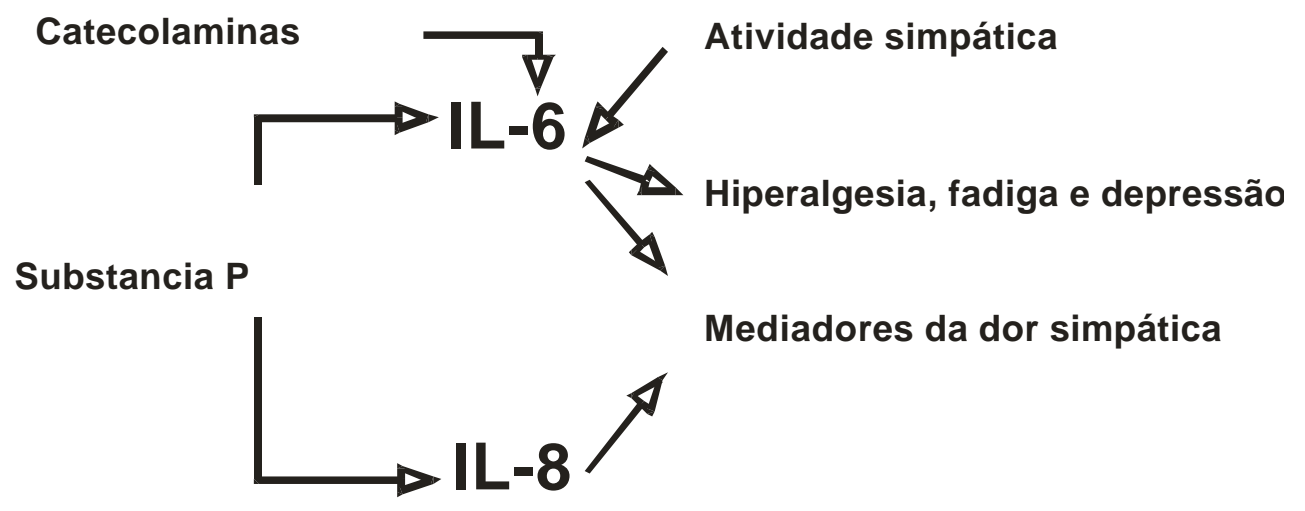

Figura 2. Esquema hipotético da possível ação das citocinas na fibromialgia. (Wallace et al., 2001).

Gür et al., em 2002, também estudaram as citocinas em fibromialgia e demonstraram que existem diferenças nos valores das citocinas de doentes com ou sem sintomas depressivos significativos. As IL-2 $r$, isto é, interleucina 2 receptora e a IL-8 apresentam aumento significativo no soro, em comparação aos voluntários saudáveis. Concluem que estes resultados sugerem que a IL-8 pode ser fator importante na fibromialgia. Os resultados 
não evidenciaram, contudo, relação entre o nível de depressão e as citocinas no soro de pacientes com fibromialgia.

Todos esses estudos levam a crer que, tanto na fibromialgia como na dor crônica, as trocas dos neurotransmissores se fazem de forma incorreta no eixo hipotálamo-hipofisário-adrenal em relação às pessoas normais. Isto é particularmente verdadeiro no relacionamento entre o eixo neuroendócrino e o sono. O eletroencefalograma do sono nos pacientes com fibromialgia, indica distúrbio da fase do sono não REM (Rapid Eye Movement) pela intrusão das ondas alfa, com progressão para os estágios 3 e 4 do sono (Roizenblatt et al., 2002). Durante a atividade normal do sono, hormônios são liberados, como o hormônio do crescimento que ocorre entre os estágios 3 e 4 do sono não-REM para as pessoas normais. Já para os pacientes com fibromialgia, o valor é baixo para o nível do fator de crescimento da insulina (GF), indicando assim a baixa liberação do hormônio de crescimento (Millea, Holloway, 2000).

\subsubsection{Diagnóstico}

O diagnóstico da fibromialgia é clínico e realizado pelo critério do Colégio Americano de Reumatologia de 1990, de acordo com consenso obtido naquele ano por Wolfe e colaboradores (Wolfe et al., 1990) com os seguintes itens:

1- História de dor crônica músculo-esquelética por todo o corpo, com persistência por mais de três meses. A dor deve estar presente em ambos 
os lados (direito e esquerdo) do corpo, acima e abaixo da cintura e também no esqueleto axial (coluna cervical, torácica e lombo-sacra), atingindo a parte anterior do tórax.

2- Exame clínico: presença de dor em pelo menos onze dos dezoito pontos dolorosos pesquisados, que são considerados positivos quando é realizada pressão com algiômetro de Fischer (Fischer,1988) apontando dor menor do que 4Kgf. Estes pontos podem ser pesquisados pelo profissional por palpação digital (polegar). O algiômetro de Fischer (Figura 3) é um dinamômetro que marca o valor da dor na velocidade de $1 \mathrm{kgf} / \mathrm{segundo}$. Os pontos são pesquisados bilateralmente.

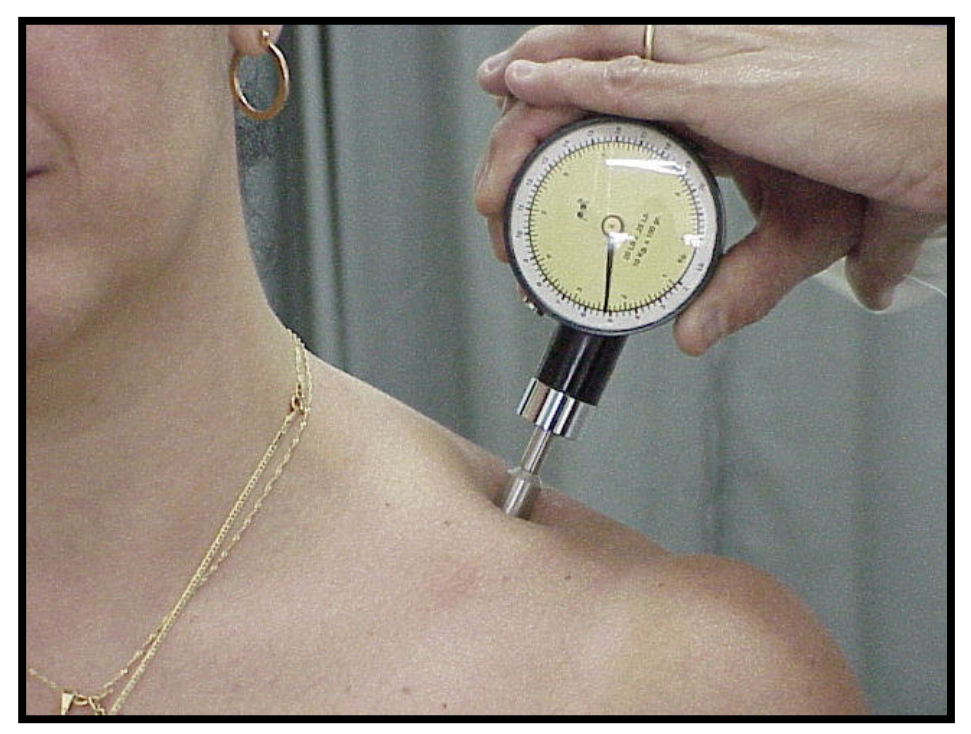

Figura 3. Quantificação do limiar de tolerância à pressão pelo algiometro de Fischer no músculo trapézio superior esquerdo. 
A fibromialgia pode ser primária ou estar associada a outros problemas, tais como artrite reumatóide, osteoartrite lupus eritematoso sistêmico (Middleton et al., 1994). Essas doenças podem ser comprovadas por meio de exames laboratoriais.

Podem apresentar, ainda, problemas hormonais, como por exemplo, hipotireoidismo, que deve ser tratado adequadamente.

Com exceção da síndrome dolorosa miofascial, todas as outras entidades nosológicas podem ser confirmadas por meio de exames laboratoriais e pelos estudos radiológicos.

\subsubsection{Tratamento}

\subsubsection{Tratamento Medicamentoso}

Os medicamentos mais usados para o tratamento da fibromialgia são os antidepressivos tricíclicos, como o cloridrato de amitriptilina, pamoato de imipramina e cloridrato de imipramina (Arnold et al., 2000). A dosagem destes medicamentos são menores do que as usadas para depressão (Millea, Holloway, 2000). Estas doses têm efeitos analgésicos, agindo no bloqueio de recaptação da serotonina e noradrenalina pelas vias supressoras de dor, alterando a atividade de neurotransmissores como a substância P (Teixeira et al., 2001).

Há muitos anos, os antidepressivos tricíclicos são usados para tratamento da dor crônica e atualmente para o da fibromialgia, reduzindo os 
sintomas devido a sua variação quanto a absorção, metabolismo e excreção. (Millea, Holloway,2000)

Para Goldenberg (1987), a depressão que acompanha a fibromialgia é de natureza psicobiológica. A depressão não foi confirmada como sintoma, do qual resultou a fibromialgia, ou se é concomitante à sindrome (Bradley, Alberts, 1999). Mesmo porque, os casos de depressão nem sempre vêm acompanhados ou desenvolvem fibromialgia (Martinez et al., 1992).

\subsubsection{Tratamento Não Medicamentoso}

Como tratamento não-medicamentoso, são muito importantes os exercícios aeróbios de baixo impacto, como caminhadas e alongamentos duas a três vezes por semana (Millea, Holloway, 2000).

A dor crônica e a fadiga afetam negativamente a qualidade de vida da maioria dos doentes com fibromialgia. Seus sintomas da fibromialgia influenciam muito no desenvolvimento diário das funções habituais, causando pronunciado impacto em todas as atividades do dia-a-dia, afetando tanto a capacidade de trabalho, como a vida familiar e também a social (Henriksson et al., 1992). A fadiga é freqüentemente citada pelos pacientes como fator incapacitante maior do que a dor (Henriksson, 1995).

O estudo de Marques et al (2005) demonstrou que tanto a dor quanto a qualidade de vida de mulheres com fibromialgia são piores do que as de mulheres sadias.

Os familiares têm dificuldade em aceitar os problemas dos doentes com fibromialgia, pois, como não existe uma causa evidente, as queixas 
tendem a cair em descrédito. Desse modo, técnicas de relaxamento individual ou em grupo (Rucco et al., 1995; Keel et al., 1998) e de terapia comportamental (Bradley, Alberts, 1999; Buskila, 2000) devem ser empregadas para aliviar os sintomas dos doentes. Técnicas de treinamento autógeno parecem melhorar a qualidade de vida deles (Rucco et al., 1995). Souza (2001) usou o método de Jacobson, denominado relaxamento progressivo e a técnica de visualização dirigida,na qual se associa o exercício e a imaginação durante o processo de relaxamento. Os resultados obtidos evidenciam que ambas as técnicas diminuem a intensidade da dor nas doentes com fibromialgia. 


\subsection{Acupuntura}

\subsubsection{Conceitos Gerais}

A acupuntura surgiu na China há quatro mil e quinhentos anos aproximadamente. A técnica desta arte milenar se vale de agulhas ou moxas para aliviar a dor ou sintomas decorrentes de doenças.

Em 1963, no interior da Mongólia, arqueólogos encontraram, em escavações, objetos pontiagudos extremamente finos, que sugeriam agulhas refiladas de pedra e catalogadas, dentre os objetos recolhidos nesses sítios arqueológicos, como agulhas de acupuntura. Tais objetos pertenciam ao período chamado como neolítico - 10.000 a 4.000 anos atrás.

Este tipo de agulha só é reconhecida a partir do livro Canônico de Medicina do Imperador Amarelo, também chamado livro de Nei Jing, por volta do século $2 \mathrm{aC}$.

Depois, as agulhas mais grosseiras de pedra deram lugar a agulhas de materiais mais nobres e adequados como o bronze, o ferro, o ouro, a prata, na medida em que a arte da forjaria avançou com a civilização. Modernamente usamos agulhas de aço inoxidável, finas e descartáveis.

A acupuntura chegou à Europa nos séculos XVI e XVII levada pelos padres jesuítas que retornavam de missões de catequese no Oriente. Foi difundida pelo mundo e hoje passou a dominar um conjunto de procedimentos e técnicas que induzem a liberação de neurotransmissores com a finalidade analgésica, antidepressiva, antiansiolítica, antiinflamatória, entre outras (Hong, 2005). 
O resultado terapêutico é obtido pela inserção de agulhas em pontos determinados seguindo as linhas dos meridianos (Figura 4). Estes meridianos são traçados imaginários distribuídos por todo o corpo, em número de doze e que tomam os nomes conforme os orgãos ou vísceras que atravessam. Possuem duas ramificações: uma externa tegumentar e a outra interna, dos orgãos ou das vísceras.

Em 1991 a Organização Mundial da Saúde (WHO, 1991) padronizou a nomenclatura internacional que descreve os pontos clássicos da acupuntura.

Os meridianos são então denominados segundo abreviaturas da denominação inglesa dos órgãos ou vísceras que representam Assim temos: pulmão (LU), intestino grosso (LI), estômago (ST), baço pâncreas (SP), coração $(\mathrm{HT})$, intestino delgado $(\mathrm{SI})$, bexiga $(\mathrm{BL})$, rins $(\mathrm{KI})$, pericárdio $(\mathrm{PC})$, fígado (LR), vesícula biliar (GB) e, por último, o triplo aquecedor (TE). Além destes, existem dois meridianos extras. Um que percorre a parte ventral do corpo, o meridiano Ren-Mai (CV) e outro, a parte dorsal, denominado meridiano Du-Mai (GV). Muitos pontos extras estão localizados em várias partes fora das linhas dos meridianos.

Nos trajetos dos meridianos, localizam-se os pontos de acupuntura, também conhecidos como "acupontos", onde se aplicam as agulhas.

Para termos certeza que a agulha atingiu o seu objetivo é necessário obter a sensação de "Qi", a que os pacientes se referem como choque ou dor discreta, peso, ardência ou sensação de dormência. 
A medicina tradicional chinesa se baseia na teoria Yin e Yang, assim os meridianos também são divididos em Yin e Yang, de acordo com o órgão ou a víscera a que se relacionam. 


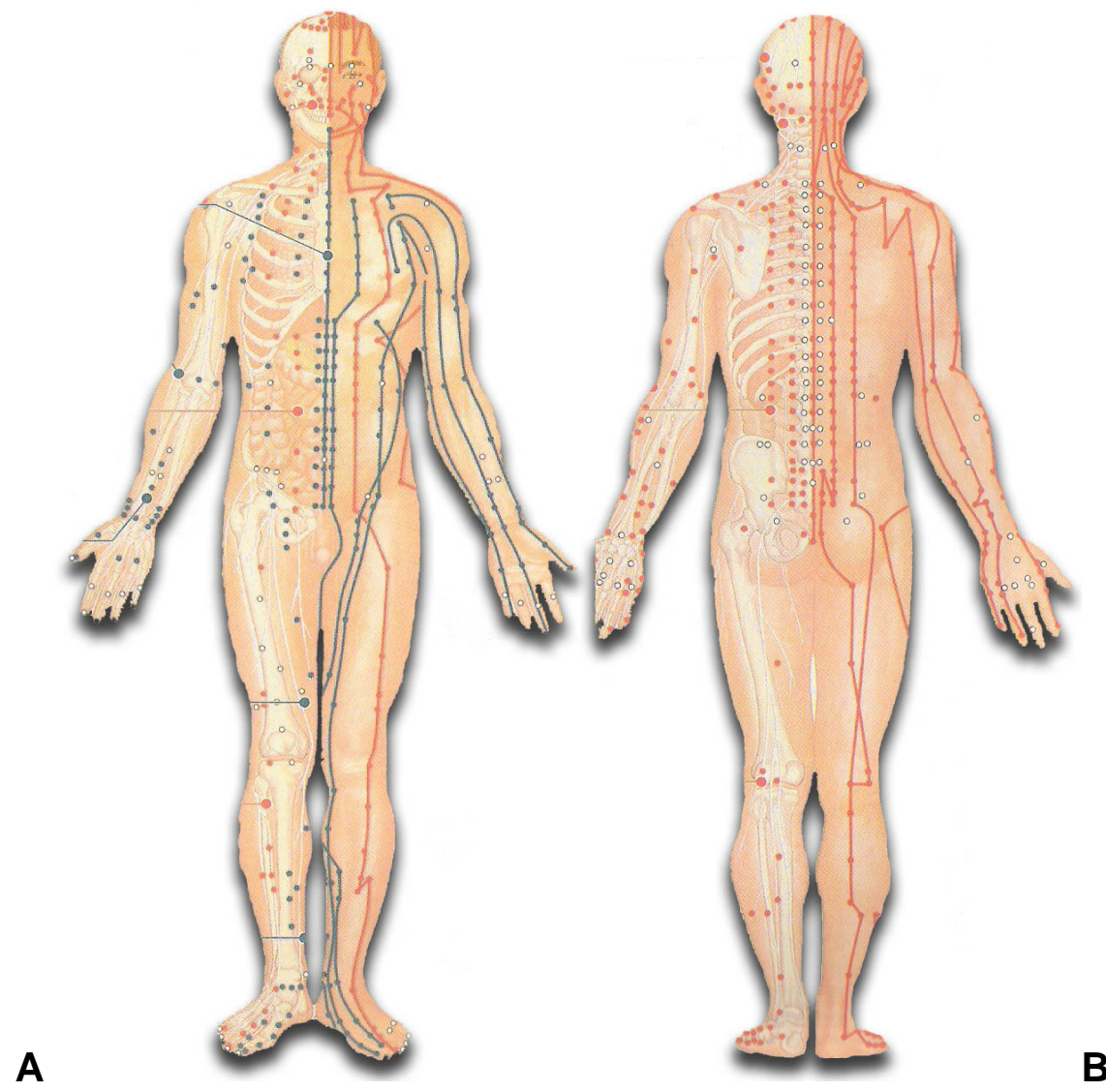

B

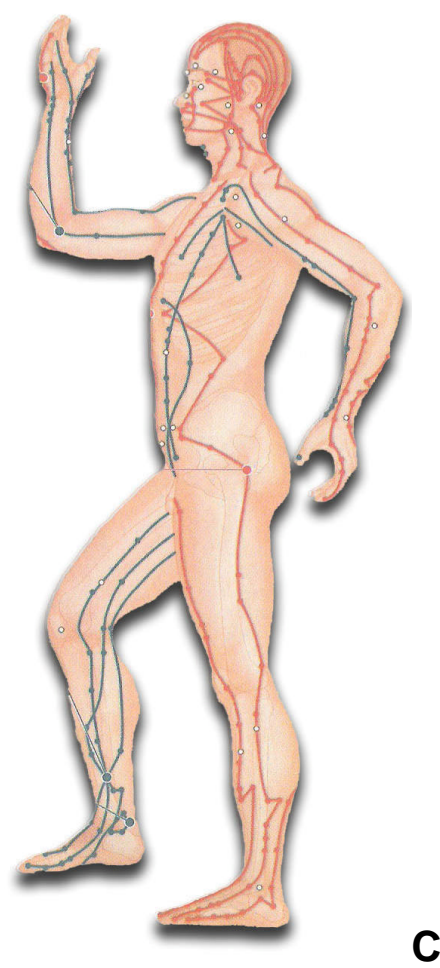

Figura 4. Representação esquemática da localização dos meridianos clássicos da acupuntura na visão ventral (A), posterior (B) e lateral do corpo (C). Reprodução autorizada pelo autor. Fonte: Hong (2005). 


\subsubsection{Acupuntura e Dor}

Por ser de origem empírica, a acupuntura nem sempre teve crédito. Entretanto, os trabalhos realizados pelo mundo nas últimas décadas comprovaram a eficácia da técnica no tratamento da dor (Ezzo et al., 2000). Deste modo, a acupuntura está sendo cada vez mais utilizada como intervenção terapêutica nos Estados Unidos (Ezzo et al., 2000) e na Europa.

Aproximadamente um milhão de norte-americanos utilizam acupuntura anualmente para o tratamento de doenças que causam dor (Ezzo et al., 2000). No Brasil, a acupuntura foi considerada especialidade médica a partir de 1995 pelo Conselho Federal de Medicina e desde 1998 pela Associação Médica Brasileira.

O consenso do National Institutes of Health a respeito da acupuntura concluiu que ela é útil como terapia alternativa ou como tratamento coadjuvante. Deve ser incluído em programas de controle da dor em pacientes com fibromialgia ou em condições como dores de cabeça, tensão pré-menstrual, lombalgias, síndrome do tunel do carpo, dentre outras $(\mathrm{NIH}$, 1998).

A estimulação nociceptiva discriminativa intensa produzida pela acupuntura resulta na elevação dos níveis basais de serotonina, noradrenalina e encefalina no líquido céfalo-raquidiano e no corno posterior da medula espinhal (Teixeira, 1995). 
Sabe-se que as estimulações elétricas das vias e dos núcleos discriminativos sensitivos e da medula espinhal e do encéfalo geram analgesia prolongada por liberação nas fendas sinápticas neurotransmissoras com atividade antinociceptiva (Teixeira, 1995). Mecanismos analgésicos semelhantes ao da estimulação elétrica parecem ocorrer quando a acupuntura é usada.

Dois mecanismos, segundo estudos modernamente realizados, podem bloquear a dor pela ação da acupuntura: a inibição da atividade de neurônios transmissores da dor ao nível medular, segundo os mecanismos de comporta; e pela inibição da aferência nociceptiva, por meio da ativação de sistemas supressores da dor supra-segmentar.

A eficiência da acupuntura começa no ponto da introdução das agulhas, pois o efeito do método é bloqueado pela anestesia local ou regional (Hong, 2005).

As fibras do tipo II, que conduzem 'a sensibilidade proprioceptiva dos nervos periféricos, precisam ser estimuladas para que o índice da eficácia da acupuntura seja elevado. Essas fibras são discriminativas e podem interferir nos sistemas supressores da dor (Chapmann, Gunn, 1990).

A analgesia é mais intensa quando se aplica a acupuntura por maior tempo, prolongando a duração dos seus efeitos, que não desaparecem com a interrupção dos estímulos, o que reforça a possibilidade de participação de neurotransmissores. 
Muito se tem discutido a respeito da aplicação da acupuntura no tratamento da dor aguda ou crônica.

Hipóteses têm sido aventadas, tais como: efeito placebo, efeito de contra-irritação, sugestão ou hipnose. Existem, porém, evidências de que outros mecanismos estão envolvidos no efeito da acupuntura (Cheng, Han, 1992; Cheng, Pomeranz, 1981). A hipnose, por exemplo, tem mecanismos que diferem da acupuntura por vários aspectos, já que provoca a analgesia em exíguo número de casos. O efeito é de curta duração e não é anulada por bloqueadores de receptadores morfínicos, ao passo que na acupuntura o efeito é prolongado e pode ser anulado por bloqueadores de receptadores morfínicos (Pomeranz, Stux, 1989).

O fator humoral deve estar envolvido na analgesia produzida pela acupuntura.

A introdução intraventricular do líquido cefalorraquidiano de animais tratados por acupuntura e transferido para outros animais não tratados por acupuntura, causaram analgesia nestes animais. Os estudos com circulação cruzada demonstram elevação do limiar da dor nestes últimos (Imamura, 1995).

O efeito da acupuntura é bloqueado pela administração de antagonistas de neurotransmissores, incluindo-se entre eles a naloxona, que bloqueia a ação das encefalinas, endorfinas e dos bloqueadores de serotonina (Pomeranz, Stux, 1989). 
O efeito da dor é potencializado pela serotonina, neurotransmissores morfínicos, acetil-colina e D-amino-acidos, sendo antagonizados pelas catecolaminas (Malliani et al., 1989).

Se houver lesão na rede nervosa periférica, ou se esta estiver afetada por alguma doença, a eficácia da acupuntura não se realiza.

Cho e colaboradores (2002) escanearam os cérebros de voluntários que se submenteram à acupuntura usando neuro imagens, obtidas por tomografia por emissão de positrons (Pet). Além da acupuntura clássica, aplicou-se a acupuntura sham. Este tipo de acupuntura é utilizado por muitos pesquisadores para investigar o efeito placebo. Trata-se da introdução das agulhas em lugares diferentes dos pontos estabelecidos pela medicina tradicional chinesa ou então inseridas um pouco abaixo ou acima de determinado ponto clássico.

Em outros casos, as agulhas apenas tocam a pele e não são introduzidas. Em outra situação, as agulhas só dão a impressão que estão sendo inseridas.

Três situações foram comprovadas pelas imagens cerebrais realizadas por Napadow et al (2007). As três diferentes imagens podem ser vistas na Figura 5.

A primeira imagem revela os locais onde se localiza a dor (Figura 5A). $\mathrm{Na}$ segunda imagem cerebral observa-se a ação da acupuntura na dor (Figura 5B) e na terceira visualiza-se a ação da sham acupuntura na dor (Figura 5C). Conclui-se, então, que também existe ação analgésica da sham acupuntura, como se pode observar na imagem cerebral (Figura 5c). 


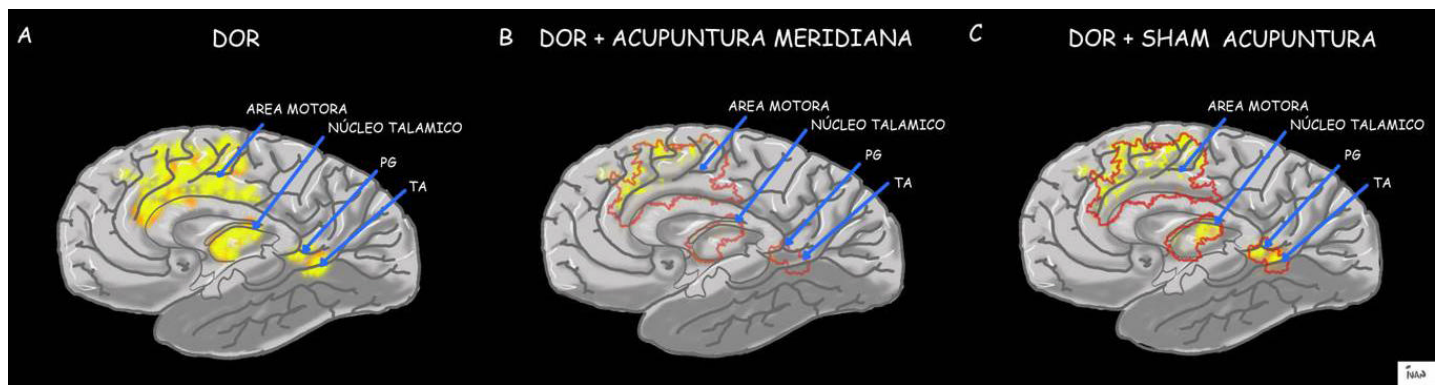

Figura 5. (A) Representação comparativa da atividade cerebral durante a vigência da dor (B), acupuntura clássica e dor (C) e sham acupuntura e dor. Modificado de Napadow et al (2007)

Ainda na década de 50, Yoshio Nakatani (1977) introduziu a eletroacupuntura Ryoduraku, relacionando a teoria da dualibilidade Yin e Yang ao sistema nervoso neurovegetativo (simpático e parassimpático). Seus estudos demonstraram que quase todos os pontos da acupuntura clássica correspondiam a pontos de baixa resistência elétrica cutânea. A estes pontos ele denominou de PREP (pontos reativos eletro permeáveis) (Imamura, 1995).

Por meio destes achados, pode-se concluir que, realmente, os pontos da acupuntura se situam nas terminações nervosas corporais. 


\subsubsection{Acupuntura e Fibromialgia}

Conforme ressaltamos, resultados promissores têm surgido, mostrando a eficácia da acupuntura em diversas situações clínicas (NIH, 1998; Berman et al., 1999; Ezzo et al., 2000). Alguns estudos controlados randomizados (Lautenschläger et al., 1989; Pasotti et al., 1990; Deluze et al., 1992; Cassisi et al., 1995; Sprott et al., 1998; Sprott et al., 2000; Costa, 2001; Assefi et al., 2005; Martin et al., 2006) e não randomizados (Waylonis, 1977) estudaram o efeito da acupuntura em fibromialgia. Poucos estudos científicos de alta qualidade foram encontrados (Deluze et al., 1992; Assefi et al., 2005; Martin et al., 2006). Na revisão feita por Lee em 2000, concluiuse que a acupuntura foi mais eficaz do que a sham acupuntura na melhora dos sintomas da fibromialgia.

Em estudo controlado, Waylonis (1977) tratou 62 pacientes diagnosticados com fibrosite crônica, termo antigo usado para denominar a fibromialgia, com eletroacupuntura subcutânea. Os resultados mostraram resposta positiva em $67 \%$ dos pacientes que receberam o tratamento por eletroacupuntura.

Lautenschläger et al. (1989) dividiram 50 pacientes com fibromialgia em dois grupos. Um grupo recebeu seis tratamentos com acupuntura e o outro grupo seis aplicações placebo, através de equipamento de laser desconectado. A avaliação pela escala visual analógica e pela dolorimetria evidenciou que o grupo que recebeu a acupuntura apresentou melhores resultados do que o grupo placebo. Estes resultados, entretanto, só foram 
observados ao término do tratamento e não se mantiveram na avaliação três meses após o final das aplicações.

Já Pasotti et al. (1990) associaram a acupuntura ao uso de antidepressivos, como a amitriptilina, para o tratamento da fibromialgia primária. Compararam os efeitos com pacientes que receberam apenas tratamento fisiátrico convencional. Redução significativa dos sintomas álgicos físicos e psicoafetivos foi observada após um, três, seis e nove meses após o tratamento.

Cassisi et al. (1995) empregaram a acupuntura para tratar 42 pacientes de fibromialgia que foram randomizadas em três grupos. No grupo A, utilizaram acupuntura; grupo B, antidepressivo e, no grupo $C$, acupuntura e antidepressivo. O antidepressivo utilizado foi a mianserina. Foi encontrado melhor benefício para o grupo que usou a combinação de acupuntura com antidepressivo, com melhora significativa até seis meses depois do tratamento.

Deluze et al. (1992) também usaram a eletroacupuntura para tratar 70 pacientes com fibromialgia. Os melhores resultados foram para o grupo de acupuntura, em relação ao grupo controle que recebeu sham acupuntura. Os resultados foram verificados nos seguintes itens: limiar de tolerância à dor, intensidade da dor medida pela EVA (Escala Visual Analógica), qualidade do sono, rigidez matinal e a verificação do estado geral de saúde por um médico clínico. O principal parâmetro de avaliação dos resultados do estudo foi o limiar de tolerância à pressão dos dezoito pontos pesquisados. 
A melhora significante observada no grupo eletroacupuntura foi de $70 \%$, comparada a $4 \%$ no grupo controle.

Sprott et al. (1998) trataram 29 pacientes com fibromialgia pela acupuntura. O tratamento evidenciou queda dos valores da EVA e do número de pontos dolorosos medidos com algiômetro. A concentração de serotonina nas plaquetas diminuiu entre os pacientes do grupo tratado com acupuntura, enquanto a concentração da serotonina sérica aumentou. Níveis de substância P no soro, um neuropeptídeo relacionado como mediador de nocicepção, também aumentou.

Em seu estudo, Costa, 2001, registrou melhora significantiva em pacientes com fibromialgia depois de dez sessões de eletroacupuntura. A melhora se verificou em vários domínios da qualidade de vida medida pelo questionário SF-36: capacidade física, aspecto físico, dor, aspecto social e saúde mental. Os dois grupos estudados, tanto a eletroacupuntura quanto o grupo controle (sham acupuntura) melhoraram no item saúde mental. Todavia, não houve melhora significativa na qualidade de vida entre os três grupos estudados: acupuntura, sham acupuntura e medicação antidepressiva.

Sprott et al. (2000) registraram o fluxo sangüíneo sobre cinco pontos dolorosos representativos da fibromialgia através da fluxometria com LaserDoppler. Avaliaram o fluxo sangüíneo sobre os pontos: cervical posterior, trapézio superior, região medial do joelho, trocanter maior e sobre o epicôndilo lateral. Os autores trataram 20 pacientes com fibromialgia pela acupuntura, usando um protocolo específico. Após o tratamento com a 
acupuntura, os autores evidenciaram o aumento do fluxo sangüíneo acima de todos os pontos dolorosos estudados. Constataram o aumento da temperatura tegumentar em 10/12 pontos dolorosos, de 0,45ํㅡ em média. Observaram ainda a redução do número de pontos dolorosos de 16,1 para 13,8 e o aumento do limiar de tolerância à dor em 10/12 pontos dolorosos após o tratamento. Estes dados sugerem que a melhora na microcirculação sobre os pontos de dolorimento possa estar associada ao alívio da dor.

Assefi et al. (2005) compararam o efeito analgésico da acupuntura com três tipos diferentes de sham acupuntura em 100 doentes com fibromialgia. Usaram pontos de acupuntura clássicos, porém não indicados para o tratamento da fibromialgia: a inserção de agulhas em pontos não clássicos da acupuntura e simulação de acupuntura sem a inserção das agulhas. O resultado foi medido através da escala visual analógica da dor. Concluíram que a acupuntura não foi superior aos três tipos de sham acupuntura estudados.

Em estudo mais recente, Martin et al. (2006), também compararam os efeitos da acupuntura com um grupo placebo na melhora dos sintomas da fibromialgia. O grupo placebo recebeu sessões simuladas de acupuntura, sem a introdução das agulhas. Os sintomas da fibromialgia foram quantificados através do Fibromyalgia Impact Questionnaire (FIQ), um mês e sete meses após o término do tratamento. Diferentemente de Assefi et al. (2005), demonstraram que a acupuntura melhora de modo significativo os sintomas da fibromialgia. As diferenças mais significativas entre os dois grupos, foram observadas na avaliação de um mês após o final do 
tratamento. A fadiga e a ansiedade foram os sintomas que mais melhoraram.

Como foi descrito acima, muitos estudos randomizados e controlados mostraram o efeito benéfico da acupuntura nos pacientes com fibromialgia. A qualidade destes estudos, entretanto, tem sido criticada por abranger escassa amostra populacional com intervalos curtos de observação (Crofford, 2001; Berman et al., 1999).

Estudos recentes de alto nivel científico descrevem achados ainda conflitantes (Assefi et al., 2005; Martin et al., 2006). Sjölund (2005), em seu editorial, afirma que o desenho de futuros ensaios clinicos deve incluir número maior de indivíduos, condição da dor bem definida, pontos de acupuntura padronizados pela medicina clássica chinesa, além da utilização de medidas precisas para a avaliação do efeito.

Desse modo, o objetivo de nosso estudo foi o de verificar o benefício da acupuntura no tratamento da dor em doentes com fibromialgia, com a amostra populacional necessária, empregando pontos de acupuntura padronizados, medidas objetivas de avalição dos resultados, em estudo prospectivo controlado randomizado, com longo intervalo de observação. 


\section{Objetivos}

2.1 Objetivo Geral:

O objetivo desse estudo foi avaliar o benefício da acupuntura associada ao tratamento convencional com antidepressivos tricíclicos e exercícios em pacientes com fibromialgia.

\subsection{Objetivos Específicos:}

Verificar se houve diminuição da intensidade da dor, do número de pontos dolorosos e do índice miálgico entre o grupo que usa só medicação e exercícios e o grupo que recebe tratamento complementar de acupuntura.

Verificar se houve mudança na qualidade de vida com o uso da acupuntura a partir da avaliação de domínios específicos relacionados à saúde física e mental. 


\section{Casuística e Métodos:}

\subsection{Desenho do estudo}

Estudo prospectivo com 58 pacientes do sexo feminino com idades entre 27 e 70 anos (média 51,70 \pm 10,97), que apresentavam dor de intensidade moderada a grave (Escala Visual Analógica: EVA>4) com diagnóstico de fibromialgia realizado de acordo com a classificação do Colégio Americano de Reumatologia de 1990 (Wolfe et al.1990). As doentes receberam medicação antidepressiva na dose analgésica de 12,5 a 75mg/dia. Foram selecionadas da Clínica de Dor da Divisão de Clínica Neurológica, do Serviço de Reumatologia da Divisão de Clínica Medica II,e da Divisão de Medicina Fisica do Instituto de Ortopedia e Traumatologia (DMF-IOT) do Hospital das Clínicas da Faculdade de Medicina da Universidade de São Paulo(HC-FMUSP). As doentes passavam por consulta clínica e eram encaminhadas para o ambulatório de Fibromialgia da DMRIOT do HC-FMUSP, para confirmação do diagnóstico de fibromialgia de acordo com o critério do Colégio Americano de Reumatologia e medicadas de acordo com o tratamento pré-estabelecido, que consistiu em antidepressivos tricíclicos na dosagem analgésica, conforme a necessidade de cada paciente, além de outras substâncias para tratamento de problemas de saúde pré-existentes. Foram submetidas aos critérios de inclusão e exclusão para participação no estudo, conforme protocolo padronizado. 
Todas as pacientes foram informadas a respeito do protocolo de tratamento e só foram admitidas para o estudo depois de assinarem o termo de consentimento livre esclarecido usado no Hospital das Clínicas da Faculdade de Medicina da Universidade de São Paulo (Anexo A).

As pacientes foram randomizadas e divididas em dois grupos, de modo aleatório, logo após a assinatura do termo de consentimento. A randomização foi feita com auxílio de tabela computadorizada de números randômicos, emitida por planilha eletrônica Microsoft Excel. O resultado da randomização foi mantido em envelopes selados e opacos para garantir a ocultação da seleção. Do grupo de acupuntura mais o tratamento convencional participaram 34 pacientes; no grupo controle, que recebia o tratamento convencional, 24 pacientes.

As participantes desse trabalho integraram o programa educativo de fibromialgia existente no IOT do HC-FMUSP, que consistia em aulas teóricopráticas que informavam sobre as melhores maneiras de controlar a dor, além de práticas de técnicas para o auto-tratamento por meio de exercícios de alongamento e de relaxamento. A finalidade deste encorajamento era tornar a pessoa consciente da natureza de seu problema e torná-la menos dependente da instituição hospitalar (Kaziyama, Souza, 1999).

O protocolo estudado teve aprovação da Comissão de Ética para Análise de Projetos de Pesquisa (CAPPesq), protocolo número 843/99 do HC-FMUSP (Anexo B). 


\subsection{Seleção das Pacientes:}

\subsubsection{Critérios de Inclusão:}

1- Doentes com idade entre 20 e 70 anos do gênero feminino.

2- Dor de intensidade moderada à grave: escala visual analógica $>4$ (EVA)

3- Conformidade ao critério do Colégio Americano de Reumatologia de 1990 (Wolfe, 1990), para diagnóstico de síndrome fibromiálgica, que consiste em:

a) História clínica: dor músculo-esquelética generalizada durante os últimos três meses, dor localizada na metade do hemicorpo direito e esquerdo, acima e abaixo da cintura na região do tórax e no esqueleto axial (cervical e lombar).

b) Exame físico, dor intensa a dígito-pressão $\left(4 \mathrm{kgf} / \mathrm{cm}^{2}\right)$ em onze ou mais dos 18 pontos anatômicos pesquisados bilateralmente, denominados pontos dolorosos (Figura 6). Avaliamos o número de pontos dolorosos (NPD). Nesta pesquisa, a quantificação do limiar de tolerância da dor, à pressão, foi realizada pelo algiômetro de Fischer (Fischer, 1988) nos seguintes pontos bilateralmente:

- $\quad$ a - Occipital:Inserção dos músculos sub occipitais na nuca;

- b - Trapézio: ponto médio da borda superior do trapézio;

- c - Supra-espinhoso: na inserção do supra espinhoso acima da parte medial da escápula; 
- d - Glúteo médio: região do quadrante superior externo do glúteo

- e - Cervical baixa: faixa anterior do espaço intratransverso da C5-C7.

- f - Segundo espaço intercostal: borda superior na junção costocondrial.

- $\mathbf{g}$ - Epicôndilo lateral: cerca de dois centimetros de distância do epicôndilo lateral

- h - Grande trocânter: parte posterior à proeminência trocantéria.

- $\mathbf{i}$ - Joelho: coxim gorduroso na interlinha articular medial.

A localização dos pontos dolorosos para o diagnóstico da fibromialgia está indicada na figura 6.(anexo D) 

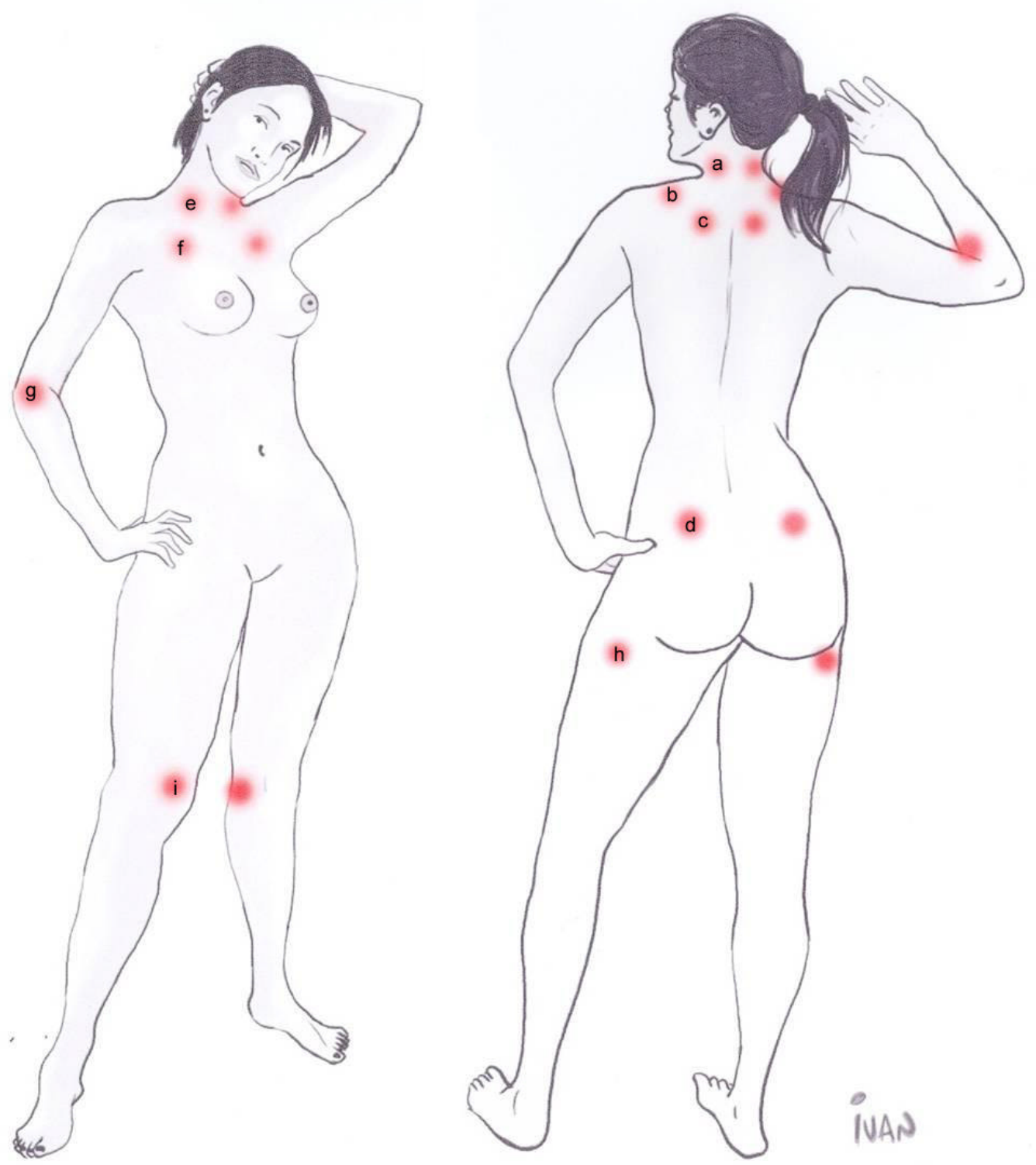

Figura 6 Representação esquemática da localização dos pontos da fibromialgia, conforme Wolfe et al. (1990). Reprodução artística de Ivan Rocha

4- Todas as pacientes foram medicadas com antidepressivos tricíclicos em dose analgésica de 12,5 a 75mg (de acordo com a dose prescrita para cada paciente), além da realização de exercícios físicos regulares. 


\subsubsection{Critérios de Exclusão:}

1- Alteração psiquiátrica grave (necessitando de acompanhamento psiquiátrico). Exemplo: depressão maior ou esquizofrenia;

2- Alteração neurológica ou seqüela neurológica;

3- Cardiopatia ou glaucoma;

4- Tratamento com acupuntura até um ano antes do começo do estudo.

\subsection{Caracterização Clínica e Instrumentos de Avaliação:}

A avaliação das medidas da dor, tais como escala visual analógica, índice miálgico, o número de pontos dolorosos foram realizadas sempre pelo mesmo médico que desconhecia a que grupo a paciente pertencia. A qualidade de vida foi aferida por psicólogo que igualmente desconhecia a que grupo a paciente pertencia.

Foram feitas cinco avaliações. A primeira, anterior ao tratamento (TO), a segunda, pós-tratamento (T1) que ocorreu em média três meses depois da randomização. Foram reavaliados seis meses (T2), um ano (T3) e dois anos após a primeira avaliação TO, conforme indicado na figura 7 . 


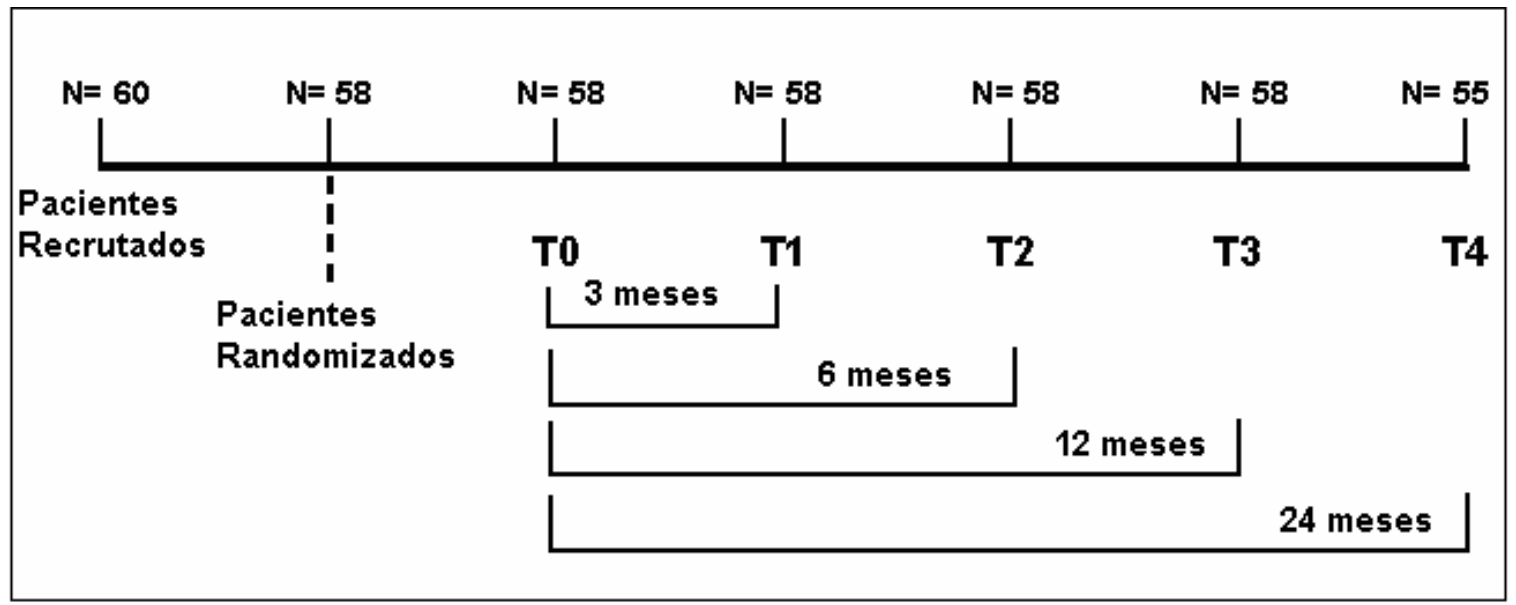

33

Figura 7. Evolução cronológica dos eventos do estudo. $\mathrm{N}=$ número de ca.sos. T0: avaliação anterior ao tratamento; T1: avaliação pós tratamento; T2: avaliação seis meses após a primeira avaliação; T3: avaliação doze meses após a primeira avaliação; T4: avaliação 24 meses após a primeira avaliação.

A anamnese consistiu na coleta de dados sobre idade, sexo, tempo de dor, intensidade da dor, doenças associadas e ocupação profissional atual (Anexo C).

O exame físico foi feito utilizando instrumentos de avaliação e medidas dos pontos dolorosos.

Os instrumentos de avaliação foram os seguintes:

\subsubsection{Dor:}

\subsubsection{Escala Visual Analógica (EVA)}

Consiste em uma linha de $10 \mathrm{cms}$, sendo o primeiro número 0 e o último 10, representando respectivamente a ausência de dor e a dor de 
máxima intensidade (Figura 8). Avalia-se a intensidade da dor de acordo com a percepção da paciente, situando-a entre os pontos 0 e 10.

O valor 0 corresponde a "sem dor" e o 10, "dor intensa". O valor é obtido medindo-se a distância entre o valor inicial 0 e o ponto marcado pela paciente.

0

Figura 8 Escala visual analógica (EVA)

\subsubsection{Número de pontos dolorosos (NPD):}

Os pontos dolorosos pré-estabelecidos pelo Colégio Americano de Reumatologia (1990) denominados de tender points foram medidos pelo Algiômetro de Fischer (Fischer, 1988), um dinamômetro de pressão, constituído por um disco de borracha na extremidade de um tubo acoplado ao dinamômetro (Figura 3). O disco tem exatamente $1 \mathrm{~cm}^{2}$ e a leitura é expressa em $\mathrm{kgf} / \mathrm{cm}^{2}$. O algiômetro quando apertado contra a superfície corpórea permite aferir a pressão que causa a dor e a totalidade dos pontos dolorosos, bem como, calcular o índice miálgico (MI). É considerado ponto positivo quando o valor for menor do que $4 \mathrm{kgf} / \mathrm{cm}^{2}$.

\subsubsection{3 Índice Miálgico (IM):}

$\mathrm{Na}$ literatura há uma proposta de Pontuação de Intensidade da Fibromialgia (Sinclair et al., 2007) que avalia 21 pontos ( 3 controles e 18 pontos dolorosos característicos da doença) aplicando-se uma pressão de 4 
$\mathrm{kg} / \mathrm{cm}^{2}$ com o dedo polegar, não sendo esta pressão variável. A paciente informa a sua sensação de dor numa escala de 0 a 10. Esta avaliação nos parece sujeita a imprecisões, dada a potencial variação da aplicação da pressão pelo examinador, e a falta de exatidão daquilo que infoma a paciente referente à dor provocada pela pressão digital.

Optamos pela criação de novo método, que aplica em parte a idéia de Sinclair e colaboradores, qual seja, o que denominamos de Índice Miálgico. Para calcular o Índice Miálgico, somam-se os valores encontrados nos 18 pontos dolorosos avaliados com algiômetro de pressão de Fischer e dividese 0 resultado por 18. Esta medida é contínua e permite um acompanhamento mais adequado da evolução da fibromialgia dada a introdução de diferentes terapêuticas.

\subsubsection{Qualidade de Vida}

Qualidade de vida SF 36 Validação Brasileira (Cicconeli et al., 1999) do MOS 36 - item short form health survey scale (Ware, Sherbourne,1992). Consiste em um questionário genérico de avaliação da qualidade de vida constando oito domínios (Ciconelli et al., 1999),(anexo E), a saber:

- Capacidade funcional (CF)

- Aspecto físico (AF)

- $\quad \operatorname{Dor}(\mathrm{DOR})$ 
- Estado geral de saúde (EGS)

- Vitalidade (VIT)

- Aspecto social (AS)

- Aspecto emocional (AE)

- Saúde mental (SM)

A partir deste questionário, pode-se demonstrar como os pacientes são capazes de executar suas tarefas diárias e qual a percepção que têm quando as executam. É importante que a aplicação deste questionário seja repetida para se avaliar a melhora ou piora do doente em diversas situações, tanto físicas quanto psíquicas.

A medição da capacidade funcional inclui um questionário a respeito das atividades que o doente pode executar a partir da sua capacidade para andar, subir ou descer escadas, fazer atividades vigorosas, como correr, levantar objetos pesados ou tomar banho e vestir-se.

Quanto ao aspecto físico, as avaliações são feitas a partir de como o doente se sentiu no último mês a respeito das suas atividades diárias como conseqüência da sua saúde física. São feitas perguntas,como se diminuiu o tempo que dedicava ao seu trabalho ou se realizou menos do que gostaria de executar nas suas atividades.

O terceiro ítem abrange a percepção da dor nas últimas quatros semanas e quanto a dor interferiu em seu trabalho diário.

No domínio estado geral de saúde, EGS, as perguntas são relacionadas com as interferências emocionais e sociais no último mês. 
Neste domínio é incluída a percepção em relação a sua saúde: de excelente a muito ruim.

$\mathrm{Na}$ vitalidade (VIT), o doente responde a respeito da sua energia e vitalidade correlacionando com o cansaço diário sentido nas últimas quatro semanas.

No domínio aspectos sociais (AS), é avaliada a saúde física e mental em relação à família, aos vizinhos e aos amigos. Além disso, pergunta-se a respeito da sua percepção em relação à sua saúde, tais como, se costuma adoecer ou se é tão saudável em relação às outras pessoas.

Quanto ao domínio aspectos emocionais $(\mathrm{AE})$, o questionário faz perguntas a respeito de suas atividades em relação a problemas emocionais, tais como sentir-se deprimido ou ansioso.

No último domínio, saúde mental (SM), a pesquisa é dirigida com a finalidade de saber como a pessoa se sente: nervosa, deprimida, tranqüila ou desanimada em relação à sua saúde.

\subsection{Método de Tratamento}

\subsubsection{Tratamento por Acupuntura:}

No grupo da acupuntura, foram realizadas 20 sessões de acupuntura clássica, duas vezes por semana, com duração de 20 minutos cada uma e sempre pelo mesmo médico, com quatro anos de experiência. Foram 
utilizadas agulhas próprias para acupuntura, flexíveis, novas e descartáveis, de $25 \mathrm{~mm}$ ou $40 \mathrm{~mm}$ de comprimento e $0,25 \mathrm{~mm}$ espessura.

Foram empregados pontos para o tratamento geral, usados na prática diária da acupuntura. Os pontos escolhidos foram aqueles usados para o alívio da dor, da ansiedade e da depressão. A descrição da localização dos pontos seguiu a nomenclatura internacional segundo a Organização Mundial da Saúde (WHO, 1991): Ex-HN3 unilateral e LR3, LI4, PC6, GB34, SP6 bilaterais. A localização e a técnica de aplicação estão representadas nas figuras 9,10 e 11.

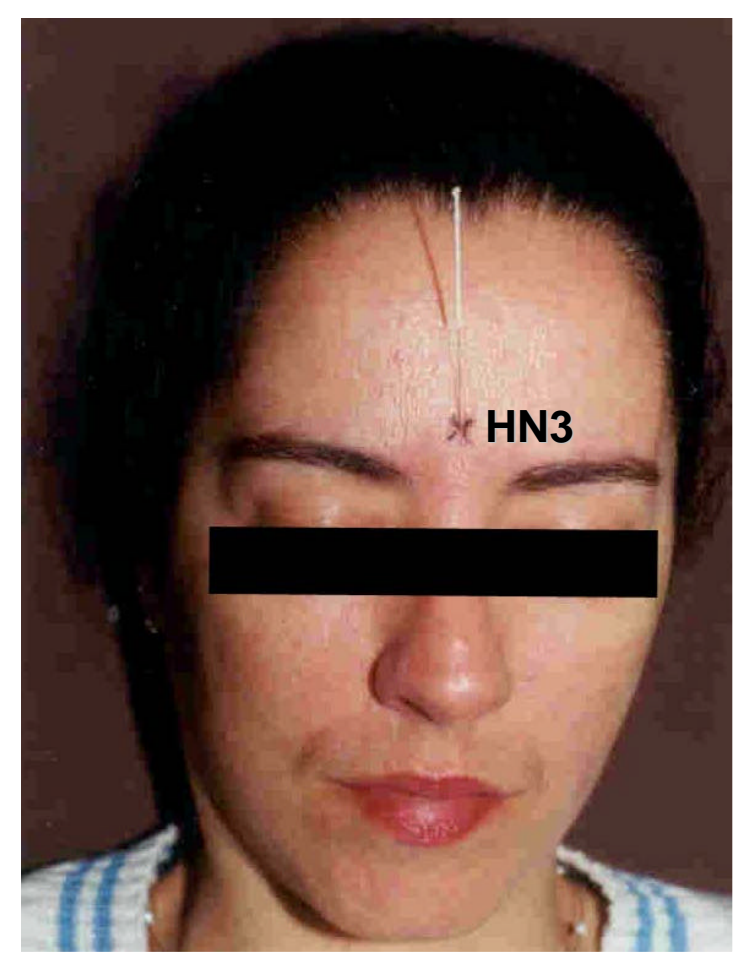

Figura 9: Localização e técnica de aplicação do ponto Ex-HN3.

\section{Ex-HN 3}

Localização: no meio da linha entre as sobrancelhas (Who1991).

Aplicação: agulhamento oblíquo, de cima para baixo com a profundidade de 0,1 a 0,2 cm na inclinação de 45 graus (Figura 9). 


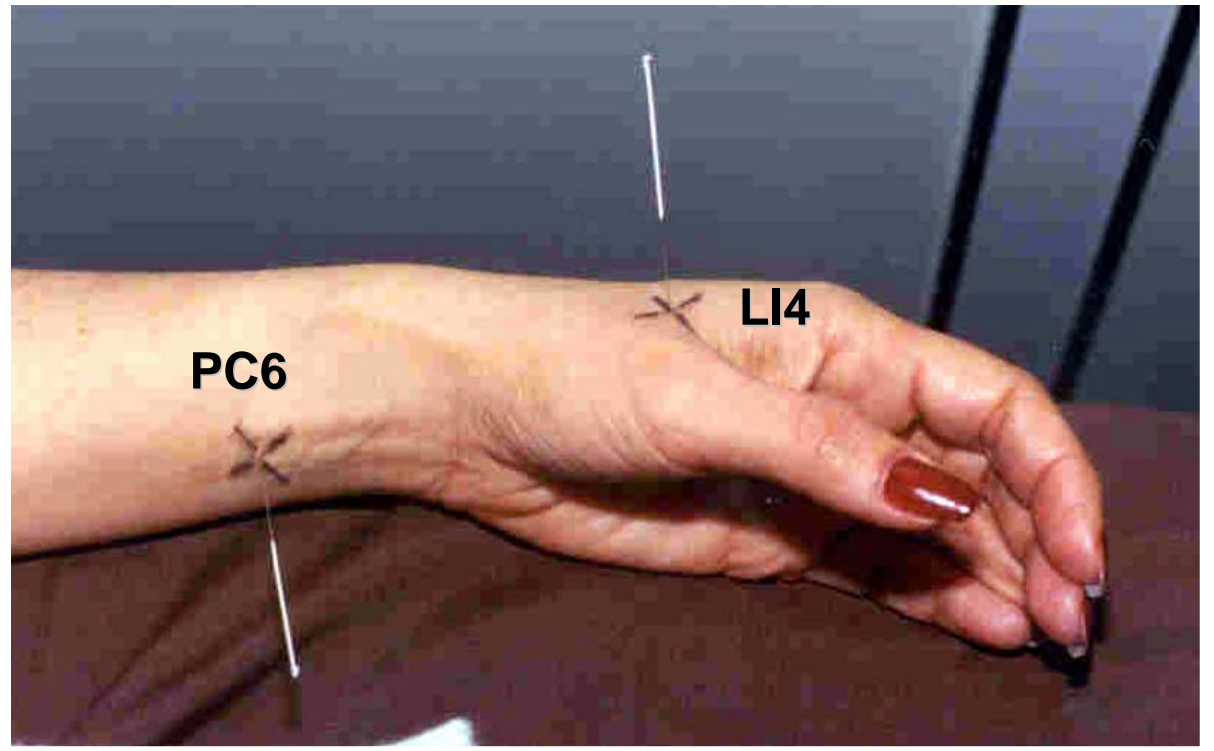

Figura 10: Localização e técnica de aplicação dos pontos PC6 e LI4

LI 4

Localização: no lado dorsal da mão, entre o primeiro e o segundo osso do metacarpo, no meio do primeiro músculo interosseo dorsal (Who1991).

Aplicação: agulhamento perpendicular com profundidade de 0,5 a 1,0 cm, bilateral (Figura 10).

PC 6

Localização: duas polegadas acima do punho, entre os tendões dos músculos palmar longo e flexor radial do carpo (Who1991)

Aplicação: agulhamento perpendicular com profundidade de 0,3 a 0,5 $\mathrm{cm}$,bilateral(figura10) 


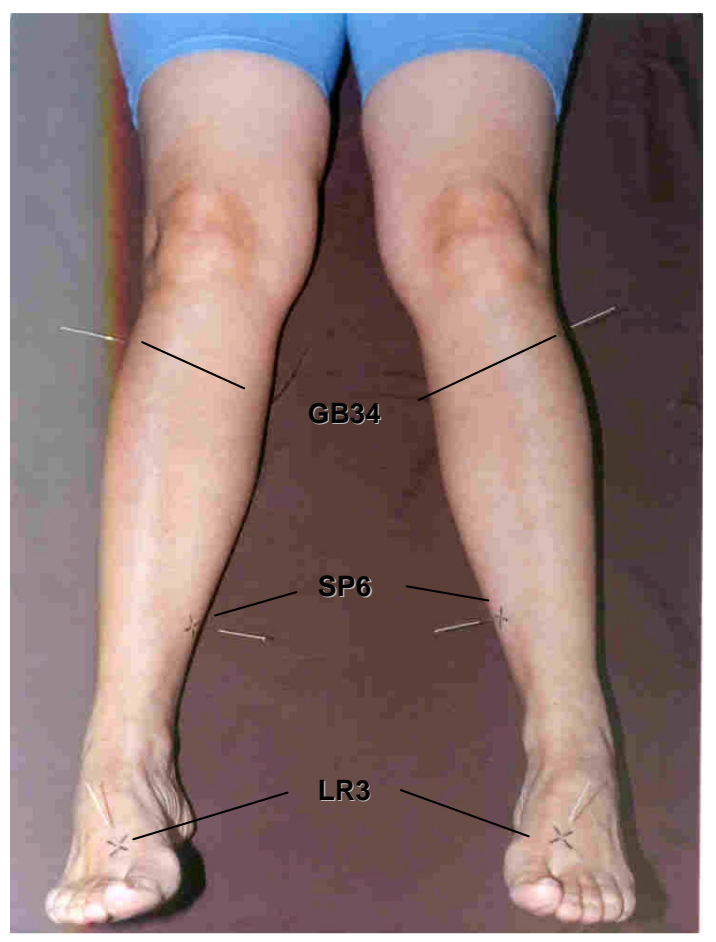

Figura 11: Localização dos pontos e aplicação dos pontos GB34, SP6 e LR3

GB 34

Localização: depressão anterior e inferior da cabeça da fíbula, uma polegada abaixo do joelho, na fáscia do musculo fibular longo (Who1991).

Aplicação: agulhamento perpendicular ,na profundidade de 0,5 a 1,5 cm, Bilateral(Figura11)

SP 6

Localização: três polegadas acima do maléolo medial na borda posterior da tíbia (Who1991).

Aplicação: agulhamento perpendicular,na profundidade de 0,3 a 1,0 cm,

\section{LR 3} bilateral (Figura 11).

Localização: entre o primeiro e o segundo ossos do metatarso, próximo da articulação metatarso falangeana, na sua bifurcação (Who, 1991).

Aplicação: agulhamento perpendicular, na profundidade de 0,5 a 1,0 cm, bilateral. (Figura 11). 
A penetração da agulha foi de $1 \mathrm{~mm}$ a $15 \mathrm{~mm}$ da superfície da pele sem rotação ou estimulação manual depois de sua inserção. A profundidade da agulha foi determinada pela sensibilidade do paciente até se obter a sensação "Qi". A inclinação da agulha foi de $90^{\circ}$ em todos os pontos, exceto para o Ex-HN 3 que foi de 45․ Durante o período de tratamento por acupuntura, todas as pacientes receberam o tratamento convencional para fibromialgia, incluindo um antidepressivo tricíclico, o cloridrato de amitriptilina na dose de 12,5 a $75 \mathrm{mg}$ por dia, além dos exercícios. A medicação antidepressiva foi mantida na mesma dosagem durante todo o estudo. Todas as pacientes foram instruídas a caminhar por 30 minutos duas vezes por semana, respirando profundamente e usando exercícios de relaxamento mental por outros 30 minutos. As doentes foram informadas da importância dos exercícios de alongamento envolvendo os músculos para-espinhais, glúteos, flexores da coxa e tríceps sural.

\subsubsection{Tratamento Convencional: Grupo controle}

O tratamento convencional para fibromialgia incluiu a dose diária de 12,5 a $75 \mathrm{mg}$ de antidepressivo tricíclico (cloridrato de amitriptilina) por dia,de acordo com a dose prescrita para cada paciente,além dos exercícios. Todas as pacientes foram instruídas com as mesmas orientações do grupo que se submeteu à acupuntura, quanto à medicação e aos exercícios. 


\subsection{Análise Estatística:}

\subsubsection{Cálculo da Amostra}

O tamanho da amostra foi determinado de acordo com os resultados obtidos em um estudo piloto realizado em 24 doentes com fibromialgia (Targino et at., 2002). Neste estudo piloto, uma redução média da intensidade da dor medida pela EVA, de $2,07 \mathrm{~cm}$ foi observada no grupo acupuntura e de $0,9 \mathrm{~cm}$ no grupo controle. Foram necessários 20 doentes em cada grupo do estudo, para detectarmos uma diferença entre os grupos de $1,2 \mathrm{~cm}$ na EVA, considerando um poder de $95 \%$ e assumindo o desvio padrão de 1,125 com nível de significância a=5\%, bicaudal.

\subsubsection{Estudo Estatístico}

Para variável contínua (IM), usou-se o teste $\mathrm{t}$ pareado para comparações dentro do grupo,e o teste t de Student, para comparação entre

grupos. Os testes de Wilcoxon e Mann Whithney foram usados para a análise de EVA, pontos dolorosos e SF 36.

Para variáveis categóricas, usou-se também o teste de $\chi^{2}$,ou o teste exato de Fisher quando indicado. O pacote estatístico SPSS, versão 13.0 para MS-Windows foi o software utilizado para as análises estatísticas. 0 nível de significância adotado foi de 5\% para testes de hipótese, bicaudais. 


\section{Resultados}

Entre 2 de Abril de 2000 e 10 de Outubro de 2001, sessenta pacientes com diagnóstico de fibromialgia foram recrutadas de diferentes serviços e divisões do HC-FMUSP , para participar da pesquisa clínica da acupuntura como tratamento complementar do tratamento convencional (medicação antidepressiva e exercícios). Das sessenta pacientes referidas, apenas duas foram excluídas: uma por ter medo das agulhas e a outra por ter feito o tratamento por acupuntura menos de um ano do início dessa pesquisa.

Das 58 mulheres com diagnóstico de fibromialgia restantes, todas estavam dentro do critério de inclusão e concordaram espontaneamente em participar da pesquisa.

A Figura 12 ilustra o fluxo do protocolo deste estudo. 


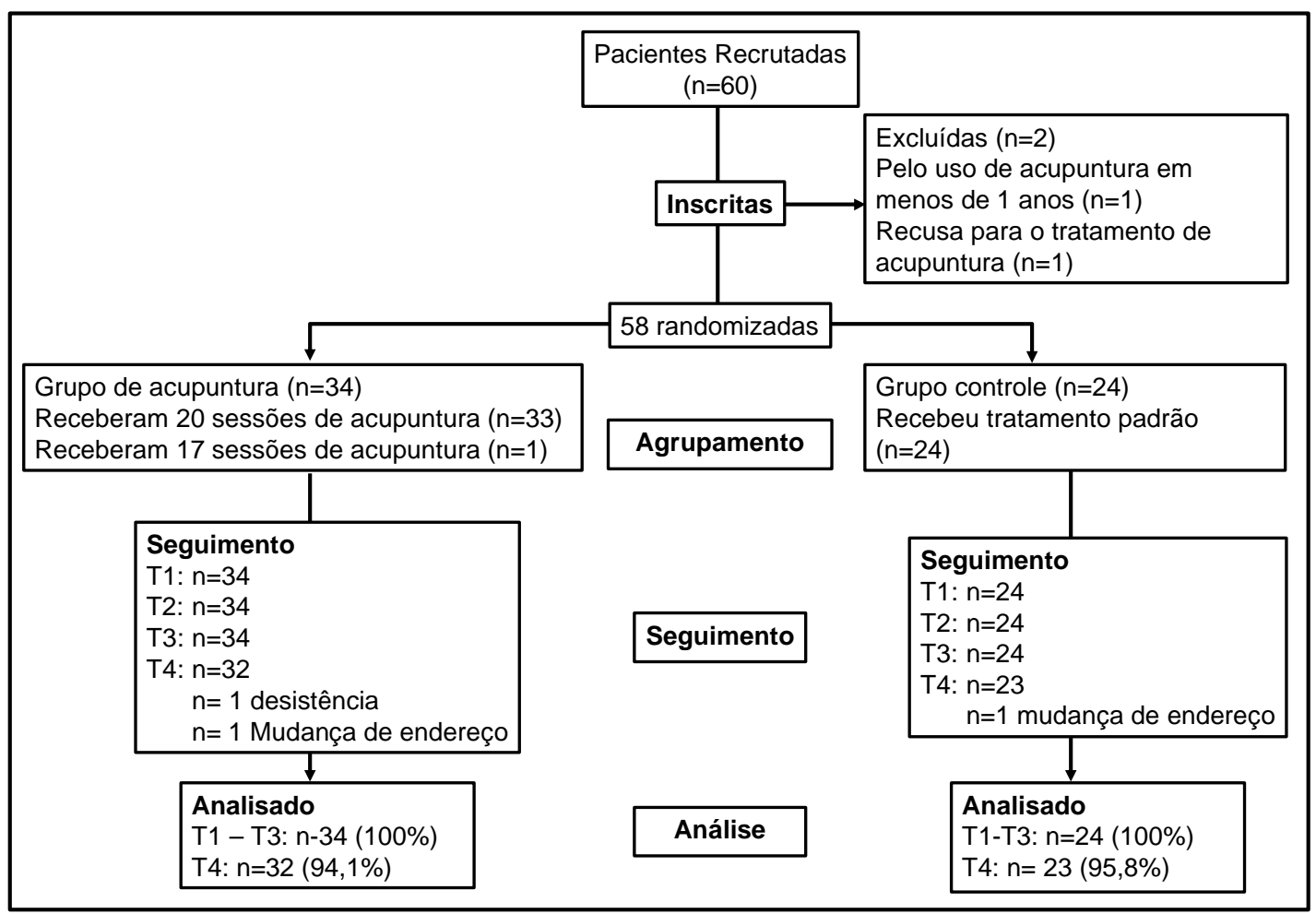

Figura 12. Fluxo do protocolo do estudo

$\mathrm{n}=$ número de casos. T0: avaliação anterior ao tratamento; T1: avaliação pós tratamento; T2: avaliação seis meses após a primeira avaliação; T3: avaliação doze meses após a primeira avaliação; T4: avaliação 24 meses após a primeira avaliação

A Tabela 1 resume as características das pacientes no início da pesquisa. Não houve diferença significativa entre os dois grupos (um tratado com medicamento e acupuntura e o outro tratado só com medicamento usual) na parte demográfica, na indicação de duração da dor, nas medidas de dor (EVA, NPD e IM) e do questionário SF-36 no início da pesquisa 
Tabela 1 - Características clínicas e demográficas das pacientes de fibromialgia por grupo de tratamento

\begin{tabular}{|c|c|c|c|}
\hline \multirow[b]{2}{*}{ Característica } & \multicolumn{2}{|c|}{ Grupo de Tratamento } & \multirow[b]{2}{*}{$\mathbf{p}$} \\
\hline & $\begin{array}{l}\text { Acupuntura } \\
n=34\end{array}$ & $\begin{array}{c}\text { Controle } \\
n=24\end{array}$ & \\
\hline Sexo (feminino) & $34(100 \%)$ & $24(100 \%)$ & \\
\hline Média da Idade, anos (DP) & $52,09(10,97)$ & $51,17(11,20)$ & $0,99 \dagger$ \\
\hline \multicolumn{4}{|l|}{ Estado Civil, \% } \\
\hline Casada ou companheira, \% & $18(52,95)$ & $14(58,33)$ & $0,89 \S$ \\
\hline Solteira, divorciada ou viúva \% & $16(47,05)$ & $10(41,67)$ & \\
\hline \multicolumn{4}{|l|}{ Educação, n (\%) } \\
\hline Fundamental Incompleto & $7(20,59)$ & $7(29,17)$ & $0,85 \S$ \\
\hline Fundamental Completo & $13(38,24)$ & $10(41,67)$ & \\
\hline Ensino Médio & $10(29,41)$ & $5(20,84)$ & \\
\hline Ensino Profissionalizante & $3(8,82)$ & $1(4,16)$ & \\
\hline Ensino Superior & $1(2,94)$ & $1(4,16)$ & \\
\hline \multicolumn{4}{|l|}{ Raça, n (\%) } \\
\hline Branca & $23(67,65)$ & $18(75,01)$ & $0,83 \S$ \\
\hline Parda & $6(17,65)$ & $5(20,83)$ & \\
\hline Negra & $4(11,76)$ & $1(4,16)$ & \\
\hline Asiática & $1(2,94)$ & $0(0)$ & \\
\hline \multicolumn{4}{|l|}{ Atividade Ocupacional, n (\%) } \\
\hline Dona de Casa & $20(58,83)$ & $10(41,66)$ & $0,55 \S$ \\
\hline Trabalhadora & $7(20,58)$ & $9(37,51)$ & \\
\hline Aposentada & $5(14,71)$ & $4(16,67)$ & \\
\hline Licença de Saúde & $1(2,94)$ & $1(4,16)$ & \\
\hline Desempregada & $1(2,94)$ & $0(0)$ & \\
\hline $\begin{array}{l}\text { Duração da Dor, mês (média, } \pm \text { DP) } \\
\text { Medidas de Dor (média, } \pm \text { DP) }\end{array}$ & $118,8(117,3)$ & $93,0(75,25)$ & $0,97 \ddagger$ \\
\hline Escala Visual Analógica (EVA) & $8,38(1,63)$ & $7,79(1,64)$ & $0,15 \ddagger$ \\
\hline Número de Pontos Dolorosos & $16,18(2,29)$ & $16,21(1,89)$ & $0,70 \ddagger$ \\
\hline (NPD) Índice Miálaico (IM) kaf/cm² & $278(053)$ & $206(0.1)$ & 0 oat \\
\hline $\begin{array}{l}\text { Medidas da Qualidade de Vida } \\
\text { SF-36 (média, } \pm \text { DP) }\end{array}$ & $2, / 8(0,53)$ & $(0,81)$ & 0,99个 \\
\hline Capacidade Funcional (CF) & $39,12(18,85)$ & $34,38(19,74)$ & $0,40 \ddagger$ \\
\hline Aspecto Físico (AF) & $12,50(26,29)$ & $15,63(23,09)$ & $0,34 \ddagger$ \\
\hline Dor (DOR) & $33,12(17,02)$ & $56,58(114,78)$ & $0,70 \ddagger$ \\
\hline Estado Geral de Saúde (EGS) & $42,12(19,98)$ & $48,25(16,97)$ & $0,24 \ddagger$ \\
\hline Vitalidade (VT) & $34,56(22,07)$ & $39,79(17,03)$ & $0,24 \ddagger$ \\
\hline Aspecto Social (AF) & $45,22(18,47)$ & $50,52(26,70)$ & $0,39 \ddagger$ \\
\hline Aspecto Emocional (AE) & $29,41(35,55)$ & $30,56(43,87)$ & $0,74 \ddagger$ \\
\hline Saúde Mental (SM) & $43,76(19,79)$ & $46,00(18,91)$ & $0,69 \ddagger$ \\
\hline
\end{tabular}

Principais medidas. Escala Visual Analógica (EVA), Número de Pontos Dolorosos (NPD), Índice Miálgico $(\mathrm{IM}) \mathrm{kgf} / \mathrm{cm}^{2}, \mathrm{n}=$ número de casos, $\mathrm{DP}=$ desvio padrão, $\dagger$ : teste t pareado, $\ddagger$ teste $U$ de Mann Whitney. $p=$ probabilidade 
Das pacientes que se submeteram ao tratamento com acupuntura, $97,1 \%$ completaram o tratamento, isto é, 33 pacientes se submeteram a 20 sessões de acupuntura. Uma paciente não completou as 20 sessões, abandonando a acupuntura após 17 sessões. Como se sentia bem, achava que não precisava completar o tratamento.

Todas as pacientes (100\%) do grupo acupuntura retornaram para as avaliações até um ano após o tratamento e 95,8\% do Grupo Controle (Figura 12). As pacientes do Grupo Controle não receberam nenhum tipo de acupuntura durante o estudo.

De acordo com os resultados da primeira avaliação (dor calculada pela Escala Visual Analógica - EVA), a adição da acupuntura ao tratamento convencional foi mais eficaz do que no grupo com tratamento padrão. Após três meses, a média da EVA mostrou no grupo que recebeu acupuntura o valor 5,35 (95\% IC: 6,29) comparado aos 7,85 (95\% IC: 7,14; 8,57) no grupo que recebeu somente o tratamento usual. Esta diferença foi estatisticamente significante $(p<0,001)$ (Figura 13 e Tabela 2). 
Figura 13. Representação esquemática da média e desvio padrão dos valores da Escala Visual Analógica (EVA)

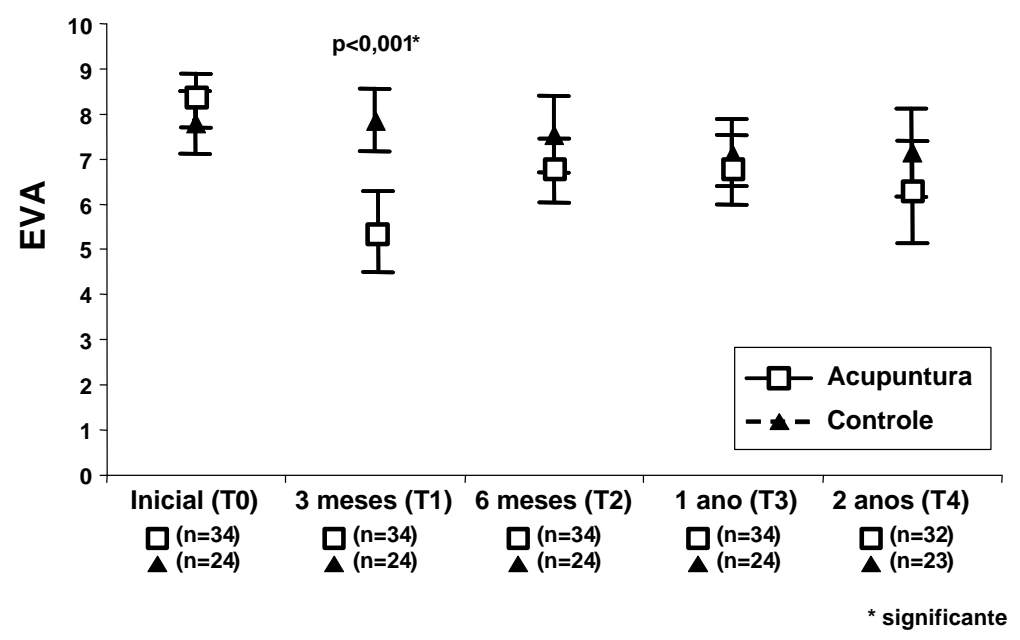

$\mathrm{n}=$ número de casos. T0: avaliação anterior ao tratamento; T1: avaliação pós tratamento; T2: avaliação seis meses após a primeira avaliação; T3: avaliação doze meses após a primeira avaliação; T4: avaliação 24 meses após a primeira avaliação; $p=$ probabilidade.

Figura 14. Representação esquemática da média e desvio padrão dos valores dos Números de Pontos Dolorosos (NPD)

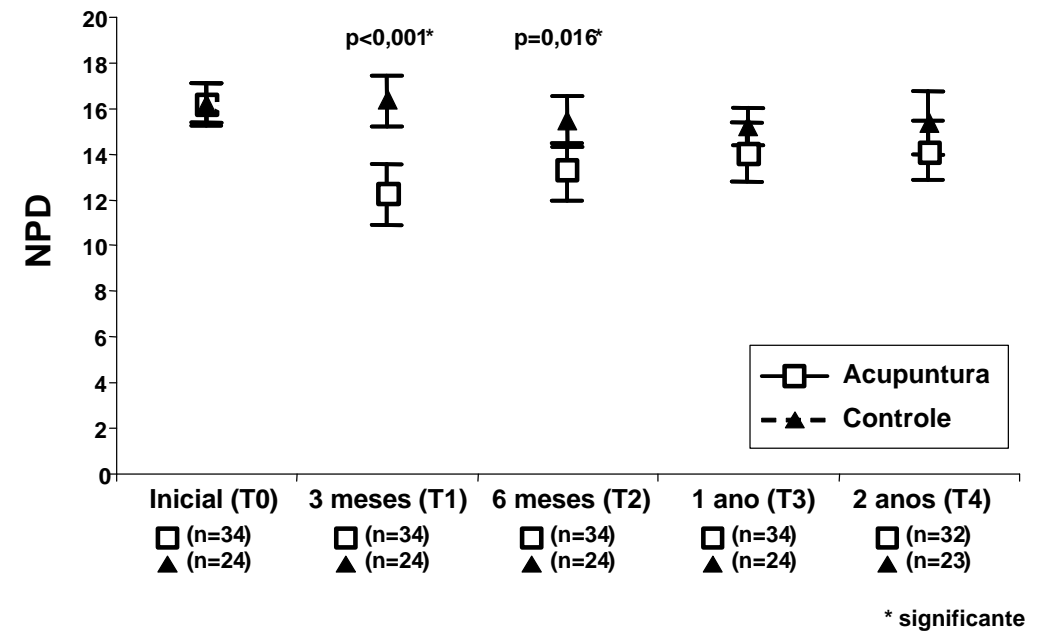

$\mathrm{n}=$ número de casos. T0: avaliação anterior ao tratamento; T1: avaliação pós tratamento; T2: avaliação seis meses após a primeira avaliação; T3: avaliação doze meses após a primeira avaliação; T4: avaliação 24 meses após a primeira avaliação; $p=$ probabilidade. 
Figura 15. Representação esquemática da média e desvio padrão dos valores do Índice Miálgico (IM)

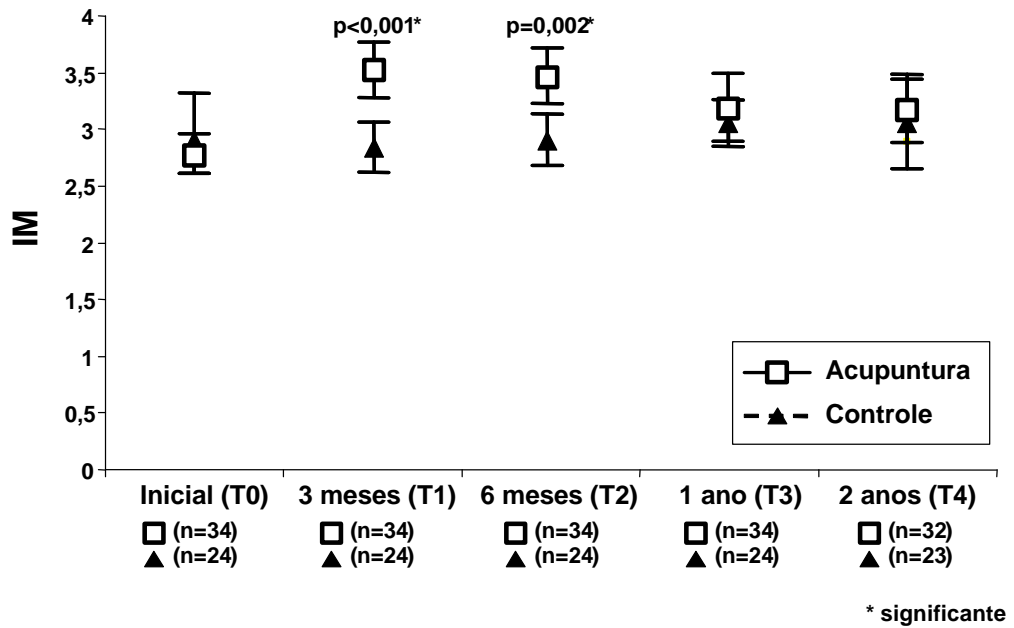

$\mathrm{n}=$ número de casos. T0: avaliação anterior ao tratamento; T1: avaliação pós tratamento; T2: avaliação seis meses após a primeira avaliação; T3: avaliação doze meses após a primeira avaliação; T4: avaliação 24 meses após a primeira avaliação; $p=$ probabilidade. 
Tabela 2 - Resultados da Escala Visual Analógica (EVA), Número de Pontos Dolorosos (NPD) e Índice Miálgico (IM) por grupo de tratamento

\begin{tabular}{|c|c|c|c|}
\hline \multirow{3}{*}{ Variável } & \multicolumn{2}{|c|}{ Tratamento por Grupo } & \multirow{3}{*}{$\mathbf{p}$} \\
\hline & Acupuntura & Controle & \\
\hline & Média (95\% IC) & Média (95\% IC) & \\
\hline Inicial (T0) & $\mathbf{N}=34$ & $N=24$ & \\
\hline EVA & $8,38(7,81-8,95)$ & $7,79(7,10-8,49)$ & 0,15 \\
\hline NPD & $16,18(15,38-16,98)$ & $16,21(15,41-17,01)$ & 0,70 \\
\hline IM & $2,78(2,60-2,96)$ & $2,96(2,62-3,31)$ & 0,99 \\
\hline 3 meses (T1) & $N=34$ & $N=24$ & \\
\hline EVA & $5,35(4,41-6,29)$ & $7,85(7,14-8,57)$ & $<0,001^{* *}$ \\
\hline NPD & $12,29(11,02-13,56)$ & $16,38(15,32-17,43)$ & $<0,001^{* *}$ \\
\hline IM & $3,53(3,29-3,77)$ & $2,84(2,61-3,06)$ & $<0,001^{* *}$ \\
\hline 6 meses (T2) & $\mathbf{N}=34$ & $\mathbf{N}=24$ & \\
\hline EVA & $6,79(6,10-7,49)$ & $7,54(6,70-8,39)$ & 0,18 \\
\hline NPD & $13,32(12,07-14,57)$ & $15,50(14,52-16,48)$ & $0,016^{*}$ \\
\hline IM & $3,47(3,22-3,71)$ & $2,90(2,67-3,13)$ & $0,002^{* *}$ \\
\hline 1 ano (T3) & $\mathbf{N}=34$ & $N=24$ & \\
\hline EVA & $6,79(6,05-7,54)$ & $7,10(6,38-7,83)$ & 0,65 \\
\hline NPD & $14,06(12,76-15,35)$ & $15,21(14,38-16,03)$ & 0,47 \\
\hline IM & $3,19(2,89-3,49)$ & $3,05(2,85-3,25)$ & 0,46 \\
\hline 2 anos (T4) & $\mathbf{N}=32$ & $\mathbf{N}=23$ & \\
\hline EVA & $6,28(5,18-7,39)$ & $7,15(6,22-8,09)$ & 0,58 \\
\hline NPD & $14,09(12,81-15,37)$ & $15,35(13,98-16,72)$ & 0,16 \\
\hline IM & $3,18(2,89-3,47)$ & $3,05(2,67-3,43)$ & 0,60 \\
\hline
\end{tabular}

$\mathrm{N}$ : número de pacientes, 95\% IC: 95\% intervalos de confiança para médias não ajustadas, DP: desvio padrão, EVA: Escala Visual Analógica, NPD: Número de Pontos Dolorosos, IM: Índice Miálgico $\left(\mathrm{kgf} / \mathrm{cm}^{2}\right)$.

* estatisticamente significante $(<0,05)$

** estatisticamente significante $(<0,005)$

$\mathrm{p}=$ probabilidade 
Houve também evidente melhora nos outros parâmetros avaliados: NPD (Figura 14 Tabela 2) e no IM (Figura 15 Tabela 2) e em cinco domínios do SF-36: CF, Dor, VIT, AE, SM (Tabelas 4), até três meses de seguimento.

Seis meses após o tratamento com a acupuntura (T2), seus benefícios em relação ao grupo controle se mantiveram somente para 0 Número de Pontos Dolorosos (NPD) (Tabela 2, Figura 14) e para o Índice Miálgico (IM) (Tabela 2, Figura 15) e para um domínio do SF-36: EGS (Tabela 4).

Após um ano de seguimento (T3), somente o ítem aspecto físico (AF) do SF-36 mostrou diferença estatística significante em relação ao Grupo Acupuntura ( Tabela 4).

Após dois anos de seguimento (T4), não houve diferença estatística significante entre os pacientes da acupuntura e do grupo controle em nenhuma medida de dor (Tabela 2, Figuras 13, 14 e 15) ou da qualidade de vida (Tabela 4).

A tabela 3 e a figura 16 mostram o perfil da evolução dos resultados segundo o número de doentes que apresentaram melhora, piora ou permaneceram inalterados, na avaliação da dor, nos diferentes tempos pesquisados em comparação à avaliação antes do tratamento.

A tabela 5 e a figura 17 mostram a evolução dos resultados da avaliação da qualidade da vida em relação à melhora, piora e inalterados nos diversos momentos em que foram avaliados. 
Tabela 3 - Evolução dos resultados segundo o número de doentes que apresentaram melhora, piora ou permaneceram inalterados, na avaliação da dor nos diferentes tempos pesquisados em comparação à avaliação antes do tratamento.

\section{Escala Visual Analógica (EVA)}

\begin{tabular}{lcccc}
\multicolumn{5}{c}{ Acupuntura } \\
\hline Melhora & T0xT1 & T0xT2 & T0xT3 & T0xT4 \\
Piora & 32 & 24 & 22 & 21 \\
Sem alteração & 1 & 4 & 6 & 6 \\
\hline $\mathbf{P}$ & 1 & 6 & 6 & 5 \\
\hline & $<0,001$ & $<0,001$ & 0,002 & 0,001 \\
\hline & & Controle & & \\
\hline Melhora & T0xT1 & T0xT2 & T0xT3 & T0xT4 \\
Piora & 9 & 9 & 14 & 9 \\
Sem alteração & 7 & 8 & 6 & 7 \\
\hline $\mathbf{P}$ & 8 & 7 & 4 & 7 \\
\hline
\end{tabular}

Número de Pontos Dolorosos (NPD)

\begin{tabular}{lcccc}
\multicolumn{5}{c}{ Acupuntura } \\
\hline Melhora & T0xT1 & T0xT2 & T0xT3 & T0xT4 \\
Piora & 27 & 26 & 23 & 22 \\
Sem alteração & 4 & 3 & 4 & 6 \\
\hline P & 3 & 5 & 7 & 4 \\
\hline & $<0,001$ & $<0,001$ & 0,001 & 0,001 \\
\hline & & Controle & & \\
\hline Melhora & T0xT1 & T0xT2 & T0xT3 & T0xT4 \\
Piora & 7 & 12 & 12 & 12 \\
Sem alteração & 8 & 8 & 7 & 9 \\
\hline P & 9 & 4 & 5 & 2 \\
\hline
\end{tabular}

Índice Miálgico (IM)

Acupuntura

\begin{tabular}{lcccc}
\hline & T0xT1 & T0xT2 & T0xT3 & T0xT4 \\
\hline Melhora & 30 & 30 & 22 & 21 \\
Piora & 2 & 1 & 6 & 5 \\
Sem alteração & 2 & 3 & 6 & 6 \\
\hline $\mathbf{P}$ & $<0,001$ & $<0,001$ & 0,002 & 0,001 \\
\hline & & Controle & & \\
\hline & T0xT1 & T0xT2 & T0xT3 & T0xT4 \\
\hline Melhora & 8 & 9 & 10 & 12 \\
Piora & 8 & 8 & 8 & 10 \\
Sem alteração & 8 & 7 & 6 & 1 \\
\hline $\mathbf{P}$ & 0,176 & 0,024 & 0,979 & 0,369 \\
\hline T0: & & &
\end{tabular}

T0: avaliação anterior ao tratamento; T1: avaliação pós tratamento; T2: avaliação seis meses após a primeira avaliação; T3: avaliação doze meses após a primeira avaliação; T4: avaliação 24 meses após a primeira avaliação; $p=$ probabilidade. 
Figura 16. Representação gráfica do número de doentes que apresentaram alterações nas medidas de dor: Escala Visual Analógica (EVA), Número de Pontos Dolorosos (NPD) e Índice Miálgico (IM).

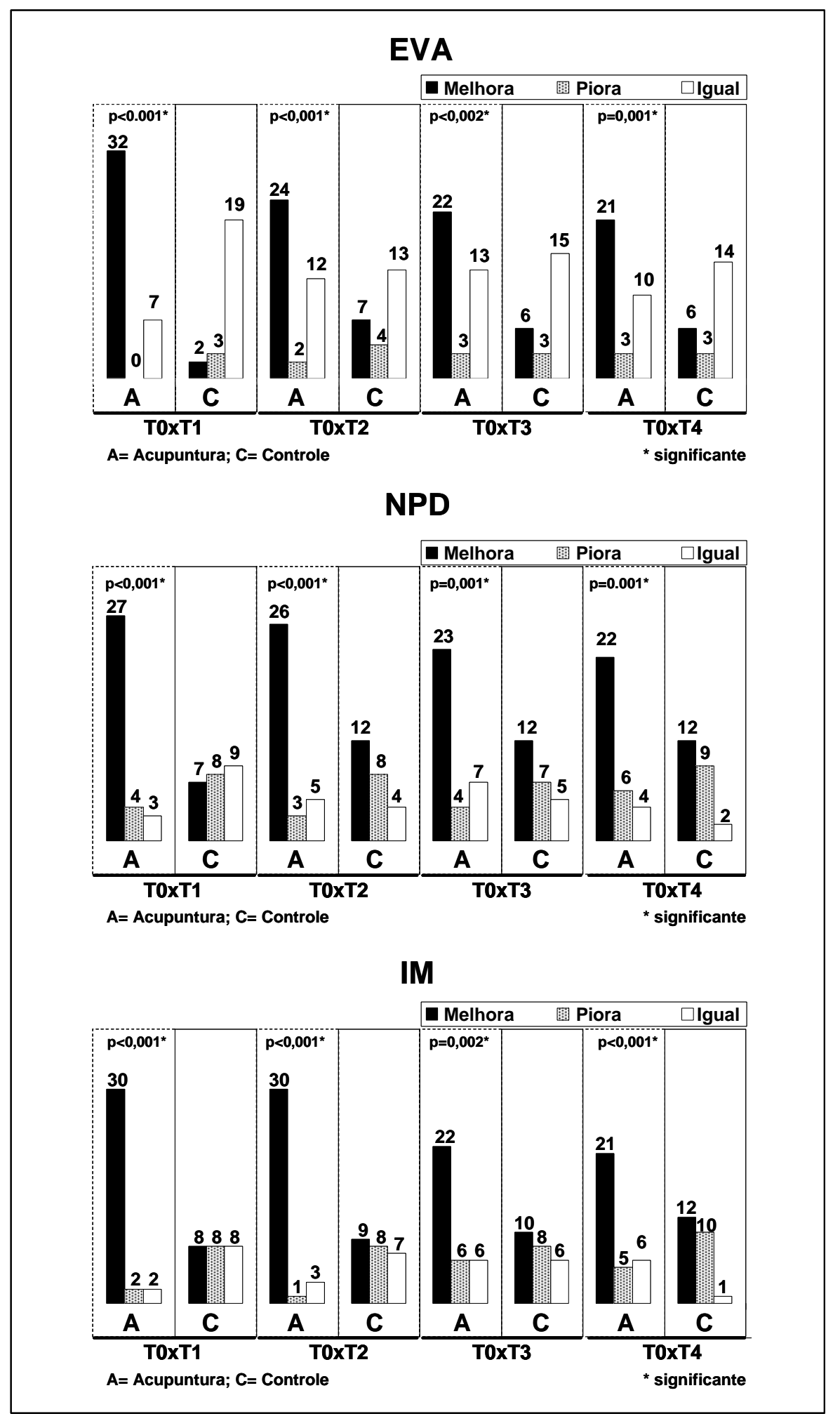

T0: avaliação anterior ao tratamento; T1: avaliação pós tratamento; T2: avaliação seis meses após a primeira avaliação; T3: avaliação doze meses após a primeira avaliação; T4: avaliação 24 meses após a primeira avaliação; $p=$ probabilidade. 
Tabela 4 - Resultados dos domínios do SF-36

\begin{tabular}{|c|c|c|c|}
\hline \multirow{3}{*}{ Variável } & \multicolumn{2}{|c|}{ Grupo de Tratamento } & \multirow{3}{*}{ p } \\
\hline & Acupuntura & Controle & \\
\hline & Média (e 95\% do IC) & Média (e 95\% do IC) & \\
\hline Início (T0) & $N=34$ & $N=24$ & \\
\hline CF & $39,12(32,54-45,69)$ & $34,38(26,04-42,71)$ & 0,396 \\
\hline AF & $12,50(3,33-21,67)$ & $15,63(5,87-25,38)$ & 0,335 \\
\hline DOR & $33,12(27,18-39,06)$ & $56,58(8,12-105,0)$ & 0,701 \\
\hline EGS & $42,12(35,15-49,09)$ & $48,25(41,08-55,42)$ & 0,238 \\
\hline VIT & $34,56(26,86-42,26)$ & $39,79(32,60-46,98)$ & 0,204 \\
\hline AF & $45,22(38,78-51,66)$ & $50,52(39,25-61,80)$ & 0,385 \\
\hline AE & $29,41(17,01-41,81)$ & $30,56(12,03-49,08)$ & 0,741 \\
\hline SM & $43,76(36,86-50,67)$ & $46,00(38,02-53,98)$ & 0,686 \\
\hline 3 meses (T1) & $\mathbf{N}=\mathbf{3 4}$ & $N=24$ & \\
\hline CF & $53,68(47,37-59,98)$ & $40,42(31,35-49,48)$ & $0,021^{*}$ \\
\hline AF & $30.88(17.99-43.78)$ & $20,83(9,33-32,34)$ & 0,347 \\
\hline DOR & $45.09(39,47-50,70)$ & $31.08(25.97-36,20)$ & $0,002^{* *}$ \\
\hline EGS & $55,06(48,21-61,91)$ & $50,25(41,58-58,92)$ & 0,308 \\
\hline VIT & $52,35(45,16-59,54)$ & $38,13(29,50-46,75)$ & $0,022^{\star *}$ \\
\hline AF & $64,34(57,12-7155)$ & $52,81(40,62-65,01)$ & 0,085 \\
\hline $\mathrm{AE}$ & $65,69(50,40-80,97)$ & $31,94(14,10-49,79)$ & $0,004^{\star *}$ \\
\hline SM & $62,00(54,65-69,35)$ & $45,00(34,63-55,37)$ & $0,008^{\star *}$ \\
\hline 6 meses (T2) & $N=34$ & $N=24$ & \\
\hline CF & $53,24(47,27-59,20)$ & $43,13(34,89-51,36)$ & 0,052 \\
\hline AF & $23,53(11,78-35,28)$ & $12,50(3,70-21,30)$ & 0,318 \\
\hline DOR & $34,29(28,57-40,02)$ & $33,17(27,54-38,79)$ & 0,994 \\
\hline EGS & $57,62(50,55-64,69)$ & $44,33(36,33-52,34)$ & $0,027^{*}$ \\
\hline VIT & $46,03(38,66-53,40)$ & $42,50(33,92-51,08)$ & 0,541 \\
\hline AF & $54,45(46,29-62,61)$ & $52,60(41,71-63,50)$ & 0,924 \\
\hline $\mathbf{A E}$ & $50,98(36,60-65,36)$ & $30,56(12,99-48,12)$ & 0,056 \\
\hline SM & $55,18(48,80-61,56)$ & $52,67(43,97-61,36)$ & 0,962 \\
\hline 1 ano (T3) & $N=34$ & $N=24$ & \\
\hline CF & $51,32(44,62-58,02)$ & $46,25(36,97-55,53)$ & 0,558 \\
\hline AF & $25,00(12,30-37,70)$ & $7,29(0,005-14,58)$ & $0,038^{*}$ \\
\hline DOR & $35,29(29,24-41,35)$ & $33,58(26,25-40,91)$ & 0,836 \\
\hline EGS & $50,12(43,79-56,44)$ & $52,04(44,13-59,95)$ & 0,943 \\
\hline VIT & $54,41(45,77-63,05)$ & $43,75(32,45-55,05)$ & 0,110 \\
\hline AF & $59,93(49,81-70,04)$ & $65,63(45,38-85,87)$ & 0,769 \\
\hline $\mathrm{AE}$ & $48,04(33,11-62,97)$ & $48,61(29,15-68,07)$ & 1,000 \\
\hline SM & $55,18(46,49-63,87)$ & $56,17(46,14-66,20)$ & 0,756 \\
\hline 2 anos (T4) & $N=32$ & $N=23$ & \\
\hline CF & $56,41(49,52-63,29)$ & $47,83(38,05-57,60)$ & 0,234 \\
\hline AF & $33,59(19,74-47,45)$ & $21,74(8,58-34,90)$ & 0,290 \\
\hline DOR & $37,16(29,68-44,64)$ & $35,43(26,62-44,25)$ & 0,993 \\
\hline EGS & $58,25(51,99-64,51)$ & $57,65(49,65-65,65)$ & 0,898 \\
\hline VIT & $49,22(41,27-57,16)$ & $51,09(42,01-60,17)$ & 0,864 \\
\hline AF & $60,94(50,34-71,54)$ & $48,91(39,15-58,68)$ & 0,079 \\
\hline AE & $57,29(42,58-72,01)$ & $55,07(36,32-73,83)$ & 0,936 \\
\hline SM & $57,63(48,86-66,39)$ & $52,00(43,74-60,26)$ & 0,274 \\
\hline
\end{tabular}

$\mathrm{N}=$ número de pacientes, 95\% IC: 95\% intervalo de confiança para médias não ajustadas, DP: desvio padrão, CF: Capacidade funcional AF: Aspecto Físico, D: Dor, EGS: Estado Geral de Saúde, VIT: Vitalidade, AS: Aspecto Social, AE: Aspecto Emocional, $\mathrm{SM}$ : Saúde Mental. *estatisticamente significante $(<0,05){ }^{* *}$ estatisticamente significante $(<0,005) ; p=$ probabilidade, IC=intervalo de confiança 
Tabela 5 - Evolução dos resultados da avaliação da qualidade de vida Capacidade Funcional (CF)

\begin{tabular}{|c|c|c|c|c|}
\hline \multicolumn{5}{|c|}{ Acupuntura } \\
\hline & T0xT1 & T0xT2 & T0xT3 & T0xT4 \\
\hline Melhora & 25 & 27 & 24 & 25 \\
\hline Piora & 6 & 5 & 9 & 4 \\
\hline $\begin{array}{l}\text { Sem } \\
\text { alteração }\end{array}$ & 3 & 2 & 1 & 3 \\
\hline $\mathbf{P}$ & $<0,001$ & $<0,001$ & 0,004 & $<0,001$ \\
\hline \multicolumn{5}{|c|}{ Controle } \\
\hline Melhora & 17 & 15 & 17 & 16 \\
\hline Piora & 6 & 8 & 6 & 6 \\
\hline $\begin{array}{l}\text { Sem } \\
\text { alteração }\end{array}$ & 1 & 1 & 1 & 1 \\
\hline $\mathbf{P}$ & 0,142 & 0,074 & 0,021 & 0,022 \\
\hline
\end{tabular}

\begin{tabular}{|c|c|c|c|c|}
\hline \multicolumn{5}{|c|}{ Aspectos Físicos (AF) } \\
\hline \multicolumn{5}{|c|}{ Acupuntura } \\
\hline & $\begin{array}{c}\text { T0 } x \\
\text { T1 }\end{array}$ & $\begin{array}{c}\text { T0 } x \\
\text { T2 }\end{array}$ & $\begin{array}{c}\text { T0 } x \\
\text { T3 }\end{array}$ & $\begin{array}{c}\text { T0 } x \\
\text { T4 }\end{array}$ \\
\hline $\begin{array}{l}\text { Melhora } \\
\text { Piora } \\
\text { Sem } \\
\text { alteração }\end{array}$ & $\begin{array}{c}13 \\
2 \\
19\end{array}$ & $\begin{array}{c}13 \\
6 \\
15\end{array}$ & $\begin{array}{c}11 \\
4 \\
19\end{array}$ & $\begin{array}{c}4 \\
15 \\
13\end{array}$ \\
\hline$p$ & 0,003 & 0,155 & 0,06 & 0,01 \\
\hline \multicolumn{5}{|c|}{ Controle } \\
\hline $\begin{array}{l}\text { Melhora } \\
\text { Piora } \\
\text { Sem } \\
\text { alteração }\end{array}$ & $\begin{array}{c}6 \\
6 \\
12\end{array}$ & $\begin{array}{c}6 \\
6 \\
12\end{array}$ & $\begin{array}{c}2 \\
7 \\
15\end{array}$ & $\begin{array}{l}9 \\
6 \\
8\end{array}$ \\
\hline$p$ & 0,381 & 0,597 & 0,114 & 0,599 \\
\hline
\end{tabular}

Dor

\begin{tabular}{lcccc}
\hline \multicolumn{5}{c}{ Acupuntura } \\
\hline & T0xT1 & T0xT2 & T0xT3 & T0xT4 \\
\hline Melhora & 23 & 15 & 16 & 10 \\
Piora & 6 & 12 & 11 & 16 \\
Sem & 5 & 7 & 7 & 6 \\
alteração & \multicolumn{5}{c}{} & & \\
\hline $\mathbf{P}$ & 0,002 & 0,904 & 0,588 & 0,401 \\
\hline \multicolumn{5}{c}{ Controle } \\
\hline Melhora & 8 & 7 & 9 & 11 \\
Piora & 12 & 10 & 12 & 10 \\
Sem & 4 & 7 & 3 & 2 \\
alteração & \multicolumn{7}{c}{0,544} & 0,876 \\
\hline $\mathbf{P}$ & 0,258 & 0,521 & 0,444 \\
\hline
\end{tabular}

Vitalidade (Vit)

\begin{tabular}{|c|c|c|c|c|}
\hline \multicolumn{5}{|c|}{ Acupuntura } \\
\hline & T0xT1 & T0xT2 & T0xT3 & T0xT4 \\
\hline $\begin{array}{l}\text { Melhora } \\
\text { Piora } \\
\text { Sem } \\
\text { alteração }\end{array}$ & $\begin{array}{l}21 \\
9 \\
4\end{array}$ & $\begin{array}{c}21 \\
10 \\
3\end{array}$ & $\begin{array}{c}28 \\
4 \\
2\end{array}$ & $\begin{array}{c}11 \\
19 \\
2\end{array}$ \\
\hline $\mathbf{P}$ & 0,002 & 0,005 & $<0,001$ & 0,008 \\
\hline \multicolumn{5}{|c|}{ Controle } \\
\hline $\begin{array}{l}\text { Melhora } \\
\text { Piora } \\
\text { Sem } \\
\text { alteração }\end{array}$ & $\begin{array}{c}12 \\
12 \\
0\end{array}$ & $\begin{array}{c}11 \\
10 \\
3\end{array}$ & $\begin{array}{c}13 \\
8 \\
3\end{array}$ & $\begin{array}{c}7 \\
15 \\
1\end{array}$ \\
\hline$\overline{\mathbf{P}}$ & 0,666 & 0,411 & 0,454 & 0,093 \\
\hline
\end{tabular}

Aspectos emocionais (AE)

\begin{tabular}{|c|c|c|c|c|}
\hline \multicolumn{5}{|c|}{ Acupuntura } \\
\hline & T0xT1 & T0xT2 & T0xT3 & T0xT4 \\
\hline $\begin{array}{l}\text { Melhora } \\
\text { Piora } \\
\text { Sem } \\
\text { alteração }\end{array}$ & $\begin{array}{c}21 \\
4 \\
9\end{array}$ & $\begin{array}{c}18 \\
8 \\
8\end{array}$ & $\begin{array}{c}16 \\
5 \\
13\end{array}$ & $\begin{array}{c}17 \\
3 \\
12\end{array}$ \\
\hline $\mathbf{P}$ & 0,001 & 0,015 & 0,031 & 0,004 \\
\hline \multicolumn{5}{|c|}{ Controle } \\
\hline $\begin{array}{l}\text { Melhora } \\
\text { Piora } \\
\text { Sem } \\
\text { alteração }\end{array}$ & $\begin{array}{c}5 \\
5 \\
14\end{array}$ & $\begin{array}{c}5 \\
6 \\
13\end{array}$ & $\begin{array}{c}9 \\
5 \\
10\end{array}$ & $\begin{array}{c}12 \\
2 \\
9\end{array}$ \\
\hline $\mathbf{P}$ & 0,877 & 0,928 & 0,111 & 0,03 \\
\hline
\end{tabular}

Estado Geral de Saúde (EGS)

\begin{tabular}{|c|c|c|c|c|}
\hline \multicolumn{5}{|c|}{ Acupuntura } \\
\hline & $\begin{array}{c}\text { T0 } x \\
\text { T1 }\end{array}$ & T0 $\times$ T2 & $\begin{array}{c}\text { T0 } x \\
\text { T3 }\end{array}$ & $\begin{array}{c}\text { T0 } x \\
\text { T4 }\end{array}$ \\
\hline $\begin{array}{l}\text { Melhora } \\
\text { Piora } \\
\text { Sem } \\
\text { alteração }\end{array}$ & $\begin{array}{c}25 \\
6 \\
3\end{array}$ & $\begin{array}{c}27 \\
7 \\
0\end{array}$ & $\begin{array}{c}23 \\
11 \\
0\end{array}$ & $\begin{array}{c}4 \\
25 \\
3\end{array}$ \\
\hline$p$ & 0,001 & $<0,001$ & 0,057 & 0,002 \\
\hline \multicolumn{5}{|c|}{ Controle } \\
\hline $\begin{array}{l}\text { Melhora } \\
\text { Piora } \\
\text { Sem } \\
\text { alteração }\end{array}$ & $\begin{array}{c}10 \\
12 \\
2\end{array}$ & $\begin{array}{c}11 \\
12 \\
1\end{array}$ & $\begin{array}{c}13 \\
11 \\
0\end{array}$ & $\begin{array}{c}14 \\
7 \\
2\end{array}$ \\
\hline $\mathbf{p}$ & 0,935 & 0,493 & 0,335 & 0,13 \\
\hline
\end{tabular}

Aspectos Sociais (AS)

\begin{tabular}{|c|c|c|c|c|}
\hline \multicolumn{5}{|c|}{ Acupuntura } \\
\hline & T0 x T1 & $\begin{array}{c}\text { T0 } x \\
\text { T2 }\end{array}$ & $\begin{array}{c}\text { T0 } x \\
\text { T3 }\end{array}$ & $\begin{array}{c}\text { T0 } x \\
\text { T4 }\end{array}$ \\
\hline $\begin{array}{l}\text { Melhora } \\
\text { Piora } \\
\text { Sem } \\
\text { alteração } \\
\end{array}$ & $\begin{array}{c}25 \\
4 \\
5\end{array}$ & $\begin{array}{c}18 \\
10 \\
6\end{array}$ & $\begin{array}{c}24 \\
6 \\
4\end{array}$ & $\begin{array}{c}9 \\
21 \\
2\end{array}$ \\
\hline$p$ & $<0,001$ & 0,043 & 0,002 & 0,011 \\
\hline \multicolumn{5}{|c|}{ Controle } \\
\hline $\begin{array}{l}\text { Melhora } \\
\text { Piora } \\
\text { Sem } \\
\text { alteração }\end{array}$ & $\begin{array}{c}11 \\
12 \\
1\end{array}$ & $\begin{array}{c}10 \\
13 \\
1\end{array}$ & $\begin{array}{c}13 \\
7 \\
4\end{array}$ & $\begin{array}{c}11 \\
10 \\
2\end{array}$ \\
\hline$p$ & 0,975 & 0,724 & 0,157 & 0,18 \\
\hline
\end{tabular}

Saúde Mental (SM)

\begin{tabular}{|c|c|c|c|c|}
\hline \multicolumn{5}{|c|}{ Acupuntura } \\
\hline & $\mathrm{T0} \times \mathrm{T} 1$ & $\begin{array}{c}\text { T0 } x \\
\text { T2 }\end{array}$ & $\begin{array}{c}\text { T0 } x \\
\text { T3 }\end{array}$ & $\begin{array}{c}\text { T0 } x \\
\text { T4 }\end{array}$ \\
\hline Melhora & 27 & 22 & 21 & 22 \\
\hline Piora & 3 & 7 & 10 & 9 \\
\hline $\begin{array}{l}\text { Sem } \\
\text { alteração }\end{array}$ & 4 & 5 & 3 & 1 \\
\hline$p$ & $<0,001$ & 0,006 & 0,007 & 0,013 \\
\hline \multicolumn{5}{|c|}{ Controle } \\
\hline Melhora & 10 & 15 & 14 & 7 \\
\hline Piora & 12 & 5 & 7 & 15 \\
\hline $\begin{array}{l}\text { Sem } \\
\text { alteração }\end{array}$ & 2 & 4 & 3 & 1 \\
\hline p & 0,708 & 0,021 & 0,055 & 0,124 \\
\hline
\end{tabular}


Figura 17. Representação gráfica do número de doentes que apresentaram alterações nas medidas da qualide de vida SF-36

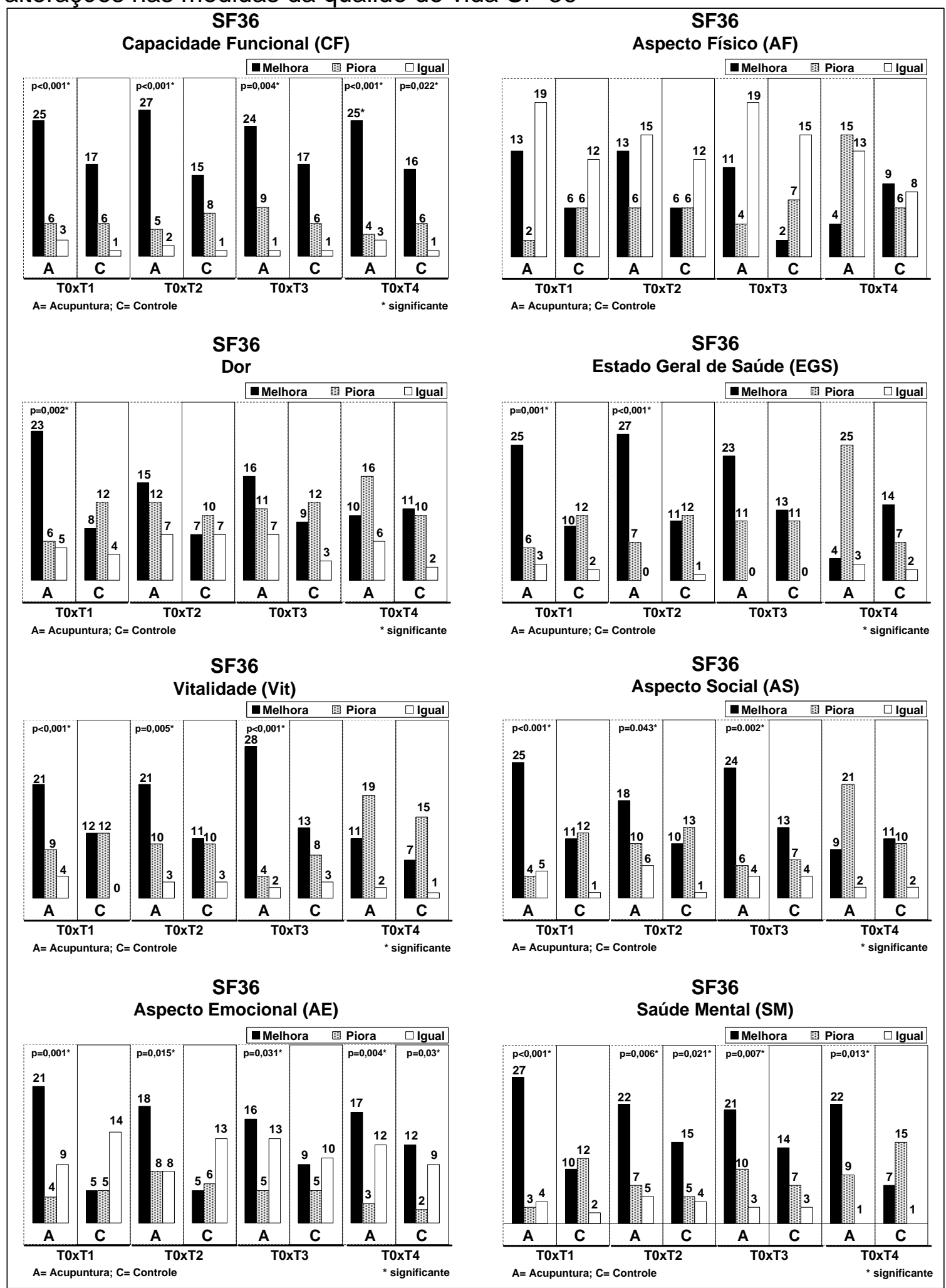

T0: avaliação anterior ao tratamento; T1: avaliação pós tratamento; T2: avaliação seis meses após a primeira avaliação; T3: avaliação doze meses após a primeira avaliação; T4: avaliação 24 meses após a primeira avaliação; $p=$ probabilidade. 
No grupo da acupuntura, 29,4\% das pacientes (10 de 34) não mais foram consideradas portadoras de $F M$, pois não apresentavam mais 0 critério diagnóstico adotado pelo Colégio Americano de Reumatologia (Wolfe et al., 1990). Somente uma das 24 doentes do grupo controle saiu do critério adotado (4,1\%). 


\section{Discussão:}

Fibromialgia foi a causa mais importante de dor músculo-esquelética entre os pacientes atendidos na clínica de dor do Hospital das Clínicas da Faculdade de Medicina da Universidade de São Paulo durante o ano de 2000 (Teixeira et al., 2001). Embora se registre o aumento do interesse sobre essa complexa síndrome, não se encontrou, ainda, um tratamento efetivo e específico (Alarcón, Bradley, 1998). Desse modo, o principal objetivo do tratamento é o alívio sintomático da dor. Devido à necessidade do uso crônico de medicamentos para o controle da dor,é importante buscar outras terapêuticas apropriadas, que cheguem à origem da dor para suprimir as suas causas e extingui-la.

Revisões sistemáticas sobre a eficácia da acupuntura na fibromialgia evidenciam a existência de poucos estudos controlados randomizados de boa qualidade científica (Berman et al., 1999; Lee, 2000). Os resultados

destes estudos ainda são controversos. Nosso objetivo foi o de verificar o benefício da adição da acupuntura ao tratamento convencional na redução da dor de doentes com fibromialgia em nosso meio, já que a maioria dos estudos controlados e randomizados, com este intuito, foram realizados em países desenvolvidos como a Alemanha (Sprott et al., 1998; Sprott et al., 2000), na Suiça (Lautenschläger et al., 1989; Deluze et al., 1992), Estados Unidos da América (Assefi et al., 2005; Martin et al., 2006), e Itália (Pasotti et al., 1990; Cassisi et al., 1995). 
Foi avaliado ainda nesta pesquisa se a inclusão da acupuntura no manejo das pacientes com fibromialgia poderia gerar efeitos significativos na melhora da sua qualidade de vida.

Assim como Martin et al. (2006), optamos por restringir a casuística de nossa amostra, visando estudar um grupo mais específico. Nossos pacientes pertenciam a um grupo homogêneo em termos de diagnóstico, duração e gravidade dos sintomas. Estudamos apenas mulheres predominantemente da cor branca. Concordamos com Martin et al. (2006) que estudos futuros devam extender estas observações aos homens e a outros grupos étnicos.

O estímulo específico da acupuntura em locais anatômicos da pele pode ser alcançado mediante a alternância de um leque variado de técnicas. Comumente, a estimulação dos pontos de acupuntura é obtida pela penetração de agulhas finas através na pele. As agulhas são introduzidas em ângulo e profundidade precisos, conforme o resultado que se almeja obter.

Cinco estudos controlados randomizados prévios já estudaram o efeito da acupuntura comparada com o placebo (Lautenschläger et al., 1989; Deluze et al., 1992; Costa, 2001; Assefi et al., 2005; Martin et al., 2006). Vários autores utilizaram a sham acupuntura como grupo controle (Deluze et al., 1992; Costa, 2001; Assefi et al., 2005; Martin et al., 2006). A sham acupuntura é entendida por alguns autores como tendo efeito placebo: as agulhas de acupuntura são inseridas fora dos pontos verdadeiros usados na acupuntura real. Optamos por não usar a sham acupuntura na presente 
pesquisa porque alguns dos efeitos biológicos da acupuntura têm sido observados quando os pontos da sham acupuntura são estimulados $(\mathrm{NIH}$, 1998; Berman et al., 1999; Lee, 2000; Assefi et. al, 2005). Concordamos ainda com Martin et al. (2006) que sugerem que a introdução de agulhas de acupuntura em pontos incorretos sham pode promover aferência neuromodulatória ao sistema nervoso sensitivo, produzindo alterações fisiológicas semelhantes e indistingüíveis dos pontos descritos como clássicos e verdadeiros. Desse modo, acreditamos que o modelo placebo utilizado por Martin et al. (2006) de simulação da introdução das agulhas de acupuntura seja mais apropriado como aplicação placebo e deva ser utilizado em estudos futuros. Assefi et al. (2005) também utilizaram a simulação da introdução das agulhas, que apenas tocavam a superfície do tegumento. Os achados são controversos aos de Martin et al. (2006) e devem ser mais bem estudados no futuro.

Como não havia sido ainda descrito na literatura a comparação com o tratamento convencional comumente usado em nosso ambulatório, decidimos avaliar o efeito da acupuntura na melhora da dor e da qualidade de vida de doentes com fibromialgia, comparando-o com o tratamento convencional com antidepressivos tricíclicos, exercícios de relaxamento, respiratórios, de alongamento, aeróbios e de fortalecimento muscular. Para se ter certeza de que as trocas biológicas decorreram unicamente ao uso da acupuntura real, o grupo controle de nosso estudo recebeu apenas o tratamento convencional para fibromialgia com o uso de medicação antidepressiva, técnicas de relaxamento e exercícios já preconizadas e 
empregadas em nossa instituição. Portanto, em nosso estudo, a acupuntura foi avaliada como um tratamento complementar ao tratamento convencional, e não como modalidade terapêutica isolada. Entendemos que para a complexidade da fibromialgia, associada à intensidade dos sintomas dolorosos, a monoterapia não está indicada.

Outra modalidade de acupuntura que pode ser utilizada é a da estimulação elétrica acoplada às agulhas de acupuntura. Decidimos não usar a estimulação elétrica dos pontos de acupuntura, porque o efeito terapêutico do eletroacupuntura já havia sido observado por Deluze et al. (1992), em uma pesquisa randomizada e controlada, de alta qualidade científica. Este mesmo efeito também já foi demonstrado por Waylonis (1977) e Sprott et al. (1998).

Apesar de não termos utilizado a eletroacupuntura, tivemos alguns resultados similares aos encontrados por Deluze et al. (1992). Comparando os efeitos da acupuntura real com a técnica sham eletroacupuntura, nos pacientes com fibromialgia, Deluze et al. (1992) encontrou melhora significativa no grupo tratado nos seguintes tópicos: o número de pontos dolorosos, no número de analgésicos usados, na dor regional, na dor visualizada na EVA, na qualidade do sono e nas avaliações clínicas realizadas por médicos quanto ao estado geral do paciente. O principal parâmetro estudado por eles foi a medida dos dezoito pontos dolorosos que melhoraram em $70 \%$ no grupo de eletroacupuntura comparado com $4 \%$ no grupo controle. Entretanto, diferente de nosso estudo, os autores não fizeram nenhuma avaliação de longo prazo. Os pacientes foram avaliados 
antes da primeira sessão de eletroacupuntura e depois de terminado o tratamento.

Em nosso estudo, adotamos a padronização dos pontos de acupuntura utilizados em nossos pacientes, assim como também fizeram outros autores (Assefi et al., 2005; Martin et al., 2006). Os pontos foram escolhidos com a finalidade de permitir a reprodução da técnica. Para isto, foram usados os mesmos pontos de acupuntura para todas as pacientes contrariando o que preceitua a acupuntura praticada na clínica de acordo com a medicina tradicional chinesa que opta sempre pelo tratamento individualizado (Assefi et al., 2005; Yamamura et al., 1996).

Yamamura et al. (1996) propõe o tratamento da fibromialgia com acupuntura pela medicina tradicional chinesa de acordo com a sintomatologia. As doentes foram então divididas em dois grupos. Um grupo com depressão e outro grupo com ansiedade. Em cada grupo, usar-se-ia o tratamento da acupuntura praticada pela medicina tradicional chinesa, conforme a indicação da síndrome. Infelizmente, estes estudos não podem ser reproduzidos com finalidade científica, porque não se pode comparar grupos com tratamentos diferentes. Por este motivo, as pesquisas em acupuntura são difíceis de serem realizadas e reproduzidas em diferentes partes do mundo.

Nós concordamos inteiramente com Assefi et al. (2005), que não existe nenhuma evidência científica sugerindo que 0 tratamento individualizado da acupuntura seja superior ao uso de pontos préestabelecidos. Além do mais, não existe um padrão-ouro para a 
determinação dos pontos de acupuntura a serem utilizados para 0 tratamento da fibromialgia e mais estudos são necessários para esclarecer estas dúvidas. $\mathrm{Na}$ ausência de dados mais concretos, também selecionamos os pontos de acupuntura baseados em nossa experiência clínica, assim como fizeram Assefi et al. (2005) e Martin et al. (2006). Os pontos da acupuntura foram escolhidos com a finalidade de aliviar os sintomas das pacientes com fibromialgia, já que a etiologia e a etiopatogenia da síndrome são ainda desconhecidas. Escolhemos os pontos LI-4, LR-3, PC-6, GB-34 e SP-6, usados no tratamento da dor músculo-esquelética e da depressão. As agulhas foram introduzidas em ambos os lados do corpo do paciente, exceto o ponto ExHN-3 para a melhora da ansiedade, cuja aplicação é única.

O presente estudo mostrou que 94\% (32 doentes) do grupo tratado com acupuntura tiveram relevante melhora da intensidade de dor medida pela EVA após o tratamento com vinte sessões de acupuntura $(p<0,001)$ (T1). Após seis meses do ínicio do tratamento, a porcentagem de melhora foi de 70,5\% (p<0,001) (T2). O índice diminui para $64,7 \%$ após um ano $(p=0,002)$ (T3). Depois de dois anos (T4), 62\% destes pacientes mantiveram a melhora $(p=0,001)$.

No seguimento de curto prazo (T1), $79 \%$ dos pacientes do grupo de acupuntura apresentaram melhora quanto ao NPD e, após três meses do término do tratamento (T2), o índice de melhora foi de $76 \%$. Após um ano (T3), o índice baixou para 67\% e depois de dois anos (T4) caiu para 64\%. 
Quanto ao IM, 88\% melhoraram após o tratamento com acupuntura (T1). Esta melhora permaneceu com o mesmo índice até três meses após o tratamento (T2), passando para 67\% depois de um ano (T3) e 64\% após dois anos (T4).

Interessante destacar que a percentagem de melhora significativa dos valores da EVA, do IM e do NPD em comparação aos valores obtidos antes do tratamento ficou restrita apenas ao grupo que realizou o tratamento adicional com a acupuntura, tanto no seguimento em curto como em longo prazo. Já o grupo que recebeu apenas o tratamento convencional não apresentou nenhuma melhora estatisticamente significante em relação aos valores iniciais, em todas as medidas de dor realizadas, tanto no curto quanto no longo prazo (Tabela 3). Sprott et al. (2000) encontraram resultados semelhantes aos nossos, quanto à redução do número de pontos dolorosos e aos valores da EVA.

Comparando os dois grupos de tratamento, nosso estudo demonstrou a melhora em todas as medidas de avaliação da dor após o término das sessões de acupuntura (T1). Ainda observamos redução significante do NPD e o aumento no limiar de tolerância à pressão sobre os dezoito pontos da fibromialgia, até três meses após o término das sessões de acupuntura (T2). Já a escala visual analógica (EVA) não manteve os benefícios obtidos após o término das aplicações de acupuntura (T1) no seguimento em curto prazo, três meses após o término das aplicações de acupuntura (T2). Interessante observar que tanto o IM quanto o NPD foram medidos pelo algiômetro de Fischer. Os dados encontrados usando-se o algiômetro são 
dados considerados objetivos, ao contrário da EVA, que é subjetivo por sua própria natureza.

Concordamos com Martin et al. (2006) que afirma que o questionário SF-36 não é específico para a fibromialgia. O questionário específico seria o Fibromyalgia Impact Questionnaire (FIQ), não usado nesta tese por ainda não estava validado para a língua portuguesa na época deste estudo. A validade do FIQ foi realizada em 2006 por Marques et al.

Desse modo, optamos pelo uso do SF-36, um questionário não específico para a fibromialgia, porém validado para a língua portuguesa e também utilizado por outros autores (Costa, 2001; Assefi et al., 2005) para avaliar o benefício da acupuntura na qualidade de vida de nossos doentes.

Quanto à qualidade de vida, a melhora se verificou no grupo de acupuntura e não no grupo controle (Tabela 5). Esses benefícios foram mais evidentes na avaliação após o tratamento com acupuntura nos seguintes domínios: CF, Dor, EGS, VIT, AS, AE, SM (Tabela 5). Costa (2001) também registrou resultados semelhantes aos obtidos em nosso estudo, relatando melhora nos domínios CF, AF, Dor, AS e SM.

Após seis meses de acompanhamento, o número de doentes que ainda apresentava melhora significante nos domínios CF, EGS, VIT, AS, AE e SM ainda apresentavam melhores índices. Quanto ao grupo controle, a melhora só foi observada no domínio SM na avaliação correspondente a seis meses de acompanhamento no grupo que recebeu a acupuntura. Após um ano de seguimento os itens que apresentaram melhora foram: CF, VIT, AS e 
SM no grupo da acupuntura. Já no grupo controle apenas o domínio CF apresentou melhora significante, em termos de número de doentes.

Neste estudo, os resultados mostraram melhora na qualidade de vida no grupo da acupuntura após dois anos de seguimento nos seguintes domínios: CF e SM. No grupo controle, por outro lado, houve melhora significante do número de doentes nos domínios CF e AE.

A experiência obtida neste estudo, com as pacientes de FM que se submeteram a vinte sessões de acupuntura, mostra resultados revelando melhora significante a curto prazo na estatística usada entre grupos, nos itens: CF, Dor, VIT, AE, SM na qualidade de vida medidos por meio do questionário SF-36. Este achado sugere que o efeito da acupuntura em curto prazo na qualidade de vida talvez necessitasse de mais sessões de acupuntura para apresentar resultados por maior tempo.

Vários estudos controlados randomizados (Lautenschäger et al., 1989; Pasotti et al., 1990; Deluze et al., 1992; Cassisi et al., 1995; Sprott et al., 1998; Sprott et al., 2000; Costa, 2001; Assefi et al., 2005; Martin et al., 2006) e não randomizados (Waylonis, 1977) prévios também estudaram o efeito da acupuntura em doentes com fibromialgia. Todos os estudos encontraram benefício da acupuntura no tratamento da fibromilagia, com exceção do estudo de Assefi et al. (2005).

Esses autores não conseguiram demonstrar nenhum efeito benéfico da acupuntura no alívio da dor, quando comparada a três tipos distintos de sham acupuntura. 
Uma possível explicação para tais achados contraditórios aos nossos, seria que estes autores não utilizaram nenhum tratamento adjuvante à acupuntura para tratar os seus doentes.

Da mesma forma, Lautenschäger et al. (1989), só obtiveram resultados melhores que o grupo placebo ao término do tratamento com a acupuntura. Este efeito não se manteve na avaliação três meses após o final do tratamento.

Já em estudo mais recente, randomizado e controlado, comparando a melhora sintomática da acupuntura em pacientes com fibromialgia, Martin et al. (2006) demonstraram que acupuntura foi muito melhor que a estimulação por placebo. Os efeitos só duraram até um mês depois do final do tratamento por acupuntura com pontos fixos padronizados. Os autores também não encontraram resultados significativos após sete meses de acompanhamento. Do mesmo modo, também evidenciamos melhora da dor e da maioria dos componentes da qualidade de vida, tanto após como três meses depois do término do tratamento, mas só quando comparado ao tratamento convencional.

Em nosso estudo, a acupuntura foi empregada como um componente integrado ao tratamento convencional e não como procedimento isolado. É possível que o benefício conseguido na pesquisa se deva ao efeito sinérgico da combinação da acupuntura com antidepressivos tricíclicos, conforme os comentários de Berman et al. (1999) e os achados do estudo de Cassisi et al. (1995). Estes autores demonstraram efeitos benéficos da acupuntura associada aos antidepressivos tricíclicos até seis meses após o término do 
tratamento, quando comparados ao grupo de pacientes que só recebeu os antidepressivos.

Também não descartamos a possibilidade de que a melhora das doentes do grupo acupuntura tenha ocorrido pelo fato de seus integrantes terem obtido mais cuidados médicos e mais atenção do pessoal de atendimento, já que compareciam ao hospital mais vezes que o grupo controle.

Os pontos de acupuntura utilizados em nosso estudo, além de propiciar melhora dos sintomas das pacientes, contribuíram também para a elevação da qualidade de vida como se observou no curto prazo. Entendemos que a utilização de pontos fixos, pré-determinados, possa não ser a realidade na prática diária da acupuntura, onde os pontos utilizados são individualizados e diferentes em doentes distintos, tendo o mesmo diagnóstico clínico. Entretanto, a padronização dos pontos utilizados em nosso estudo permitiu as comparações com outros estudos controlados e randomizados.

Selecionamos pontos de acupuntura comumente usados para proporcionar o alívio sintomático em nossos pacientes, já que a etiologia e a etiopatogenia da doença continuam desconhecidas.

Foi interessante notar que Martin et al. (2006) também escolherem pontos similares aos utilizados em nosso estudo. Ambos utilizamos os pontos LI4, SP6 e PC6. Diferente de Martin et al. (2006), nós não utilizamos os pontos HT7 e LI2. Escolhemos os pontos LR3 e Ex-HN3. 
Nossos resultados, entretanto, foram semelhantes aos de Martin et al. (2006), que também demonstraram que a acupuntura promoveu alívio sintomático significante dos sintomas nas doentes com fibromialgia em curto prazo, mas o resultado não permaneceu por um período mais longo.

Também consideramos importante salientar que o uso de um número excessivo de pontos de acupuntura, não proporciona maiores benefícios aos doentes com fibromialgia.

No estudo de Lautenschläger et al. (1989) os autores introduziram as agulhas em oito a dez pontos de acupuntura bilateralmente, escolhidos entre 25 pontos selecionados e aplicados de acordo com a medicina tradicional chinesa. Nota-se que eles só encontraram resultados satisfatórios da acupuntura ao término das sessões e não após três meses de acompanhamento.

Uma possível explicação talvez seja o efeito sinérgico do tratamento convencional, usado concomitantemente em nossas doentes.

Deluze et al. (1992), por exemplo, utilizaram mais de seis pontos diferentes dos pré-estabelecidos, de acordo com a sintomatologia do paciente. Estes pontos não são descritos em seu estudo, o que torna a comparação dos dados difícil de ser realizada e reproduzida.

As comparações entre diferentes estudos randomizados e controlados, realizados em vários centros médicos no Ocidente, permitiram afirmar que a acupuntura é uma boa opção para o tratamento adjuvante das doentes com fibromialgia mesmo que os pontos de acupuntura usados nas diversas pesquisas sejam diferentes. 
Em dois estudos de alta qualidade científica, os pacientes só foram avaliados até seis meses (Assefi et al., 2005) e sete meses (Martin et al., 2006) após o término do tratamento. Já no presente estudo, nossas pacientes foram acompanhados após doze e 24 meses do início do tratamento.

Diferente do que se verificou em outros estudos, como os de Deluze et al. (1992) e Cassisi et al. (1995), nesta pesquisa não houve abandono do tratamento pelas pacientes até um ano depois do seu início. Após dois anos do início do tratamento, apenas três pacientes abandonaram o estudo; duas por mudança para endereço não informado e uma que desistiu da avaliação.

Uma das vantagens do tratamento por acupuntura é apresentar menos efeitos adversos quando comparados com muitos medicamentos usados para tratar os sintomas da fibromialgia $(\mathrm{NIH}, 1998)$.

Assim como McCartney et al. (2000), que reporta um caso de edema bilateral da mão depois do uso do ponto de acupuntura LI-4, bilateral para tratamento de dor lombar crônica e ciática, duas pacientes $(5,8 \%)$ deste estudo desenvolveram edema na mão esquerda na inserção da agulha no ponto LI-4. Assim como evidenciado por Costa (2001), Assefi et al. (2005) e Martin et al. (2006), nossas pacientes também apresentaram boa tolerância à acupuntura. Não houve relato de desconforto, dolorimento pós-aplicação ou reação vagal durante ou posteriormente ao período de tratamento.

Existe evidência de que o efeito da acupuntura pode permanecer por anos após o término do tratamento. Waylonis (1977), ao estudar os efeitos da acupuntura no tratamento da fibrosite, destacou que $56 \%$ dos pacientes 
foram beneficiados não só após um mês, mas após um ano de tratamento. Nossos resultados também demonstraram efeitos benéficos até um ano após o término da aplicação, quando comparados às medidas iniciais, antes do tratamento. As comparações com o grupo controle, entretanto, só demonstraram benefícios no tratamento da dor até três meses após o término das aplicações da acupuntura. Nós conseguimos apenas detectar um resultado estatisticamente melhor no domínio atividade física do SF-36 em doze meses após o final do tratamento.

O presente estudo foi controlado, randomizado e considerado de alto nível científico para avaliação de intervenção terapêutica. Somente três pacientes deixaram de comparecer $(5,2 \%)$ na última avaliação de dois anos após o tratamento. Duas pacientes eram do grupo de acupuntura e uma do grupo controle. A perda, contudo, é ínfima quando a aproximamos dos dados relatados por Deluze et al. (1992) e por Cassisi et al. (1995).

O resultado obtido na pesquisa pode ser usado no tratamento dos pacientes que são atendidos nas clínicas de dor de São Paulo e possivelmente em clínicas especializadas em dor em outras regiões do país. 


\section{Conclusões:}

1. A associação da acupuntura ao tratamento convencional da fibromialgia com antidepressivos tricíclicos e exercícios é benéfica para doentes com fibromialgia, no período de três meses após o término do tratamento.

2. O tratamento complementar de acupuntura reduz a intensidade da dor, o número de pontos dolorosos e o índice miálgico em doentes com fibromialgia.

3. O uso da acupuntura melhora a qualidade de vida de doentes com fibromialgia nos seguintes domínios: capacidade funcional, dor, vitalidade, aspectos social e emocional e a saúde mental. 
7. Anexos 
Anexo A: Termo de consentimento livre e esclarecido

\section{REGISTRO DAS EXPLICAÇÕES DO PESQUISADOR AO PACIENTE OU SEU REPRESENTANTE LEGAL SOBRE A PESQUISA}

\section{Explicações e esclarecimento ao paciente}

1- A senhora é portadora de síndrome da fibromialgia que é responsável por dor em todo o corpo. Geralmente de forte intensidade e que prejudica as atividades de vida diária. Como os remédios não são suficientes para melhorar a dor e também existir pessoas que não se dão bem com a medicação, estamos tentando o uso da Acupuntura com a finalidade de melhorar a dor e a qualidade de vida.

Serão introduzidas agulhas finas esterilizadas, descartáveis em locais determinados do corpo (pés, pernas, mãos e antebraços) durante 20 minutos aproximadamente. A senhora deverá sentir ligeira dor ou choque no local da introdução da agulha que desaparecerá logo em seguida. Raramente pode haver pequeno sangramento local após a retirada da agulha que desaparece pela compressão de algodão com álcool.

Geralmente não ocorre nenhum outro sintoma durante o tratamento.

O propósito deste estudo é observar e medir as vantagens e avaliação da Acupuntura no tratamento desta doença.

Vamos verificar o quanto de dor a senhora sente antes e depois de cada sessão de Acupuntura, através de um questionário chamado escala analógica de dor (o questionário baseia-se em dar nota de 0 a 10 para a intensidade de dor). Seu tratamento será feito 2 vezes por semana, no total de 20 sessões seguidas. Seu acompanhamento será feito pelo menos até um ano, quando terá alta.

2- A liberdade de retirar seu consentimento a qualquer momento e de deixar de participar do estudo, sem que isto traga prejuízo na continuidade do seu tratamento.

3- Todos os dados serão utilizados exclusivamente para esta pesquisa e garantimos sua confidencialidade, sigilo e privacidade do seu nome.

4- Se houver qualquer complicação, terá assistência do grupo de Acupuntura da Divisão de Medicina Física e Reabilitação do Instituto de Ortopedia e Traumatologia do Hospital das Clínicas FMUSP.

Nome do pesquisador - Rosa Alves Targino de Araujo

Endereço - Av. Giovanni Gronchi, n1106

Telefone - (11) - 3722-2209

Declaro que após convenientemente esclarecido pelo pesquisador e ter entendido o que me foi explicado, consinto em participar do presente protocolo de pesquisa.

Assinatura do sujeito da pesquisa

Ou responsável legal
Assinatura do pesquisador (carimbo ou assinatura legível) 
Anexo B: Aprovação do comitê de ética.
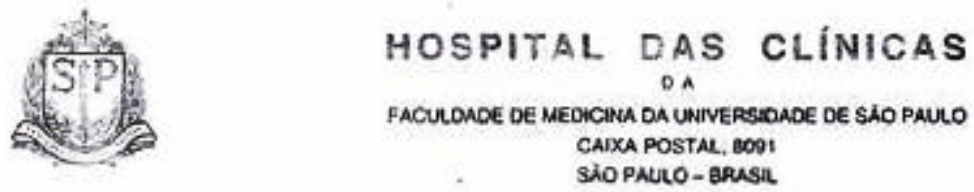

DIRETORIA CLÍNICA

\section{Comissão de Ética para Análise de Projetos de Pesquisa \\ APROVAÇÃO}

A Comissão de Ética para Análise de Projetos de Pesquisa - CAPPesq da Diretoria Clínica do Hospital das Clínicas e da Faculdade de Medicina da Universidade de São Paulo, em sessão de 15/03/2000, APROVOU ○ Protocolo de Pesquisa $\mathrm{n}^{\circ} 843 / 99$ intitulado: "Tratamento da dor na fibromialgia com acupuntura", apresentado pelo(a) pesquisador(a) Rosa Alves Targino de Araujo, do Departamento de Ortopedia e Traumatologia, bem como o Termo de Consentimento Livre e Esclarecido.

CAPPesq, 16 de Março de 2000.

PROF. DR. JORGE KALIL FILHO

Presidente da Comissão Ética para Análise de Projetos de Pesquisa

\footnotetext{
OBSERVAÇÄO: Cabe ao pesquisador elaborar e apresentar à CAPPesq, os relatórios parclals e final sobro a pesquisa (Resoluçáo do Conselho Nacional do Saúde $n^{\circ}$ 196, de 10.10.1996, Inciso DX.2, letra "c")
} 
Anexo C: Ficha de avaliação e acompanhamento dos doentes.

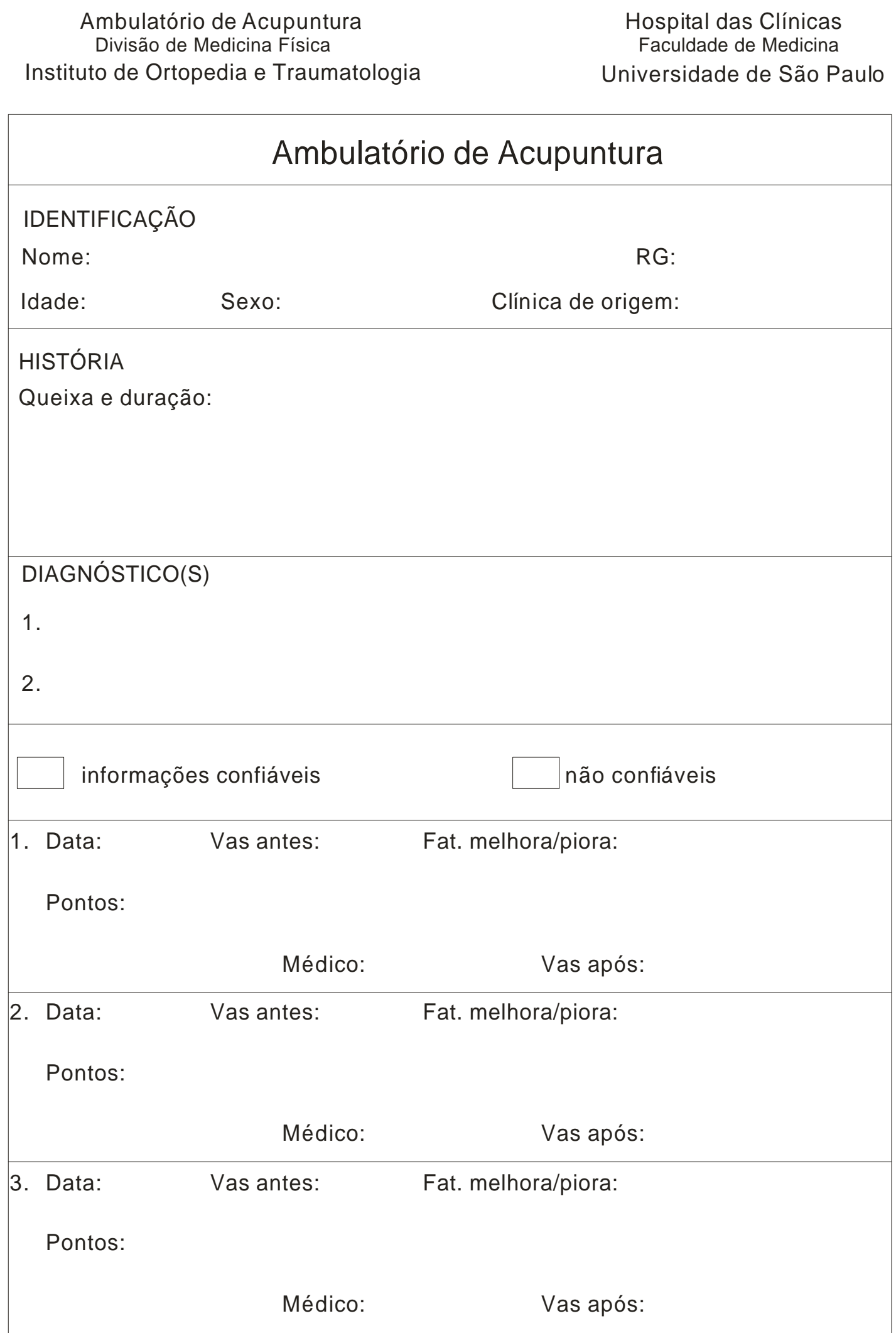




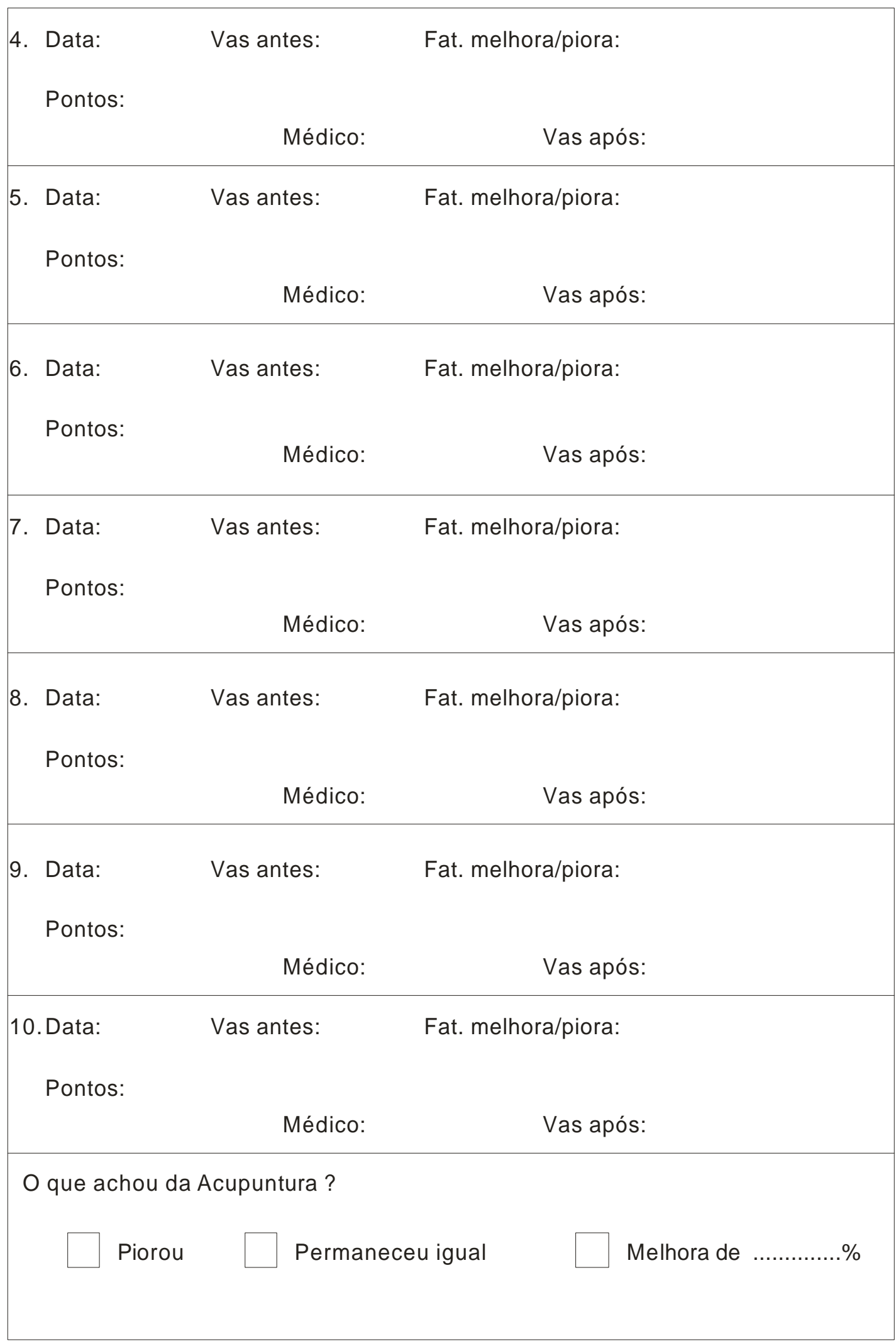




\section{Anexo D: Pesquisa dos pontos dolorosos}

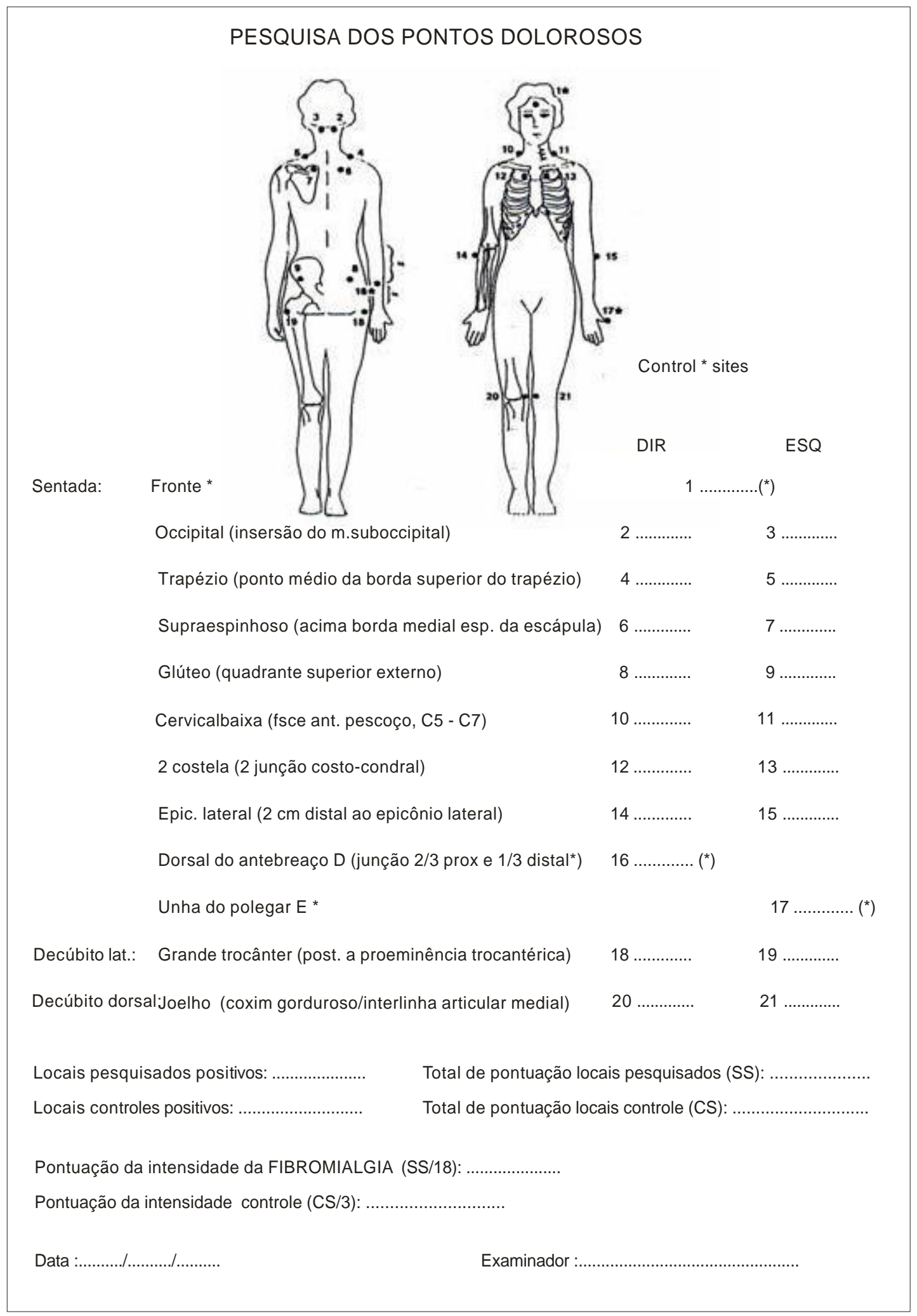


Anexo E: Questionario SF 36

SF-36 PESQUISA EM SAÚDE SCORE:

Instruções: Esta pesquisa questiona você sobre sua saúde. Estas informações nos manterão informados de como você se sente e quão bem você é capaz de fazer suas atividades de vida diária. Responda cada questão marcando a resposta como indicado. Caso você esteja inseguro em como responder, por favor tente responder o melhor que puder.

1. Em geral, você diria que sua saúde é:

Excelente

(circule uma) 2

3

4

5

2. Comparada a um ano atrás, como você classificaria sua saúde em geral, agora ?

Muito melhor agora do que há um ano atrás.

(circule uma)

........... 1

Quase a mesma de um ano atrás.

Um pouco pior agora do que há um ano atrás............................................ 4

Muito pior agora do que há um ano atrás............................................... 5

3. Os seguintes ítens são sobre atividades que você poderia fazer atualmente durante

4. um dia comum. Devido a sua saúde você tem dificuldade para fazer essas atividades. Neste caso, quanto?

\begin{tabular}{|l|c|c|c|}
\hline \multicolumn{1}{|c|}{ Atividades } & $\begin{array}{c}\text { Sircule um número em cada linha) } \\
\text { Dificulta muito }\end{array}$ & $\begin{array}{c}\text { Sim. } \\
\text { Dificulta um } \\
\text { pouco }\end{array}$ & $\begin{array}{c}\text { Não. } \\
\text { Não dificulta de } \\
\text { modo algum }\end{array}$ \\
\hline $\begin{array}{l}\text { A- Atividades vigorosas, que exigem muito esforço, } \\
\text { tais como correr, levantar objetos pesados, } \\
\text { participar em esportes árduos. }\end{array}$ & 1 & 2 & 3 \\
\hline $\begin{array}{l}\text { B-Atividades moderadas, tais como mover uma } \\
\text { mesa, passar aspirador de pó, jogar bola, varrer a } \\
\text { casa. }\end{array}$ & 1 & 2 & 3 \\
\hline C- Levantar ou carregar mantimentos & 1 & 2 & 3 \\
\hline D- Subir vários lances de escada & 1 & 2 & 3 \\
\hline E- Subir um lance de escada & 1 & 2 & 3 \\
\hline F- Curvar-se, ajoelhar-se ou dobrar-se & 1 & 2 & 3 \\
\hline G-Andar mais de um quilômetro & 1 & 2 & 3 \\
\hline H- Andar vários quarteirões & 1 & 2 & 3 \\
\hline I- Andar um quarteirão & 1 & 2 & 3 \\
\hline J- Tomar banho ou vestir-se & 1 & 2 & 3 \\
\hline
\end{tabular}


9.Estas questões são sobre como você se sente e como tudo tem acontecido com você durante as últimas 4 semanas. Para cada questão, por favor dê uma resposta que mais se aproxime da maneira como você se sente. Em relação as últimas 4 semanas.

(circule um número para cada linha)

\begin{tabular}{|l|c|c|c|c|c|c|}
\hline & $\begin{array}{c}\text { Todo } \\
\text { tempo }\end{array}$ & $\begin{array}{c}\text { A maior } \\
\text { parte do } \\
\text { tempo }\end{array}$ & $\begin{array}{c}\text { Uma boa } \\
\text { parte do } \\
\text { tempo }\end{array}$ & $\begin{array}{c}\text { Alguma } \\
\text { parte do } \\
\text { tempo }\end{array}$ & $\begin{array}{c}\text { Uma } \\
\text { pequena } \\
\text { parte do } \\
\text { tempo }\end{array}$ & Nunca \\
\hline $\begin{array}{l}\text { A - Quanto tempo você tem se sentido } \\
\text { cheio de vigor, cheio de vontade, cheio } \\
\text { de força? }\end{array}$ & 1 & 2 & 3 & 4 & 5 & 6 \\
\hline $\begin{array}{l}\text { B - Quanto tempo você tem se sentido } \\
\text { uma Pessoa muito nervosa? }\end{array}$ & 1 & 2 & 3 & 4 & 5 & 6 \\
\hline $\begin{array}{l}\text { C- Quanto tempo você tem se sentido } \\
\text { tão Deprimido que nada pode animá- } \\
\text { lo? }\end{array}$ & 1 & 2 & 3 & 4 & 5 & 6 \\
\hline $\begin{array}{l}\text { D - Quanto tempo você se sentido } \\
\text { calmo ou Tranqüilo? }\end{array}$ & 1 & 2 & 3 & 4 & 5 & 6 \\
\hline $\begin{array}{l}\text { E - Quanto tempo você tem se sentido } \\
\text { com muita energia? }\end{array}$ & 1 & 2 & 3 & 4 & 5 & 6 \\
\hline $\begin{array}{l}\text { F- Quanto tempo você tem se sentido } \\
\text { desanimado e abatido? }\end{array}$ & 1 & 2 & 3 & 4 & 5 & 6 \\
\hline $\begin{array}{l}\text { G- Quanto tempo você tem se sentido } \\
\text { esgotado? }\end{array}$ & 1 & 2 & 3 & 4 & 5 & 6 \\
\hline $\begin{array}{l}\text { H - Quanto tempo você tem se sentido } \\
\text { uma pessoa feliz? }\end{array}$ & 1 & 2 & 3 & 4 & 5 & 6 \\
\hline $\begin{array}{l}\text { I- Quanto tempo você tem se sentido } \\
\text { cansado? }\end{array}$ & 1 & 2 & 3 & 4 & 5 & 6 \\
\hline
\end{tabular}

10.Durante as últimas 4 semanas, quanto do seu tempo a sua saúde física ou problemas emocionais interferiram com as suas atividades sociais( como visitar amigos, parentes, etc.)?

(circule uma)

Todo o tempo .1

A maior parte do tempo................................................... 2

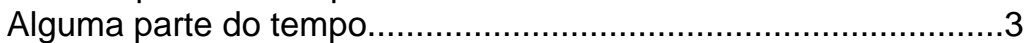

Uma pequena parte de tempo..................................................... 4

Nenhuma parte do tempo........................................................... 5

11.O quanto verdadeiro ou falso é cada uma das afirmações para você?

(circule um número em cada linha)

\begin{tabular}{|l|c|c|c|c|c|}
\hline & $\begin{array}{c}\text { Definitivamen } \\
\text { te verdadeiro }\end{array}$ & $\begin{array}{c}\text { A maioria das } \\
\text { vezes } \\
\text { verdadeiro }\end{array}$ & $\begin{array}{c}\text { Não } \\
\text { sei }\end{array}$ & $\begin{array}{c}\text { A maioria } \\
\text { das vezes } \\
\text { falsa }\end{array}$ & $\begin{array}{c}\text { Definitiva } \\
\text { mente } \\
\text { falsa }\end{array}$ \\
\hline $\begin{array}{l}\text { A - Eu costumo adoecer um } \\
\text { pouco mais facilmente que as } \\
\text { outras pessoas }\end{array}$ & 1 & 2 & 3 & 4 & 5 \\
\hline $\begin{array}{l}\text { B - Eu sou tão saudável quanto } \\
\text { qualquer pessoa que eu conheço }\end{array}$ & 1 & 2 & 3 & 4 & 5 \\
\hline $\begin{array}{l}\text { C - Eu acho que a minha saúde } \\
\text { vai piorar }\end{array}$ & 1 & 2 & 3 & 4 & 5 \\
\hline D - Minha saúde é excelente & 1 & 2 & 3 & 4 & 5 \\
\hline
\end{tabular}


Cálculo do Raw Scale (0 a 100)

\begin{tabular}{|c|c|c|c|}
\hline & Questão & Limites & Score Range \\
\hline $\begin{array}{c}\text { Capacidade } \\
\text { funcional }\end{array}$ & $3(\mathrm{a}+\mathrm{b}+\mathrm{c}+\mathrm{d}+\mathrm{e}+\mathrm{f}+\mathrm{g}+\mathrm{h}+\mathrm{i}+\mathrm{j})$ & 10,30 & 20 \\
\hline Aspectos Físicos & $4(\mathrm{a}+\mathrm{b}+\mathrm{c}+\mathrm{d})$ & 4,8 & 4 \\
\hline Dor & $7+8$ & 2,12 & 10 \\
\hline $\begin{array}{c}\text { Estado Geral de } \\
\text { Saúde }\end{array}$ & $1+11$ & 5,25 & 20 \\
\hline Vitalidade & $9(\mathrm{a}+\mathrm{e}+\mathrm{g}+\mathrm{i})$ & 4,24 & 20 \\
\hline Aspectos Sociais & $6+10$ & 2,10 & 8 \\
\hline Aspecto Emocional & $5(\mathrm{a}+\mathrm{b}+\mathrm{c})$ & 3,6 & 3 \\
\hline Saúde Mental & $9(\mathrm{~b}+\mathrm{c}+\mathrm{d}+\mathrm{f}+\mathrm{h})$ & 5,30 & 25 \\
\hline
\end{tabular}

Raw Scale:

Ex: Item $=[$ Valor obtido - Valor mais Baixo $] \times 100$

$$
\text { variação }
$$

Ex. Capacidade funcional $=21 \quad$ Ex: $21-10 \times 100=55$

Valor mais Baixo +10

$$
20
$$

Variação $=20$

Obs. A questão $\mathrm{n}$ 2 não entra no cálculo dos domínios

Dados Perdidos:

Se responder mais de $50 \%=$ substituir o valor pelo média

\begin{tabular}{|c|c|}
\hline Questão & Pontuação \\
\hline 01 & $1=5,0 \quad 2=4,4 \quad 3=3,4 \quad 4=2,0 \quad 5=1,0$ \\
\hline 02 & Soma normal \\
\hline 03 & Soma normal \\
\hline 04 & Soma normal \\
\hline 05 & Soma normal \\
\hline 06 & $1=5 \quad 2=4 \quad 3=3 \quad 4=2 \quad 5=1$ \\
\hline 07 & $1=6,0 \quad 2=5,4 \quad 3=4,2 \quad 4=3,1 \quad 5=2,2 \quad 6=1,0$ \\
\hline 08 & $\begin{array}{ll}\text { Se } 8=1 \text { e } 7=1 & 6 \\
\text { Se } 8=1 \text { e } 7=2 \text { a } 6 & 5 \\
\text { Se } 8=2 \text { e } 7=2 \text { a } 6 & 4 \\
\text { Se } 8=3 \text { e } 7=2 \text { a } 6 & 3 \\
\text { Se } 8=4 \text { e } 7=2 \text { a } 6 & 2 \\
\text { Se } 8=5 \text { e } 7=2 \text { a } 6 & 1 \\
\text { Se a questão } 7 \text { não for respondida, o escore da questão } 8 \text { passa a } \\
\text { ser o seguinte: } \\
1=6,0 \\
2=4,75 \\
3=3,5 \\
4=2,25 \\
5=1,0\end{array}$ \\
\hline 09 & $\begin{array}{l}\text { A,d,e,h }=\text { valores contrários }(1=6 ; 2=5 ; 3=4 ; 4=3 ; 5=2 ; 6=1) \\
\text { Vitalidade }=a+e+g+i \\
\text { Saúde mental }=b+c+d+f+h\end{array}$ \\
\hline 10 & Soma normal \\
\hline 11 & $\begin{array}{l}A, C=\text { valores normais } \\
B, d=\text { valores contrários }(1=5 ; 2=4 ; 3=3 ; 4=2 ; 5=1)\end{array}$ \\
\hline
\end{tabular}

\section{Pontuação do questionário SF-36}




\section{Referências Bibliográficas}

Alarcón GS, Bradley LA. Advances in the treatment of fibromyalgia: current status and future directions. Am J Med Sci. 1998; 315:397-404.

Arnold LM, Keck PE Jr, Welge JA. Antidepressant treatment of fibromyalgia. A meta- analysis and review. Psychosomatics. 2000;41:104-13.

Assefi NP, Sherman KJ, Jacobsen C, Goldberg J. Smith WR, Buchwald D. A randomized clinical trial of acupuncture compared with sham acupuncture in fibromyalgia. Ann Intern Med. 2005;143:10-9.

Berman BM, Ezzo J, Hadhazy V, Swyers JP. Is acupuncture effective in treatment of fibromyalgia? J Fam Pract. 1999;48:213-8.

Bradley LA, Alberts KR. Psychological and behavioral approaches to pain management for patients with rheumatic diseases. Rheum Dis Clin North Am. 1999;25:215-32.

Buskila D: Fibromyalgia, chronic fatigue syndrome, and myofascial pain syndrome. Curr Opin Rheumatol. 2000;12:113-23.

Cassisi G, Roncaglione A, Ceccherelli F, Donolato C, Gagliardi G, Todesco S. Trattamento agopunturale della fibromialgia primaria. Confronto con mianserina. G Ital Riflessot Agopunt. 1995;7:33-6.

Cathebras P, Lauwers A, Rousset H. Fibromyalgia.A critical review. Ann Med Interne (Paris) 1998;149:406-14.

Chapmann CR, Gunn CC. Acupuncture. In: BonicaJJ, editor. The management of pain. Pensivalnia: Lea\&Febinger; 1990:v. 1, cap.11, p.1805-21. 
Cheng RSS, Pomeranz B. Mono aminergic mechanism of electro acupuncture analgesia. Brain Res.1981;215:77-92.

Chen $\mathrm{XH}$, Han JS. All three types of opioid receptors in the spinal cord are important for $2 / 15 \mathrm{~Hz}$ electro acupuncture analgesia. Eur $J$ Pharmacol.1992;21:203-10.

Cho ZT, Oleson TD, Alimi D, Niemtzow RC.Acupuncture the search for biologic evidence with functional magnetic resonance imaging and positron emission tomography techniques. J Altern Complement Med .2002;8:399-01.

Ciconelli RM, Ferraz MB, Santos W, Meinão I, Quaresma MR. Brazilian Portuguese version of the SF-36. A reliable and valid quality of life outcome measure. Rev Bras Reumatol. 1999;39:143-50.

Coderre TJ, Katz J, Vaccarino AL, Melzack R. Contribuition of central neuroplasticity to pathological pain: review of clinical and experimental evidence. Pain. 1993;52:259-85.

Costa EDGM. Evaluate the efficacy of acupuncture as a treatment for fibromyalgia: Prospective study, randomized and controlled. [tese]. Escola Paulista de Medicina, Universidade Federal de São Paulo; São Paulo: 2001.

Crofford TJ,Appleton BE.Complementary and alternative therapies for fibromyalgia.Curr Rheumatol Rep 2001;3:147-56.

De Stefano R, Selvi E, Villanova M, Frati E, Manganelli S, Franceschini E, Blast G, Marcolongo R. Image Analysis quantification of substance $P$ immunoreativity in the trapezius muscle of patients with fibromyalgia and myofascial pain syndrome. J Rheumatol. 2000;27:2906-10. 
Deluze C, Bosia L, Zirbs A, Chantraine A, Vischer TL. Electroacupuncture in fibromyalgia: results of a controlled trial. BMJ. 1992;305:1249-52.

Ezzo J, Berman B, Hadhazy VA, Jadad AR, Lao L, Singh B.B. Is acupuncture effective for treatment of chronic pain? A systematic review. Pain. 2000;86:217-25.

Fischer AA. Documentation of myofascial Trigger Points. Arch Phys Med Rehabil . 1988;69:286-91.

Forseth KO, Gran JT. The prevalence of fibromyalgia among aged 20-49 years in Arendal, Norway. Scand J Rheumatol. 1992;21:74-8.

Goldenberg DL. Fibromyalgia syndrome: an emergent but controversial condition. JAMA. 1987;257:2782-7.

Gracely RH, Petzke F, Wolf JM, Clauw DJ. Functional magnetic resonance imaging evidence of augmented pain processing in fibromyalgia. Arthritis Rheum. 2002;46:1333-43.

Gür A, Karakoç M, Nas K, Çevik R, Denli A, Saraç J. Cytokines and depression in cases with fibtomyalgia. J Rheumatol. 2002;29:358-61.

Hawley DJ, Wolfe F. Pain, disability, and pain/disability relationships in seven rheumatic disorders: a study of 1522 patients.J Rheumatol. 1991;18:1552-7.

Henriksson C, Gundmark I, Bengstsson A, Ek AC. Living with fibromyalgia. Consequences for everyday life. Clin J Pain. 1992;8:138-44.

Henriksson CM. Living with continuous muscular pain - patients perspectives part I: encounters and consequences. Scand J Caring Sci. 1995;9:67-76. 
Hong JP. Acupuntura. De terapia alternativa a especialidade médica. São Paulo: Centro de Estudos Integrado de Medicina Chinesa (CEIMEC); 2005. p. 57-68: Parte especial - Meridianos.

Hong JP. Acupuntura. De terapia alternativa a especialidade médica. São Paulo: Centro de Estudos Integrado de Medicina Chinesa (CEIMEC); 2005. p. $182-4$.

Imamura ST. Eletrocupuntura Ryodoraku. São Paulo: Sarvier; 1995.

Kaziyama HHS, Souza LPM. Aderência de pacientes às atividades físicas ensinadas no programa educacional para fibromialgia. Acta Fisiatrica. 1999;6:113. (Presented at XVI Congresso de Medicina Física e Reabilitação; 1996, São Paulo, Brazil. Abstracts).

Keel PJ, Bodoky C, Gerhard U, Muller W. Comparison of integrated group therapy and group relaxation training for fibromyalgia. Clin $J$ Pain. 1998;14:232-8.

Klein R, Berg PA. High Incidence of antibodies to 5 Hydroxy Tryptamine Gangliosides and phospholipids in patiens with chronic fatigue and fibromyalgia syndrome and their relatives; evidence for a clinical entity of both disorders. Eur J Med. 1995; 1: 21-6.

Lautenschläger J, Schnorrenberger CC, Muller W. Akupunktur bei generalisierter Tendomyopathie (Fibromyalgie-syndrome). Dtsch Zscbr Akup. 1989;32:122-8.

Lee TL. Acupuncture and chronic pain management. Ann Acad Med Singapore. 2000;29:17-21. 
Lindell L, Bergman S, Petersson IF, Jacobsson LTH, Herrström P. Prevalence of fibromyalgia and chronic widespread pain. Scand $J$ Prim Health Care. 2000;18:149-53.

Malliani A, Pagani M, Lombardi F. Visceral versus somatic mechanisms. In: Wall P, Melzack J, editores. Textobook of pain. Edinburg: Churchill Livingstone;1989. p 128-40.

Marques AP, Ferreira EAG, Matsutani LA. Pereira CAB, Assumpção A .Quantifying pain threshold and qualyti of life of fibromyalgia patients.Clin Rheumatol.2005;24:266-71.

Marques AP, Barsante-Santos AM ,Assumpção A ,Matsutan iLA ,Lage LV, Pereira CAB.Validation of the brazilian version of the Fibromyalgia Impact Questionnaire(FIQ).Rev Bras Reumatol.2006;46:24-31.

Martin DP, Sletten CD, Williams BA, Berger IH. Improvement of fibromyalgia symptoms with acupuncture: Results of a randomized controlled trial. Mayo Clin Proc. 2006;81:749-57.

Martinez JE, Atra E, Fontana AM, Dacol E, Castro P, Amaral R, Oliveira ST, Jorge T. Aspectos psicologicos em mulheres com fibromialgia. Rev Bras Reum. 1992;32:51-60.

McCartney CJL, Herriot R, Chambers WA. Bilateral hand oedema related to acupuncture. Pain. 2000;84:429-30.

Merskey H, Bogduk N. Classification of chronic pain. Description of chronic pain syndromes and definitions of terms. 2 $2^{\underline{a}}$ ed. Seattle: IASP Press; 1994. p.45: Fibromyalgia. 
Middleton GD, Mc Fairlin JE, Lipsky PE. The prevalence and clinical impact of fibromyalgia in systemic lupus erythematosus. Arthritis Rheum. $1994 ; 37: 1181-8$.

Millea PJ, Holloway RL. Treating fibromyalgia. Am Fam Physician. 2000; 62:1575-82.

Mountz JM, Bradley LA, Modell JG, Alexander RW, Triana-Alexander M, Aaron AL, Stewart KE, Alarcon GS, MountzJD. Fibromyalgia in women. Abnormalities of regional blood flow in the thalamus and the caudate nucleus are associated with low pain threshold levels. Arthritis Rheum. 1995;38:926-38.

Nakatani Y, Yamashita K. Ryodoraku acupuncture. A guide for the application of Ryodoraku therapy electrical acupuncture. A new autonomic nerve regulation therapy. Tokyo: Ryodoraku Research Institute; 1977.

Napadow V, Liu J, Li M , Kettner N, Ryan A, Kwong KK ,Hui KKS,Audette JF.Somatosensory cortical plasticity in carpal tunnel syndrome treated by acupuncture.Hum Brain Mapp.2007;28:159-171.

NIH consensus conference on Acupuncture. JAMA. 1998;280:1518-24.

Paiva ES, Deodhar A, Jones KD, Bennett R. Impaired growth Hormone secretion in fibromyalgia patients. Evidence for augmented hypothalamic somatostatin tone. Arthritis Rheum. 2002;46:1344-50.

Pasotti D, Montanari E, Capobianchi B, Ercolani M. L'agopuntura nella síndrome fibromialgica primaria (SFP) primi risultati di uma ricerca. Giorn Ital di Riflessoti ed Agopunt.1990;2:23-31.

Pomeranz B, Stux G. Scientific basis of acupuncture. Berlin: Springer Verlag; 1989. 
Pongratz DE, Sievers M. Fibromyalgia - Symptom or diagnosis: a definition of the position. Scand J Rheumatol. 2000;29(Suppl 113):3-7.

Provenza JR, Morita DM, Hanaoka NM, Cunha ML, Oliveira IC, Volpi DJ, Pontes AR, Rama NH. Spect cerebral em pacientes com fibromialgia. Rev Bras Reumatol. 2002;42:25-9.

Raspe $\mathrm{H}$, Baumgartner $\mathrm{C}$. The epidemiology of the fibromyalgia syndrome in a German town. Scand J Rheumatol. 1992;8(suppl 94):8.

Roizenblatt S, Benedito-Silva AA, Tufik S, Moldofsky H. Caracteristicas do sono alfa na fibromialgia. Rev Bras Reumatol. 2002;42:15-23.

Rucco V, Ferruglio C, Genco F, Mosanghini R. Autogenic training versus Erickson's analogical technique in treatment of fibromyalgia syndrome. Riv Med Sci Pharmacol .1995;17:41-50.

Russell IJ, Orr MD, Littman B, Vipraio GA, Alboukrek D, Michalek JE, Lopes $\mathrm{Y}$, MacKillp F. Elevated cerebrospinal fluid levels of substance $\mathrm{P}$ in patients with the fibromyalgia syndrome. Arthritis Rheum. 1994;37:1593-1601.

Russell IJ. Fibromyalgia syndrome. In: Loeser JD, Butler SH, Chapman CR, Turkey DC, editores. Bonica's management of pain. $3^{\text {rd }}$ ed. Philadelphia: Lippincott Williams \& Wilkins; 2001. p. 543-56.

Senna ER, Barros ALP, Silva EO, Costa IF, Pereira LVB, Ciconelli RM, Ferraz MB. Prevalence of rheumatic diseases in Brazil: a study using the COPCORD approach. J Rheumatol. 2004;31:594-7.

Sinclair SJ, Starz TW, Turk DC. The manual tender point survey (MTPS). Pittsburgh: University of Pittsburgh School of Medicine. Center for Continuing Education in the Health Sciences; acessado em 25 de maio de 2007 no URL http://www.fmaware.org/doctor/tenderpt.htm 
Sjolund BH. Acupuncture or acupuncture? [editorial] Pain. 2005;114:311-2.

Souza LPM. A utilização de técnicas de relaxamento no tratamento de pacientes com fibromialgia. [dissertação]. São Paulo: Faculdade de Medicina, Universidade de São Paulo; 2001.

Sprott $H$, Franke $S$, Kluge $H$, Hein G. Pain treatment of fibromyalgia by acupuncture [letter]. Rheumatol Int. 1998;18:35-6.

Sprott H, Jeschonnek M, Grohmann G, Hein G. Changes in microcirculation above tender points in patients with fibromyalgia mediated by acupuncture. Wien Klin Wochenschr. 2000;112:580-6.

Targino RA, Imamura M, Kaziyama HHS, Souza LPM, Hsing WT, Imamura ST. Pain treatment with acupuncture for patients with fibromyalgia. Curr Pain Headache Reports. 2002;6:379-83.

Teixeira MJ, Teixeira WGJ, Santos FPS, Andrade DCA, Bezerra SL, Figueiró JB, Okada M. Clinical epidemiology of musculoskeletal pain. Rev Med. (São Paulo) 2001;80:1-21.

Teixeira MJ. Mecanismo de ação da acupuntura. In: Imamura ST, editor. Eletroacupuntura Ryodoraku. São Paulo: Sarvier, Associação Paulista de Medicina (APM); 1996. p.25-41.

Wallace DJ, Linker-Israeli M, Hallegua D, Silverman S, Silver D, Weisman $\mathrm{MH}$. Cytokines play an aetiopathogenetic role in fibromyalgia: a hypothesis and pilot study. Rheumatology. 2001;40:743-9.

Ware JE, Sherbourne CD. The MOS-36 item Short Form Health Survey (SF36). Conceptual framework and item selection. Med Care. 1992;30:473-83. 
Waylonis GW. Long term follow-up on patients with fibrositis treated with Acupuncture. Ohio State Med J. 1977;73:299-302.

White KP, Speechley M, Harth M, Ostbye T. Comparing self-reported function and work disability in 100 community cases of fibromyalgia syndrome versus controls in London, Ontario. Arthritis Rheum. 1999;42:76-83a.

White KP, Speechley M, Harth M, Ostbye $T$. The London fibromyalgia epidemiology study: The prevalence of fibromyalgia syndrome in London, Ontario. J Rheumatol. 1999;26:1570-6b.

WHO. World Health Organization. A proposed Standard International Acupuncture Nomenclature. Geneve: WHO;1991.

Wolfe F, Smythe HA, Yunus MB, Bennett RM, Bombardier C, Goldenberg DL, Tugwell P, Campbell SM, Abeles M, Clark P, Fam AG, Farber SJ, Fiechtner JJ, Franklin CM, Gatter RA, Hamaty D, Lessard J, Lichtbroun AS, Masi AT, McCain GA, Reynolds J, Romano TJ, Russell IJ, Sheon RP. The American College of Rheumatology 1990 criteria for the classification of fibromyalgia. Report of the multicenter criteria committee. Arthritis Rheum. 1990;33:16072.

Yamamura Y, Tabosa A, Andrade-Puertas DMA, Goldenberg ED. The extraordinary acupuncture meridians and fibromyalgia. Rev Paul Acupunt. 1996;2:102-7. 